FRANCISCO LEONARDO TORRES-LEAL

LEUCINA INTENSIFICA O GANHO DE ADIPOSIDADE E AS RESPOSTAS METABOLICAS DO TECIDO ADIPOSO EM RATOS PREVIAMENTE OBESOS POR DIETA HIPERLÍPIDICA E A GORDURA SUBCUTÂNEA É UMA DAS MAIS AFETADAS

Tese apresentada ao Programa de PósGraduação em Fisiologia Humana do Instituto de Ciências Biomédicas da Universidade de São Paulo, para obtenção do Título de Doutor em Ciências. 
FRANCISCO LEONARDO TORRES-LEAL

LEUCINA INTENSIFICA O GANHO DE ADIPOSIDADE E AS RESPOSTAS METABOLICAS DO TECIDO ADIPOSO EM RATOS PREVIAMENTE OBESOS POR DIETA HIPERLÍPIDICA E A GORDURA SUBCUTÂNEA É UMA DAS MAIS AFETADAS

Tese apresentada ao Programa de PósGraduação em Fisiologia Humana do Instituto de Ciências Biomédicas da Universidade de São Paulo, para obtenção do Título de Doutor em Ciências.

Área de Concentração: Fisiologia Humana

Orientador: Prof. Dr. Fábio Bessa Lima

Versão original 
DADOS DE CATALOGAÇÃO NA PUBLICAÇÃO (CIP)

Serviço de Biblioteca e Informação Biomédica do

Instituto de Ciências Biomédicas da Universidade de São Paulo

๑) reprodução total

Torres-Leal, Francisco Leonardo.

Leucina intensifica o ganho de adiposidade e as respostas metabólicas do tecido adiposo em ratos previamente obesos por dieta hiperlipídica e a gordura subcutânea é uma das mais afetadas / Francisco Leonardo Torres Leal. -- São Paulo, 2012.

Orientador: Prof. Dr. Fabio Bessa Lima.

Tese (Doutorado) - Universidade de São Paulo. Instituto de Ciências Biomédicas. Departamento de Fisiologia e Biofísica. Área de concentração: Fisiologia Humana. Linha de pesquisa: Fisiologia do tecido adiposo.

Versão do título para o inglês: Leucine intensifies adiposity and metabolic responses in adipose tissue of previously hyperlipidic diet obese rats and subcutaneous fat is one the most affected.

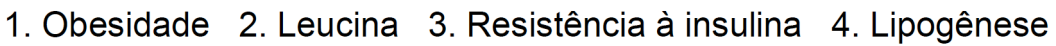
I. Lima, Prof. Dr. Fabio Bessa II. Universidade de São Paulo. Instituto de Ciências Biomédicas. Programa de Pós-Graduação em Fisiologia Humana III. Título. 
Candidato(a):

Título da Tese:

\section{Francisco Leonardo Torres Leal.}

Leucina intensifica o ganho de adiposidade e as respostas metabólicas do tecido adiposo em ratos previamente obesos por dieta hiperlipídica e a gordura subcutânea é uma das mais afetadas.

Orientador(a): $\quad$ Prof. Dr. Fabio Bessa Lima.

A Comissão Julgadora dos trabalhos de Defesa da Tese de Doutorado, em sessão pública realizada a ...................., considerou
( ) Aprovado(a)
( ) Reprovado(a)

\begin{tabular}{|c|c|}
\hline Examinador(a): & $\begin{array}{l}\text { Assinatura: } \\
\text { Nome: ....... } \\
\text { Instituição: . }\end{array}$ \\
\hline Examinador(a): & $\begin{array}{l}\text { Assinatura: } \\
\text { Nome: ....... } \\
\text { Instituição: }\end{array}$ \\
\hline Examinador(a): & $\begin{array}{l}\text { Assinatura: } \\
\text { Nome: ....... } \\
\text { Instituição: . }\end{array}$ \\
\hline Examinador(a): & $\begin{array}{l}\text { Assinatura: } \\
\text { Nome: ........ } \\
\text { Instituição: }\end{array}$ \\
\hline Presidente: & $\begin{array}{l}\text { Assinatura: } \\
\text { Nome: ....... } \\
\text { Instituição: . }\end{array}$ \\
\hline
\end{tabular}


Telefone :(55) (011) 3091.7733 - e-mail: cepaicb.usp.br

\section{Certificado}

Certificamos que o protocolo registrado sob $n^{\circ} \mathbf{0 1 3}$ nas fls. 83 do livro 02 para uso de animais em experimentação, sob a responsabilidade do Prof(a) $\operatorname{Dr}(a)$ Fabio Bessa Lima, Coordenador(a) da Linha de pesquisa Influência da leucina sobre a adiposidade em ratos magros e obesos: um estudo metabólico e endócrino do tecido adiposo branco(TAB) do qual participou(aram) o(s) alunos Ariclécio Cunha de Oliveira, Amanda Baron Campaña, André Ricardo Gomes de Proença, Andressa Bolsoni Lopes, Arnaldo Henrique de Souza, Francisco Leonardo Torres Leal, Natalie Carolina de Castro, Patricia Chimin, Rogério Antonio Laurato Sertié, Talita da Silva Mendes de Farias, está de acordo com os Principios Éticos de Experimentação Animal adotado pela Sociedade Brasileira de Ciência de Animais de Laboratório (SBCAL) e foi aprovado pela COMISSÃO DE ÉTICA NO USO DE ANIMAIS (CEUA) em 15.03.2010, com validade de 3 anos.

São Paulo, 15 de março de 2010.

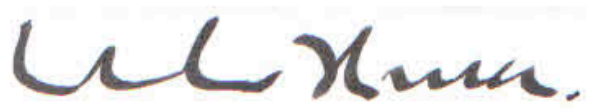

Prof.Dr.Wothan TAVARES DE LIMA

Coordenador CEEA - ICB/USP

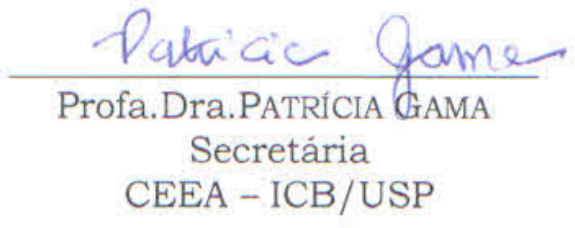


Bem-aventurado, por saber que posso contar com o apoio de muitos amigos e familiares. Estes últimos, por sua vez, são especiais por viverem intensamente cada momento da minha vida mesmo estando longe de casa. Dia a dia, sabia e sei que meus pais (Alfredo Avelino e Dasneves Torres) e irmãs (Olivia Torres Leal, Olivânia Torres Leal e Thaline Borges) são as pessoas mais importantes da minha vida, a quem esta tese é dedicada. Sem o amor, o apoio e acima de tudo o companheirismo nada disso teria sido realizado com tamanha dedicação e apreço. 


\section{AGRADECIMENTO ESPECIAL}

Aos meus pais (Alfredo Avelino e Dasneves Torres) que tanto se dedicaram para que este sonho fosse realizado. Obrigado pela fiel amizade e confiança. Agradeço também por me ensinarem a ser correto, justo e acima de tudo por me guiarem através de seus principios, e saibam, que estes são aplicados até os dias de hoje. 


\section{AGRADECIMENTOS}

Ao Pai superior que sem dúvida é meu maior porto seguro... sou muito grato por compartilhar as alegrias e as conquistas contigo meu DEUS.

Agradeço ao professor Fábio Bessa Lima pela orientação ao logo destes anos.

Destaco que a partir deste paragrafo, serei um pouco mais informal nos comentários com os amigos e colegas, pois, a TESE em si já é cheia de formalidades.

Aos meus amigos e colegas de laboratório, que ao longo destes anos compartilharam bons e maus momentos, Ariclecio Oliveira, Arnaldo Henrique, Andressa Bolsoni (Cola ou Colatina), Talita Fárias, Patricia Chimin (Verrrdinha e Veinha), Amanda Baron, Natali Castro, Rennan Caminhotto, Carol Leal e André Proença, pois sem vocês tudo seria mais dificil.

Gostaria de ser mais especifico nos comentários com alguns amigos. Ariclecio Oliveira, amigão do Ceará, uma das pessoas que mais me acrescentou conhecimento sobre pesquisa. Além disso, tive o prazer de conviver com sua familia (Danielle, Ariel, David, senhor Evangelista e senhora Ana Célia), pessoas amadas. Um amigão para todas as horas que me ajudou muito a partir da sua grande experiência de vida. Um amigo que, com certeza, irei trabalhar junto em breve. Arnaldo Henrique, amigão de Maringá, terra boa...vizinha de Teresina. Parceiro, que tive a satisfação de compartilhar o apartamento ao longo de vários meses e durante esse período dividimos muitas alegrias. Talita Farias, amiga muito especial, pessoa íntegra, com personalidade indiscutível. Para mim, a melhor pessoa que já tive a oportunidade de trabalhar na bancada. Você é diferenciada menina. Gostaria de destacar mais uma qualidade sua Talita, a alegria, você proporciona muita paz. Patricia Chimin (Verrrrdinha), a amiga mais neura que tenho, rsrsrsrs, uma amiga parceira, que é facilmente encontrada no terceiro andar do ICB, cheia de manias..tiques...e neuras, mas que é gente boa para caramba. Muito criteriosa e essa sua qualidade me ajudou muito na pesquisa. Andressa Bolsoni, amiga de Colatina, terra boa que tudo dá... é Cola, quem diria, você vindo de Colatina e sendo muito amiga de um pretinho de Teresina, mas são coisas da vida...trabalhar com 
você Cola, me proporcinou algumas coisas, uma delas é saber o quanto sou lerdo na bancada...ela trabalha a mil por hora e muito bem. Mas uma característica indiscutível é o seu "toc toc" sempre presente nos corredores do ICB. Ao Felipe Natali, amigo de Maringá, parceiro demais. Obrigado pela alegria diária sempre compartilhada. Aprendi muito com você seu cabra. Michele Trindade (Xêxê) amiga sempre presente e que hoje mora longe, alegria muito boa a qual vivemos juntos. Augusto César, o ser mais chato do qual sou amigo... mas independente disso, uma pessoa de suma qualidade na pesquisa e como pessoa...Trabalhar com vocês me proporcionou o maior sentimento entre amigos que é a união... E espero que em breve possamos trabalhar juntos novamente.

À Maria Isabel Alonso-Vale, amiga verdadeira que tive o prazer de conviver na pesquisa e no dia-a-dia...Alonso-Vale, saiba que você me ajudou muito ao longo desse tempo aqui em São Paulo. Pessoa que vou ter o prazer de dizer aos meus filhos o quanto és especial. Em breve vamos dividir projetos e trabalhos.

A amiga Miriam Fonseca-Alaniz, pessoa que me apresentou o tecido adiposo e responsável por gostar tanto do que faço. Saiba que você é muito querida e nada vai desconfigurar a nossa amizade.

Ao amigo Emidio Matos, conterrâneo do Piauí, pessoa com a qual dividi dificuldades devido a nossa distância familiar, mas sem dúvidas conseguimos conduzir tudo de forma simples e positiva. E logo logo iremos trabalhar juntos em nosso estado...Aproveito, para agradecer também o lado fraternal da sua família que sempre esteve presente (Tia Totonha e Leila).

Aos meus amigos de Teresina-PI, Alisson Alves, Ana Raquel, Rochelle Castro, Slania Bastos, Gabriela Graziane, Wilker Rangel, Junior (Malleta) e Delfina, Mara Arrais, Ana Raquel, Anderson Silva, Carol Silva, Mara Pierote, Savya Ralley, Savio Nery, Antônia Claudia, Prof. David Emérito, Marcos Antônio, Vanessa Lima, Artemizia Francisca, Juliana Paz, Prof. Francisco Teixeira, Prof. Carminha, Moises Tolentino, Sr. José Oliveira, Dona Creuza Rabelo, Lucillia Rabelo, Jorge Belchior, Amanda Marreiro, Taline Figueiredo (familia), Tupy Neto, Rodrigo Figueiredo, Cintia Silva, Raquel Figueiredo, Erica Figueiredo, Erisvaldo Leal meu muito obrigado pelo apoio de sempre. 
Aos meus amigo-irmãos Aureliano Machado, Túlio Melo, Ayse Suzel e George Sales muito obrigado por tudo. Saibam que vocês fizeram parte no meu diaa-dia ao longo deste período. Aproveito o ensejo para agradecer as famílias Machado de Oliveira (Nonato in memoriam e Raimunda) e Melo Castelo Branco (Tancredo e Fátima).

Agradeço a minha família Torres-Leal pelo carinho, afeto e amor sempre compartilhado e saibam que essa conquista também é de vocês.

À Profesora Dilina Marreiro minha fiel orientadora que tenho o prazer de manter um excelente contato até os dias de hoje. Logo estou chegando para trabalharmos juntos. Não tenho dúvidas que vamos continuar mantendo esse nosso laço bem forte.

Aos amigos da Faculdade de Ciências Farmâceuticas-USP, Elaine Midori, Jorge de Lima, Ana Mara, Liliane Pires, Kaluce Gonçalves, Alexandre Lobo, Michelle Garcêz, Michelle Trindade, Ivanir Pires, Mariana Rezende, José Donato, Rogerio Pedrosa, Andrea Bonvini, Moniquinha Yamada, Tatiane Mieko, Patricia Jacob, Edilson Feitosa, Mônica Dealis (secretária), Patricia Borges, Milessa (Oreia seca), Claudimar, Felipe Gomes, Mariana Carrapeiro, Eliane Bonifacio, Rosangela Pavan, Ariana Rocha, Illana Louise, Barbara Rita Cardoso, João Alfredo, Lucina Nishimura, Marcelo Rogero, Viviane Rocha vocês são especiais.

Ao meu ex-orientador de mestrado e amigo Professor Julio Tirapegui, meu muito obrigado pela amizade e confiança. Obrigado por sempre manter as portas abertas. Nossa convivência gerou vários frutos.

À professora Silvana Bordin, pela amizade, por me ajudar de forma especial nos meus experimentos, ao abrir as portas do seu laboratório. Serei eternamente grato.

Ao professor Angelo Rafael Carpineli e sua técnica Marlene pela colaboração em meus experientos de secreção de insulina.

Aos professores que participaram da minha qualificação Willian Festtucia e Lício Velloso. 
Ao amigo Lucas Pantaleão, parceiro desde a época do mestrado que me ajudou e me ajuda sempre que preciso. Muito obrigado Buiu, saiba que ainda iremos trabalhar juntos.

Às Fernanda's Santana e Shinagawa... como é fácil falar de vocês. A definição de amizade pode ser díficil de ser dita. Mas saibam que suas atitudes falam por si. Obrigado pela alegria e compartilha. E agredado a nossa amizade tem o Pedin, o portuga mais gente boa que conheço rsrsrs um amigo que gosto muito, as conversas com você são muito proveitosas. E o Jonh (o are we) não tenho muito o que falar...mas Santana desejo felicidades a vocês.

Aos amigos que fiz em São Paulo, Guilherme Almeida, Boi, Limeira, Aladir, Renata, Mariana, Renato Nachbar, Diogo Vasconcelos, Carlão Flores, Gabi Moreira, Teca, Laila Romagueira, Roberto Peinado, Daniel Simões, Pablo, Lauriane Masi, Amanda Martins, Bruna Lima, Virginia Facundo e Guga Oliveira, muito obrigado pelos momentos de alegria.

Às contemporaneas de mestrado Gabriela Teodoro e Daiana Vianna, hoje vendo o que construímos me enche de orgulho...muito obrigado pela amizade verdadeira.

À Fundação de Amparo à Pesquisa do Estado de São Paulo (FAPESP), pela concessão da bolsa (processo 2010/50093-7).

Embora esta lista seja extensa, peço desculpas aos que colaboraram, mas, por falha da minha memória, não foram aqui citados.

Abraço a todos e fiquem com DEUS. 
"Rather than love, than money, than fame, than equity, give me truth"

(Henry Thoreau)

"Vi claramente que as coisas corruptíveis são boas. Não se poderiam corromper se fossem sumamente boas, ou se não fossem boas. Se fossem absolutamente boas, não seriam corruptíveis. $E$ se não fossem boas, nada haveriam a corromper. $A$ corrupção de fato é um mal, porém, não seria nociva se não diminuísse um bem real. Portanto, ou a corrupção não é um mal, o que é impossível, ou - e isto é certo - tudo aquilo que se corrompe sofre uma diminuição de bem. Mas privadas de todo bem, deixariam inteiramente de existir. Se de fato continuassem a existir sem que pudessem corromper-se, seriam melhores, porque permaneceriam incorruptíveis.

Mas haverá maior absurdo do que afirmar que as coisas se tornariam melhores perdendo todo o bem? Portanto, se são privadas de todo o bem, deixarão totalmente de existir. Logo, enquanto existem, são boas. Portanto, todas as coisas, pelo fato de existirem, são boas. E aquele mal, cuja origem eu procurava, não é uma substância. Porque, se o fosse, seria um bem. Na verdade, ou seria substância incorruptível, e então, se não fosse boa, não poderia corromper. Desse modo, vi e me pareceu evidente que criaste boas todas as coisas, e que nada existe que não tenha sido criado por ti. E porque não as criaste todas iguais, cada uma em particular existe porque é boa, e tomadas em conjunto são muito boas. De fato, o nosso Deus "criou todas as coisas muito boas". 


\section{RESUMO}

Torres-Leal FL. Leucina intensifica o ganho de adiposidade e as respostas metabolicas do tecido adiposo em ratos previamente obesos por dieta hiperlípidica e a gordura subcutânea é uma das mais afetadas [Tese (Doutorado em Fisiologia Humama)]. São Paulo: Instituto de Ciências Biomédicas, Universidade de São Paulo; 2012.

Investigar os efeitos do consumo de leucina sobre a adiposidade e a funcionalidade do tecido adiposo branco (TAB) em ratos alimentados com dietas controle ou hiperlipídicas (HL). Para tanto, ratos foram submetidos a dieta HL por 10 semanas para indução do modelo de obesidade (EXPERIMENTO I). Foi observado que a obesidade por dieta HL promove: maior adiposidade, maior hipertrofia de adipócitos, intolerância à glicose, resistência à insulina, maior captação de glicose na condição basal realizada pelos adipócitos, menor captação de glicose quando estimulados com insulina, reduzida lipogênese e síntese de novo de ácidos graxos na condição estimulada, menor síntese de glicerol e por fim, expressiva redução na atividade máxima das enzimas que participam da síntese de novo de ácido graxo. Após a caracterização do modelo de obesidade, os animais foram submetidos a 6 semanas de suplementação com leucina. Ao final, podemos observar que a suplementação com leucina exerceu efeitos distintos, dependente da condição metabólica em vários parâmetros relacionacidos como a adiposidade. Estas respostas foram pronunciadas no grupo de animais alimentados com dieta HL e suplementados com leucina, principalmente pela maior massa adiposa em diferentes coxins adiposos, maior hipertrofia de adipócitos da região subcutânea (SC), incremento na síntese de novo de ácidos graxos em adipócitos SC, bem como, aumento na incorporação de ácidos graxos (palmitico e oleico) em adipócitos SC. Além disso, observamos efeitos da suplementação com leucina sobre a expressão gênica de PPAR $\gamma$, GPAT, FABP e PEPCK no tecido adiposo SC. Assim, foi demonstrado que a suplementação com leucina quando utilzada em modelo de obesidade e resistência à insulina acaba favorecendo maior incremento da massa de gordura SC via PPAR $\gamma$.

Palavras-chave: Obesidade. Leucina. Resistência à insulina. Lipogênese. 


\begin{abstract}
Torres-Leal FL. Leucine intensifies adiposity and metabolic responses in adipose tissue of previously hyperlipidic diet obese rats, and subcutaneous fat is one of the most affected [Ph. D. thesis (Human Fisiology)]. São Paulo: Instituto de Ciências Biomédicas, Universidade de São Paulo; 2012.

Investigate the effects of leucine consumption on adiposity and functionality of white adipose tissue (WAT) in rats fed with control or hyperlipidic (HL) diets. Rats were submitted to $\mathrm{HL}$ diet for 10 weeks to induce obesity (EXPERIMENT I). It was observed that HL-induced obesity promotes: increased adiposity, larger adipocytes (hypertrophy), glucose intolerance, insulin resistance, increased glucose uptake in basal condition, decreased glucose uptake when stimulated with insulin, reduced lipogenesis and de novo fatty acids synthesis in stimulated condition, lower glycerol synthesis, and expressive reduction in maximal activity of enzymes involved in de novo fatty acids synthesis. After obesity characterization, animals were submitted to 6 weeks of leucine supplementation. At the end, we could observe that leucine supplementation exerted distinct effects, depending on the metabolic condition in several parameters related to adiposity. These responses were more pronounced in animalsfed with HL diet and supplemented with leucine, mainly due to higher adipose mass in different fat pads, larger adipocytes in subcutaneous fat (SC), increase of de novo fatty acids synthesis, as well as, an increase in fatty acids incorporation (palmitic and oleic) in SC adipocytes. Furthermore, we observed effects of leucine supplementation on PPAR $\gamma$, GPAT, FABP and PEPCK gene expression in SC fat. Thus, it was demonstrated that leucine supplementation, when used in an obesity and insulin resistance model, favors the increase of adipose mass in SC fat via PPAR $\gamma$.
\end{abstract}

Keywords: Obesity. Leucine. Insulin resistance. Lipogenesis. 


\section{SUMÁRIO}

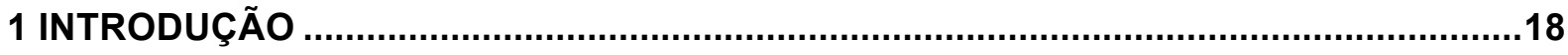

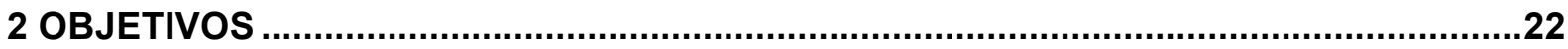

2.1 Geral

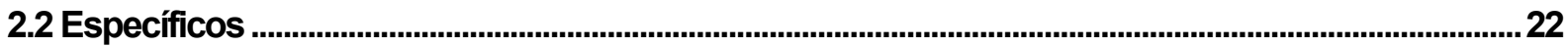

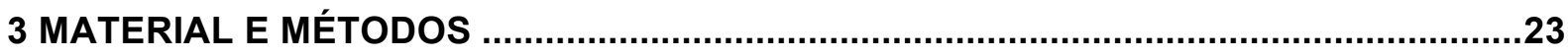

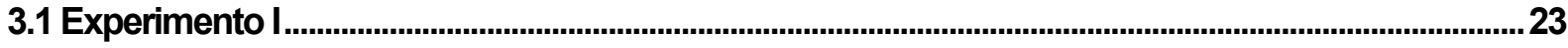

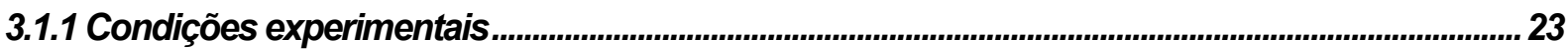

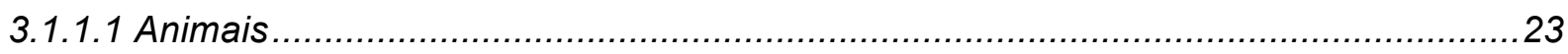

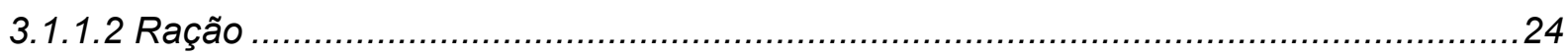

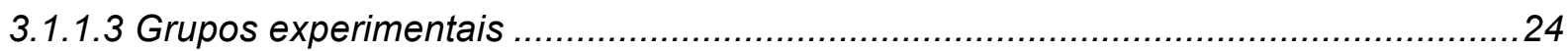

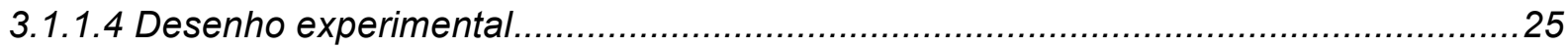

3.1.1.5 Manipulação dos animais e determinação do peso corporal e do consumo de ração e

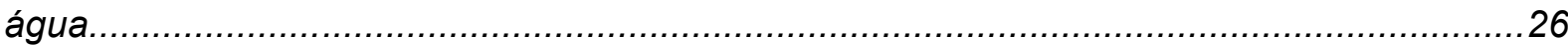

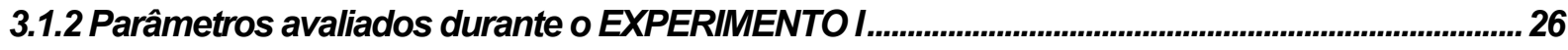

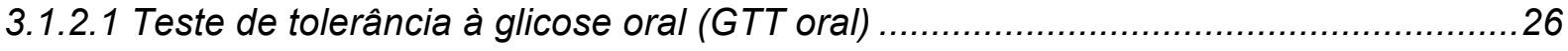

3.1.2.2 Teste intravenoso de tolerância à insulina (ITT) ................................................26

3.1.2.3 Sacrifício dos animais e coleta de sangue e tecidos.............................................27

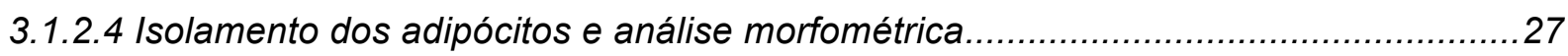

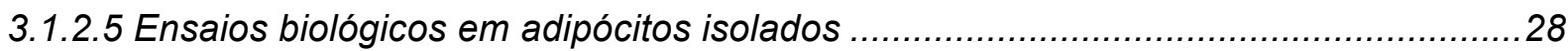

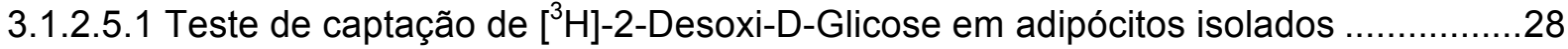

3.1.2.5.2 Teste de incorporação de D-[U- $\left.{ }^{14} \mathrm{C}\right]$-Glicose em lipídios e oxidação de D-[U- $\left.{ }^{14} \mathrm{C}\right]-$

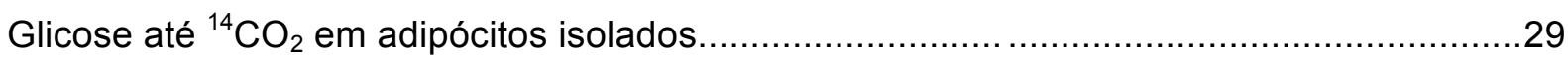

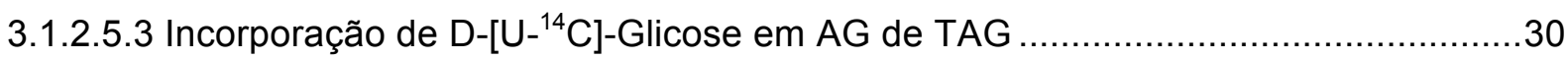

3.1.2.6 Determinação da atividade de enzimas lipogênicas ............................................. 31

3.1.2.6.1 Atividade da glicose-6-fosfato-desidrogenase (G6PDH) ......................................

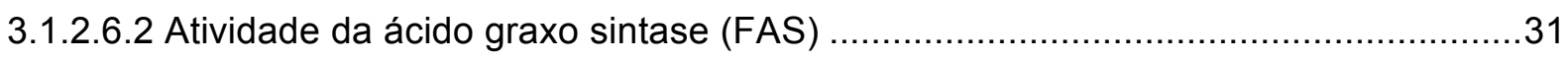

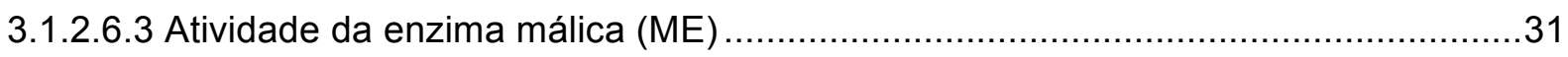

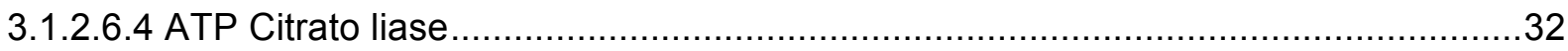

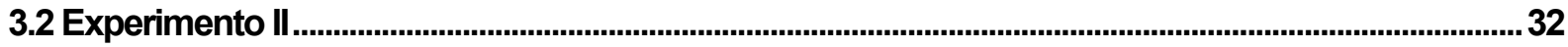

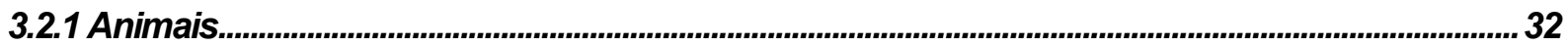

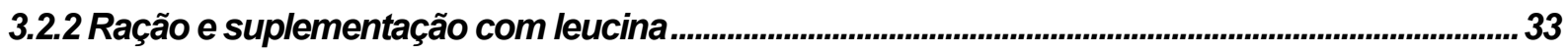

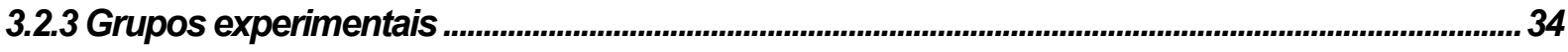

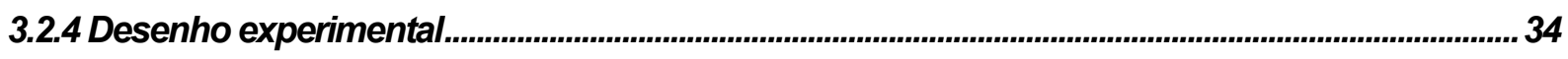

3.2.5 Manipulação dos animais e determinação do peso corporal e do consumo de ração e água..35

3.2.6 Parâmetros avaliados durante o EXPERIMENTO II.......................................................................... 35 


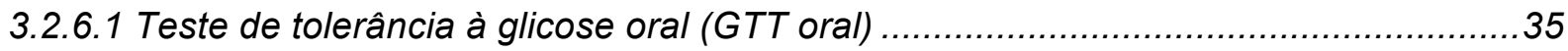

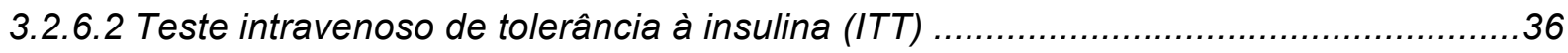

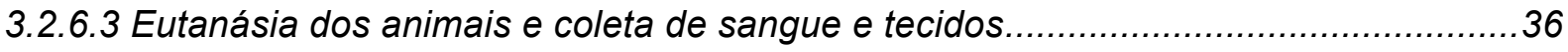

3.2.6.4 Isolamento dos adipócitos e análise morfométrica dos adipócitos.............................36

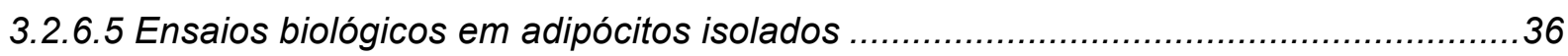

3.2.6.5.1 Teste de incorporação de D-[U- $\left.{ }^{14} \mathrm{C}\right]$-Palmitato e $\left[{ }^{3} \mathrm{H}\right]$-Oleico em lipídios em

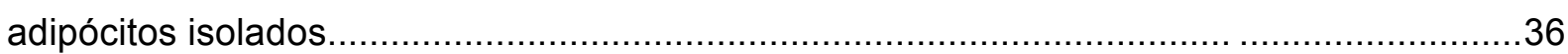

3.2.6.5.2 Teste de avaliação da atividade lipolítica frente a estímulo com isoproterenol (ISO)

3.2.6. 6 Determinação da atividade de enzimas lipogênicas ............................................ 38

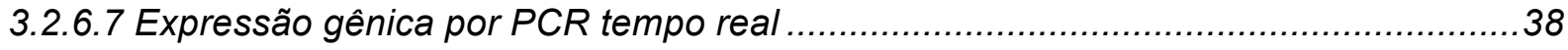

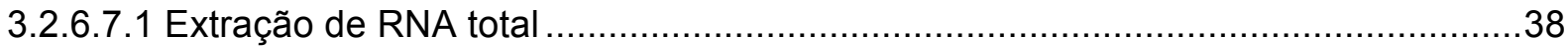

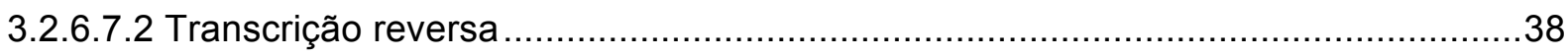

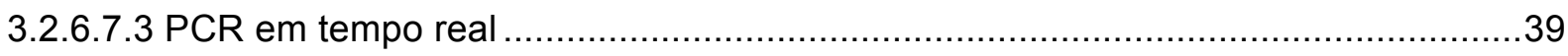

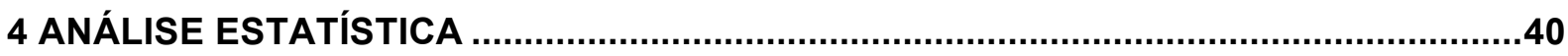

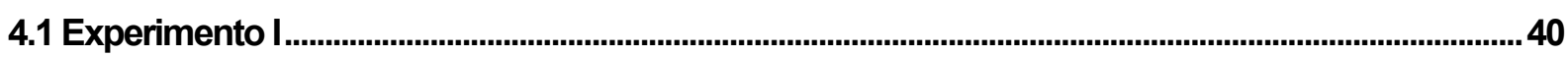

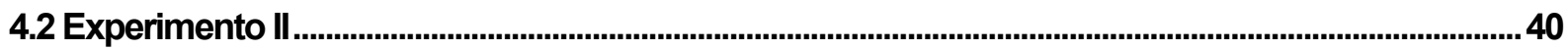

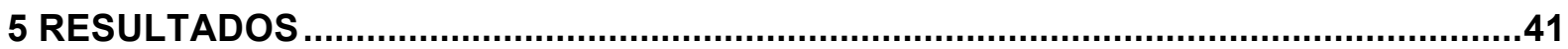

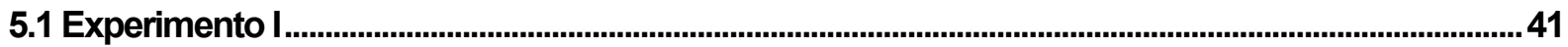

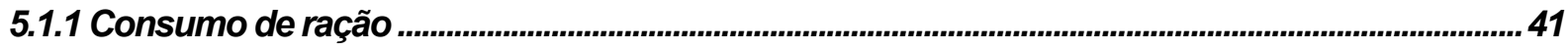

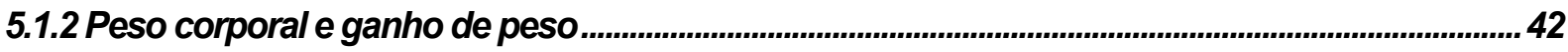

5.1.3 Efeitos da dieta hiperlipídica sobre a adiposidade, a hipertrofia adiposa e o número de adipócitos ........................................................................................................................................................................ 43

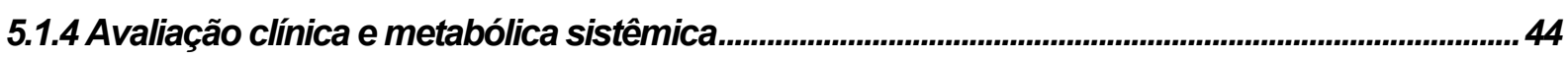

5.1.4.1 Teste oral de tolerância à glicose (GTT oral) ....................................................... 44

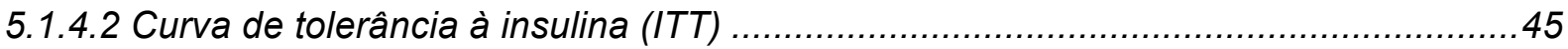

5.1.5 Ensaios com adipócitos isolados ................................................................................................................ 46

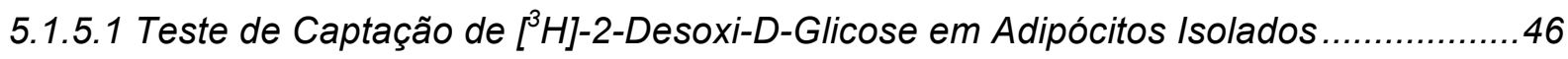

5.1.5.2 Incorporação de $D-\left[U-{ }^{14} C\right]$-Glicose em lipídios de adipócitos isolados ......................47

5.1.5.3 Incorporação de $D-\left[U-{ }^{14} C\right]$-Glicose em AG de TAG ...............................................48

5.1.5.4 Incorporação de $D-\left[U-{ }^{14} C\right]$-Glicose em glicerol do TAG ........................................49

5.1.6 Atividade máxima das enzimas envolvidas na lipogênese de novo........................................... 50

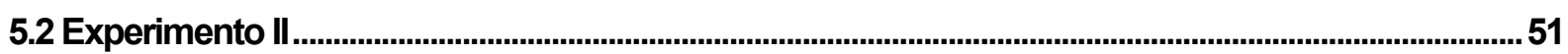

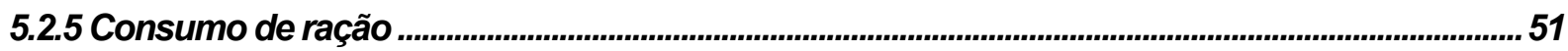

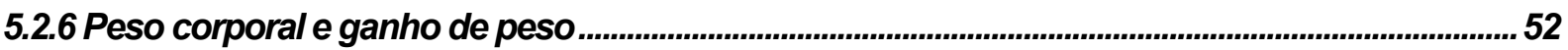

5.2.7 Efeitos da suplementação com leucina sobre a adiposidade e o volume de adipócitos.. 
5.2.8 Avaliação clínica e metabólica sistêmica.

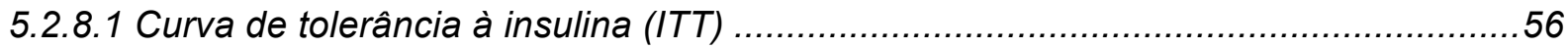

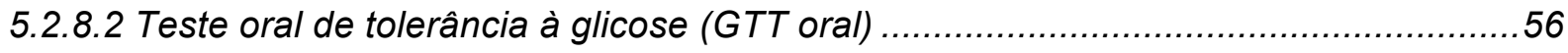

5.2.8.3 Secreção estática de insulina pela ilhota pancreática isolada e insulina de jejum.....57

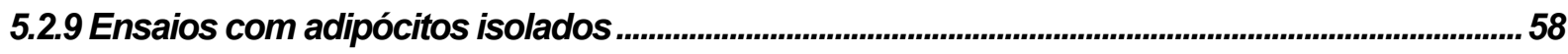

5.2.9. 1 Avaliação da capacidade de adipócitos isolados em captar [ $\left.{ }^{3} \mathrm{H}\right]-2-D e s o x i-D$-glicose 58

5.2.9. 2 Avaliação da capacidade de oxidação .................................................................60

5.2.9.3 Avaliação da capacidade de incorporação de $D-\left[U-{ }^{14} C\right]$-Glicose em lipídios.............61

5.2.9.4 Avaliação da incorporação de $D-\left[U-{ }^{14} C\right]$-Glicose em ácidos graxos de TAG.............62

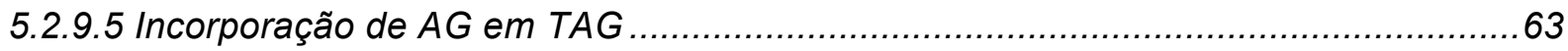

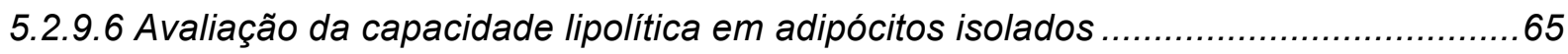

5.2.10 Avaliação da atividade máxima de enzimas envolvidas na lipogênese de novo........................67

5.2.11 Expressão gênica por PCR em tempo real (qPCR) no tecido periepididimal (PE) e subcutâneo (SC)...................................................................................................................................................69

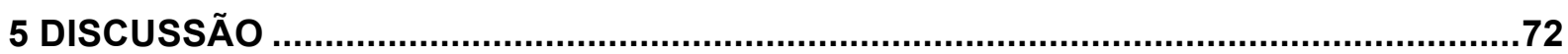

5.1 Caracterização do modelo de obesidade e resistência à insulina no EXPERIMENTO I..................72

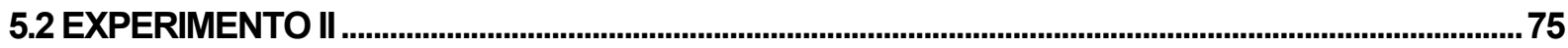

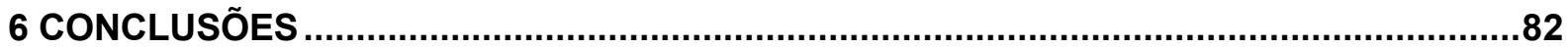

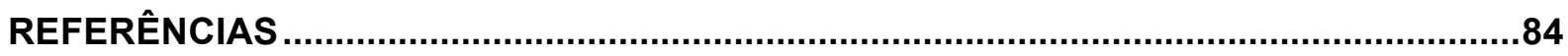

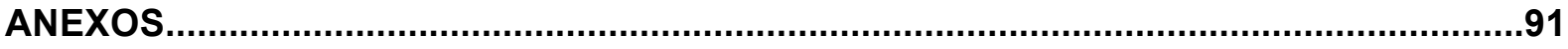

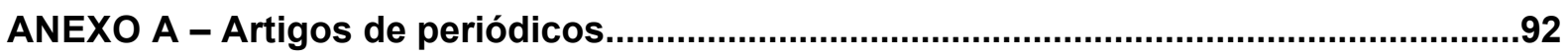

ANEXO B - Gel para verificar a integridade do RNA total extraído no TAB subcutâneo

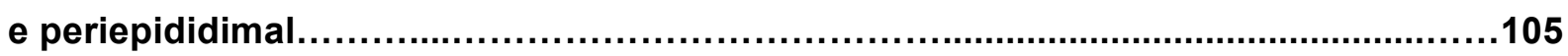




\section{INTRODUÇÃO}

A vida moderna trouxe profundas alterações para o estilo de vida que acarretaram maior incidência de doenças metabólicas. Entre essas alterações estão o consumo de dietas cada vez menos saudáveis e hábitos de vida cada vez mais sedentários que desencadeiam aumento constante da massa gorda corporal e dos riscos cardiometabólicos. Há muito tempo, a obesidade e o diabetes mellitus tipo 2 (DM2) tornaram-se problemas de saúde pública de proporções epidêmicas (Grundy, 2002).

A obesidade é considerada fator de risco para desenvolvimento de DM2, hipertensão arterial sistêmica, doença coronariana, acidente vascular cerebral, osteoartrite, apneia do sono, e diversos tipos de câncer (Kahn e Flier, 2000; Spielgelman e Flier, 1996). O excesso de adiposidade corporal é o maior contribuinte do DM2, caracterizado por resistência à insulina (RI), hiperglicemia e progressiva perda de função das células $\beta$-pancreáticas (Blaschke et al., 2006). A $\mathrm{RI}$, definida como menor resposta biológica para uma determinada dose de insulina, apresenta maior incidência em indivíduos obesos, embora haja grande margem de variação (Prentki et al., 1997).

A relação entre o aumento do peso corporal e da adiposidade e a menor sensibilidade insulínica tem sido demonstrada em humanos e animais (Bak et al., 1992; Friedman et al., 1992; Torres-Leal et al., 2010, 2011). Destaca-se, ainda, que a RI está relacionada à obesidade visceral, sendo componente da síndrome metabólica - conjunto de anormalidades metabólicas e fisiológicas que inclui adiposidade visceral, hipertensão arterial, hiperinsulinemia, RI, fibrinólise diminuída, dislipidemia aterogênica e intolerância à glicose (Koffler et al., 1989; Reaven, 1988, 1995). Sob este contexto, tratamentos efetivos são necessários para reduzir esta progressão.

A alimentação é considerada uma ferramenta de ação direta seja ela no ganho ou perda de peso corporal. No primeiro caso, as dietas ocidentais caracterizadas pela alta densidade energética são apontadas como um dos fatores de maior destaque na epidemia da obesidade. Por outro lado, intervenções dietoterápicas como a re-educação alimentar e o uso de suplementos alimentares tem ganhado destaque ao longo dos anos como estratégias eficazes e seguras no combate ao excesso de gordura corporal. 
Nesse sentindo, estudos prévios têm demonstrado que a suplementação com leucina apresenta potencial terapêutico por regular o peso corporal e a homeostase glicêmica (Cota et al., 2006; Donato et al., 2006, 2007; Freudenberg et al., 2012; Halton et al., 2004; Layman, 2003; Macotela et al., 2011; Teodoro et al., 2012; Vianna et al., 2012; Zhang et al., 2007). Desse modo, alguns estudos suportam a hipótese de que a leucina exerce um importante papel na regulação do balanço energético e do metabolismo por influenciar diretamente tecidos periféricos, como o tecido adiposo branco (TAB), o fígado e o músculo esquelético. Nesta perspectiva, os efeitos metabólicos dos aminoácidos de cadeia ramificada (ACR) - leucina, valina e isoleucina - têm recebido muita atenção no decorrer dos anos e, em especial, a leucina é descrita como nutriente sinalizador de ação direta em adipócitos (Lynch et al., 2002).

O TAB é considerado muito ativo na utilização dos $A C R$, especialmente em um estado nutricional adequado. A capacidade do TAB em metabolizar ACR é consideravelmente alta, podendo ser maior que a do músculo esquelético. A concentração de leucina no meio intracelular do TAB é quatro vezes maior que a do músculo esquelético; no entanto, o tecido muscular apresenta de 25 a $50 \%$ mais leucina no meio extracelular (Hutson et al., 1980; Minemura et al., 1970).

Tem sido observado que indíviduos obesos apresentam altas concentrações plasmáticas de ACR em decorrência de alterações nas enzimas que participam do metabolismo destes aminoácidos (She et al., 2007). Nesse sentido, em modelos animais de obesidade ob/ob ou Zucker observou-se que a expressão proteica da enzima amino-transferase de cadeia ramificada mitocondrial (BCATm) e desidrogenase de cetoácidos de cadeia ramificada (BCKD-E1) estão significativamente reduzidas no TAB destes animais (She et al., 2007). Por outro lado, humanos quando submetidos a perda de peso por cirurgia bariátrica apresentam reduções significativas nas concentrações plasmáticas de ACR (She et al., 2007).

A degradação da leucina no TAB é estimulada pela insulina (Rosenthal et al., 1974), gerando acetil-CoA e acetoacetato, que podem ser oxidados como energia ou ser usados para a síntese de ácidos graxos de cadeia longa e colesterol (Meikle e Klain, 1972). Em animais no estado pós-prandial, os produtos do catabolismo da leucina são utilizados para a síntese de ácidos graxos, enquanto que em animais em jejum podem desempenhar papel na geração de cetoácidos (Rous et al., 1980). 
Além disso, foi descrito que a leucina estimula a lipogênese, por ativar a enzima acetil-CoA carboxilase (Krause et al., 2002).

A leucina é conhecida por estimular a secreção de insulina, glucagon, hormônio do crescimento $(\mathrm{GH})$ e fator de crescimento semelhante à insulina (IGF-1), também atuando como reguladora mais potente da síntese proteica no TAB, por mecanismos independentes da insulina (Lynch et al., 2002). Os efeitos da leucina na síntese proteica no adipócito envolvem a ativação do mTORC1 (complexo 1 da proteina alvo da rapamicina em mamiferos). Neste processo, mTORC1 ativado parece ser essencial na diferenciação de pré-adipócitos, na morfogênese do TAB, no crescimento hipertrófico e na secreção de leptina. Todas estas funções parecem ser reguladas pela leucina. Por exemplo, foi relatado em estudos anteriores com adipócitos que este nutriente regula sua organização (Fox et al., 1998), a secreção e a síntese de leptina e de adiponectina (Roh et al., 2003; Torres-Leal et al., 2011) e a síntese proteica (Lynch et al., 2002). Vários estudos sugerem que mTORC1 seja essencial para a diferenciação e a manutenção dos adipócitos in vitro (Bell et al., 2000; Cho et al., 2004; El-Chaar et al., 2004; Gagnon et al., 2001; Kim e Chen, 2004; Yeh et al., 1995).

Em relação à adiposidade corporal, há evidências de efeitos da suplementação com leucina em reduzir ou não a adiposidade de ratos na dependência das condições experimentais. Nestes estudos, foram utilizadas condições drásticas de restrição alimentar (Donato et al., 2006; Mourier et al., 1997). Em estudo anterior destacamos que ratos previamente obesos e resistentes à insulina quando submetidos à suplementação com leucina por 6 semanas, apresentaram maior potencial lipogênico (Torres-Leal et al., 2011), podendo esta resposta estar diretamente associada à condição metabólica incial de obesidade e resistência à insulina. Em oposição a estes efeitos, a leucina reduziu a massa do TAB de roedores (Donato et al., 2006; Macotela et al., 2011; Vianna et al., 2011; Zhang et al., 2007). Por outro lado, Nairizi et al. (2009), não destacaram este efeito antiobesidade da leucina. Em nossa observação, este aminoácido não reduziu o volume dos adipócitos epididimais e da massa de três distintos coxins adiposos (subcutâneo, epididimal e retroperitoneal) em ratos previamente submetidos à dieta hiperlipídica (HL) (Torres-Leal et al., 2011). Semelhantemente, Teodoro et al. (2012), Balage et al. (2011), e Zeanandin et al. (2012) vêm demonstrando que a suplementação com leucina favorece o ganho da massa adiposa. Paralelamente, 
uma outra pesquisa avaliou o efeito da suplementação crônica (22 semanas) com leucina em ratos idosos e verificou que estes animais apresentam maior peso corporal, maior massa adiposa do coxim perirenal e aumento na expressão gênica de PPAR $\gamma$ (Zeanandin et al., 2012).

É conhecido que o mTORC1 apresenta associação direta com a adiposidade, por modular a atividade do PPAR $\gamma$, em especial, no TAB subcutâneo e marrom (Blanchard et al., 2012), caracterizando uma íntima "conversa" entre estas duas proteinas. A inibição farmacológica do mTORC1 in vitro, por exemplo, compromete a diferenciação de pré-adipócitos em adipócitos maduros pela inibição do PPAR $\gamma$. No entanto, este efeito é completamente revertido pela presença de ligantes sintéticos de PPAR (Kim e Chen, 2004). O tratamento in vivo com rapamicina reduz a expressão gênica no TAB de alguns genes alvos do PPAR $\gamma$ (Houde et al., 2010). A partir das evidências acima podemos destacar um possível papel lipogênico da leucina que é dependente da condição metabólica, no entanto, tal efeito não foi ainda explorado mais diretamente em modelos experimentais de animais alimentados com leucina mediante estudos in vivo e ex vivo.

Considerando que a suplementação com leucina exerce efeito lipogênico dependente da condição metabólica e que o mTOR aparece como um importante regulador da adiposidade via PPAR $\gamma$, avaliou-se, no presente estudo, de qual seria o comportamento desse nutriente na síntese de novo de ácido graxo e de TAG e na esterificação de ácidos graxos em animais controles e obesos resistentes à insulina. Para este fim, ratos tratados com leucina foram avaliados em vários ensaios usando adipócitos subcutâneos e periepididimais na: captação de glicose, incorporação de glicose em lipídio e em ácido graxo, capacidade lipólitica, incorporação de ácido graxo em TAG; bem como, a atividade máxima das enzimas que participam da síntese de novo de ácidos graxo e a expressão de vários genes envolvidos na deposição e captação de ácidos graxos em duas diferentes regiões adiposas (subcutânea e periepididimal). 


\section{OBJETIVOS}

\subsection{Geral}

Investigar os efeitos do consumo de leucina sobre a adiposidade e a funcionalidade do TAB em ratos alimentados com dietas controle ou hiperlipídicas.

\subsection{Específicos}

Avaliar o efeito da ingestão de leucina em ratos submetidos às dietas controle ou hiperlipídica sobre:

a) a ingestão alimentar e a evolução ponderal dos animais;

b) a tolerância à glicose e a sensibilidade sistêmica à insulina;

c) a função metabólica do $T A B$, mediante a quantificação da captação de glicose, da resposta lipolítica, da síntese de triacilgliceróis (a partir de glicose, palmitato e ácido oleico), da atividade das principais enzimas envolvidas na síntese de novo de ácidos graxos, bem como a avaliação da expressão gênica do PPAR $\gamma$ e demais enzimas-chaves que participam do processo de esterificação dos ácidos graxos (DGAT, GFAT, PEPCK, LPL e FABP). 


\section{MATERIAL E MÉTODOS}

\subsection{Experimento I}

O EXPERIMENTO I consistiu no estudo do efeito da dieta HL sobre a adiposidade e suas consequências metabólicas em dois coxins adiposos (SC e PE) advindas do excesso de gordura corporal e do tipo de gordura consumida. Os parâmetros de controle foram o acesso à ração e o peso corporal.

Para isso, houveram dois grupos no EXPERIMENTO I, que foram estudados: i) Grupo controle (GCON) ( $n=5)$, que recebeu ração controle (AIN-93M) no período de 10 semanas, e ii) Grupo hiperlipídica (GHL) ( $n=5)$, que serviu como referencial das alterações que ocorrem durante a exposição crônica à dieta HL.

\subsubsection{Condições experimentais}

\subsubsection{Animais}

Foram utilizados Rattus norvergicus da linhagem Wistar, machos, desmamados no $21^{\circ}$ dia de vida, obtidos de colônias de produção do Biotério Central do Instituto de Ciências Biomédicas I da Universidade de São Paulo. Os animais, desmamados, foram mantidos em caixas individuais $(46 \times 24 \times 20 \mathrm{~cm})$, sob condições ambientais controladas, temperatura de $22 \pm 2{ }^{\circ} \mathrm{C}$, umidade relativa de $55 \pm 10 \%$ e ciclo de iluminação 12/12 horas claro/escuro (luz acesa às 6 h).

Todos os procedimentos realizados com os animais foram aprovados pela a Comissão de Ética no Uso de Animais (CEUA) do Instituto de Ciências Biomédicas da Universidade de São Paulo, de acordo com as normas do Sociedade Brasileira de Ciências em Animais de Laboratório (SBCAL). 


\subsubsection{Ração}

As dietas foram preparadas de acordo com as recomendações do American Institute of Nutrition (AIN-93M) (Reeves, 1997), formuladas para a manutenção de roedores (PRAGSoluções, São Paulo, SP) (Tabela 1).

Tabela 1 - Composição das rações utilizadas no EXPERIMENTO I (AIN-93M e AIN-93M modificada).

\begin{tabular}{lcc}
\hline \multirow{2}{*}{ Ingredientes } & Ração controle & Ração hiperlipídica \\
\cline { 2 - 3 } & gramas por 1.000 kcal de ração \\
\hline Amido & 155,40 & 36,25 \\
Sacarose & 25,04 & 25,04 \\
Caseína & 35,05 & 35,05 \\
Óleo de soja & 10,01 & 10,01 \\
Banha de porco & ---- & 56,24 \\
Celulose & 12,52 & 12,52 \\
Mistura salina & 8,76 & 8,76 \\
Mistura vitamínica & 2,50 & 2,50 \\
L-cistina & 0,45 & 0,45 \\
Bitartarato de colina & 0,63 & 0,63 \\
\hline
\end{tabular}

Fonte: Reeves (1997); Torres-Leal et al. (2011).

\subsubsection{Grupos experimentais}

a) Grupo Controle (GCON): consumo ad libitum de ração AIN-93M e água. Animais com livre acesso à ração durante todo o experimento $(n=5)$;

b) Grupo Hiperlipídica (GHL): ingestão ad libitum de ração hiperlipídica e água. Animais com livre acesso à ração durante todo o experimento $(n=5)$. 


\subsubsection{Desenho experimental}

Os grupos foram compostos objetivando a homogeneidade na idade (nascimento e desmame) e no peso corporal inicial, adotando para o peso corporal uma distribuição aleatória, sendo que cada grupo de animais apresentava coeficiente de variação do peso corporal inferior a 10\%. Os animais foram mantidos em gaiolas individuais durante todo o experimento. Os 10 animais do GCON ( $n=5)$ e do $\mathrm{GHL}(n=5)$ foram alimentados com as suas respectivas rações durante 10 semanas e, posteriormente, foram eutanasiados, para caracterização da condição baseline, ou seja, excesso de gordura corporal e consequências metabólicas no TAB atribuídas pela maior deposição deste tecido e pelo tipo de gordura consumido. Durante todo período experimental, os animais dos grupos CON e HL tiveram livre acesso à água e a suas respectivas rações (ração AIN-93M e HL).

Figura 1 - Desenho experimental do EXPERIMENTO I.

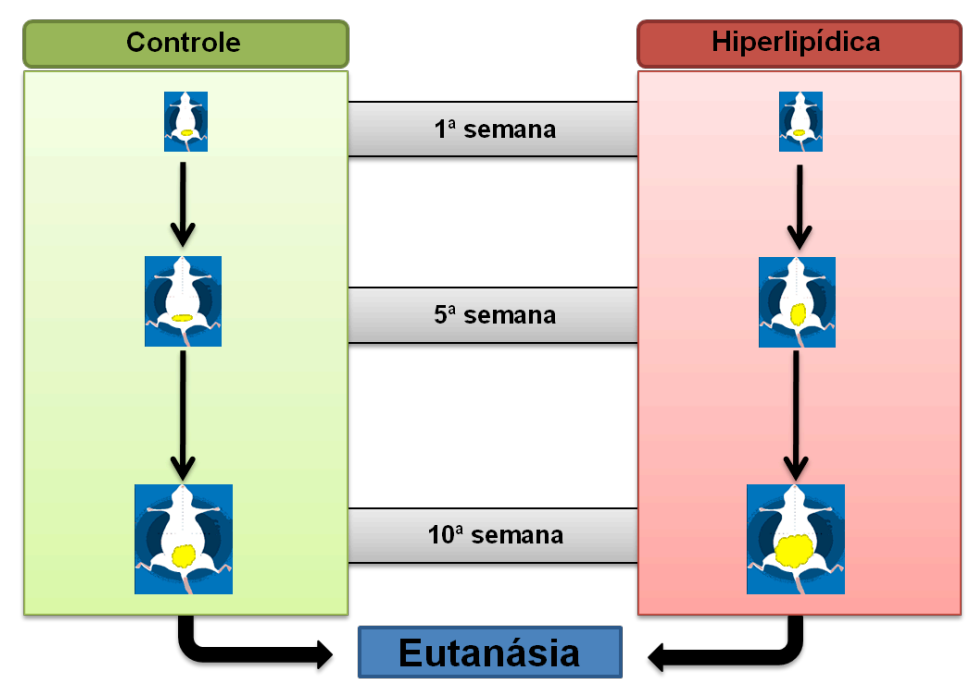

Fonte: Torres-Leal (2012). 
3.1.1.5 Manipulação dos animais e determinação do peso corporal e do consumo de ração e água

Toda manipulação dos animais foi realizada sempre no horário da manhã. Os mesmos foram pesados 1 vez por semana em balança de precisão 0,1 g. Nesse mesmo dia, a ração e a água foram providenciadas e o consumo do período foi determinado. Para a avaliação do consumo de ração e água foi calculada a diferença entre a quantidade oferecida anteriormente e a sobra.

\subsubsection{Parâmetros avaliados durante o EXPERIMENTO I}

\subsubsection{Teste de tolerância à glicose oral (GTT oral)}

Para a determinação da curva glicêmica após sobrecarga de glicose oral, os animais em jejum prévio de $12 \mathrm{~h}$ receberam uma dose de glicose (75 mg/100 g p.c.) via gavagem intragástrica. A glicemia foi determinada através de glicosímetro (One Touch Ultra Johnson \& Johnson's $\left.{ }^{\circledR}\right)$ e os tempos de retirada de sangue pela cauda dos animais foram: 0 (basal), 5, 15, 20 e 60 minutos após a administração de glicose.

\subsubsection{Teste intravenoso de tolerância à insulina (ITT)}

Para a determinação da curva glicêmica após administração de insulina endovenosa, os animais foram anestesiados com Tiopentax® (Tiopental sódico, Cristália, SP, Brasil) (2 mg/100 g de p.c.), com jejum prévio de 12 h. Em seguida, injetou-se uma dose de insulina $(1,12 \mathrm{U} / \mathrm{kg})$ através da veia peniana. A glicemia foi determinada através de glicosímetro (One Touch Ultra Johnson \& Johnson's ${ }^{\circledR}$ ) e os tempos de retirada de sangue foram: 0 (basal), 3, 6, 9, 12, 15, 20, 30 e 45 minutos após a carga de insulina. 


\subsubsection{Sacrifício dos animais e coleta de sangue e tecidos}

Os animais foram mantidos em jejum de $12 \mathrm{~h}$, variando conforme o horário em que o animal foi sacrificado. A ração foi removida por volta das $20 \mathrm{~h}$ e o sacrifício ocorreu na manhã do dia seguinte.

Os animais inicialmente foram anestesiados por via intraperitoneal com Tiopentax - $4 \mathrm{mg} / 100 \mathrm{~g}$ p.c., aplicado por meio de uma seringa de insulina com agulha 20-G. Posteriormente, foram eutanasiados por decapitação, utilizando-se uma guilhotina. Esse procedimento foi realizado de forma muito rápida, visando minimizar qualquer tipo de sofrimento ou estresse, por parte dos animais.

Após a decapitação, o sangue do tronco foi coletado em um tubo, sem anticoagulante, para obtenção da porção sérica do sangue. As amostras foram centrifugadas a 3.000 rotações/minuto, por 20 minutos, a $4{ }^{\circ} \mathrm{C}$. Entre um animal e outro, os tubos para obtenção do soro foram mantidos em gelo, até a centrifugação, quando foram, então, separadas as respectivas porções séricas de cada tubo. As amostras de soro foram devidamente armazenadas em microtubos do tipo eppendorf $1,5 \mathrm{~mL}$ e alocadas em freezer a $-80{ }^{\circ} \mathrm{C}$ para análises posteriores.

Logo após a coleta de sangue, a região abdominal de cada animal foi depilada com lâmina de barbear a fim de evitar que pelos entrassem em contato com as amostras de TAB. Somente após este procedimento os coxins adiposos foram dissecados e coletados para pesagem: subcutâneo (SC), da região abdominal e inguinal, periepididimal (PE) e retroperitoneal (RP). Depois, aproximadamente 1 grama do TAB (SC e PE) foi coletado e, posteriormente, isolado, para realização dos testes biológicos em adipócitos isolados. Amostras dos 3 tecidos adiposos foram armazenadas a $-80^{\circ} \mathrm{C}$ para análises posteriores.

\subsubsection{Isolamento dos adipócitos e análise morfométrica dos adipócitos}

Os adipócitos foram isolados mediante a técnica de digestão de tecido pela colagenase, descrita por Rodbell (1964), com algumas modificações para adaptar o método às nossas condições laboratoriais. Em resumo, os coxins adiposos SC, PE e $\mathrm{RP}$ foram retirados e incubados em $4,0 \mathrm{~mL}$ de tampão digestivo [DMEM, HEPES 25 $\mathrm{mM}, \mathrm{BSA} 4 \%$, colagenase tipo II (Sigma Chemical, St. Louis, MO, Estados Unidos) $1,25 \mathrm{mg} / \mathrm{mL}, \mathrm{pH} 7,45$ ] por cerca de 120 minutos, a $37^{\circ} \mathrm{C}$, em banho-maria, com 
agitação orbital (150 rpm). Em seguida, a amostra foi filtrada em peneira plástica com malha fina (que retém restos teciduais e vasos não digeridos) e lavada por três vezes com $25 \mathrm{~mL}$ de tampão EHB (sais de EARLE, HEPES $25 \mathrm{mM}$, BSA 1\%, piruvato de sódio $1 \mathrm{mM}$, sem glicose, $\mathrm{pH} 7,45)$ mantido a $37^{\circ} \mathrm{C}$. Para a determinação do lipócrito (porcentagem de adipócitos contidos na suspensão celular total), aproximadamente $40 \mu \mathrm{L}$ da suspensão celular em tampão EHB foram colocados em capilar de vidro e submetidos à rápida centrifugação (2.000 rpm por 1 minuto). O volume total da suspensão corresponde a $100 \%$ e o volume de adipócitos obtido após a centrifugação nos fornece o lipócrito da amostra. Para análise morfométrica, alíquotas de suspensão celular foram avaliadas em microscópio óptico (aumento de 100x) acoplado à câmera digital 1.3 MP (Moticam 1000 - MOTIC). Utilizou-se o programa Motic-Images Plus 2.0 para medição da área transversal celular, da qual se obteve o raio celular médio. Em cada preparação foram medidas 50 células. A partir deste valor, assumindo-se que o adipócito isolado é esférico, foram calculados o volume, a área de superfície celular média e o número de células, conforme as fórmulas propostas por Fine e Girolamo (1997).

\subsubsection{Ensaios biológicos em adipócitos isolados}

Os ensaios biológicos foram realizados em adipócitos isolados dos coxins adiposos SC e PE.

\subsection{Teste de captação de $\left[{ }^{3} \mathrm{H}\right]-2-$-Desoxi-D-Glicose em adipócitos isolados}

As taxas de captação de $\left[{ }^{3} \mathrm{H}\right]$-2-desoxi-D-glicose $\left(\left[{ }^{3} \mathrm{H}\right]-2 \mathrm{DG}\right)$ em adipócitos isolados foram mensuradas na ausência (basal) e na presença (de concentração maximamente estimulante, $10 \mathrm{nM}$ ) de insulina, afim de investigar a capacidade de transportar especificamente glicose para dentro da célula. $A\left[{ }^{3} \mathrm{H}\right]-2 \mathrm{DG}$ é captada pela célula e é transformada em 2-DG-6-P, porém a partir desta etapa, não é mais metabolizada, além de atuar como inibidor alostérico da enzima subsequente da via glicolítica, a fosfo-glico-mutase (PGM), sendo, assim, um importante marcador de transportador de glicose. 
Alíquotas de $40 \mu \mathrm{L}$ de suspensão celular foram pipetadas em tubos plásticos, contendo ou não $2 \mu \mathrm{L}$ de insulina (concentração final de $10 \mathrm{nM}$ ) e incubadas por 15 minutos a $37{ }^{\circ} \mathrm{C}$. Em seguida, foram adicionados $10 \mu \mathrm{L}$ de ${ }^{3} \mathrm{H}-2 \mathrm{DG}$ (concentração final de $0,4 \mathrm{mM}$ e $1850 \mathrm{~Bq} /$ tubo) e, passados exatos 3 minutos, o transporte foi interrompido com a adição de $250 \mu \mathrm{L}$ de phloretin 0,6 mM (em EHB e DMSO 0,05\%) a $4{ }^{\circ} \mathrm{C}$. Para avaliação da captação, $200 \mu \mathrm{L}$ da mistura final foram transferidos para tubos de microcentrífuga $(0,4 \mathrm{~mL})$ contendo $200 \mu \mathrm{L}$ de óleo de silicone (densidade $0,963 \mathrm{~g} / \mathrm{mL}$ ), que foram centrifugados por 10 segundos em microcentrífuga (Microfuge E, Beckman Instruments Inc. Palo Alto, Calif.).

A centrifugação teve como objetivo separar a mistura em três fases: uma superior, contendo células compactadas (agregado celular), uma intermediária, correspondente ao óleo, e a mais inferior, constituída pelo tampão aquoso. Feito isso, foi recolhido o agregado celular, mediante a secção do tubo com um estilete na altura da porção média da camada de óleo. Após a separação, a porção contendo o agregado celular foi transferida para um tubo contendo $2,5 \mathrm{~mL}$ de líquido de cintilação (EcoLume ${ }^{T M}$, ICN Pharmaceuticals, Costa Mesa, CA, Estados Unidos) e a radiação emitida foi aferida em contador beta (Micro Beta Trilux 1450LsC luminecense counter). Foi realizada uma determinação de incorporação inespecífica no agregado celular, na qual se quantificou a radioatividade ali retida e que não foi captada pela célula. Esse valor foi subtraído do resultado obtido no final do teste. Isso garante que a contaminação presente no agregado celular não interfira no resultado da captação propriamente dito. Para a determinação da incorporação inespecífica, foram adicionados, primeiramente, a suspensão celular (40 $\mu \mathrm{L})$, em um tubo de ensaio, e, em seguida, o phloretin (inibidor do transporte de glicose), antes de se acrescentar $\left[{ }^{3} \mathrm{H}\right]-2 \mathrm{DG}$. Os resultados foram expressos em $\mathrm{pmol} / \mathrm{cm}^{2} \mathrm{de}$ superfície celular.

3.1.2.5.2 Teste de incorporação de D-[U- $\left.{ }^{14} \mathrm{C}\right]$-Glicose em lipídios e oxidação de D-[U${ }^{14} \mathrm{C}$-Glicose até ${ }^{14} \mathrm{CO}_{2}$ em adipócitos isolados

Adipócitos (concentração final 30-40\%) em tampão Krebs/Ringer/Fosfato /BSA/glicose $1 \mathrm{mM}, \mathrm{pH}=7,4$ a $37^{\circ} \mathrm{C}$, saturado de uma mistura gasosa de carbogênio $5 \%$, foram pipetados em tubos de ensaio de polipropileno $17 \times 100 \mathrm{~mm}$ contendo D$\left[\mathrm{U}-{ }^{14} \mathrm{C}\right]$-glicose $(0,05 \mu \mathrm{Ci} / \mathrm{tubo})$, com ou sem insulina (10 $\left.\mathrm{nM}\right)$. Estes tubos foram 
vedados com tampas de borracha. A seguir, os tubos foram enriquecidos com uma atmosfera com $95 \%$ de $\mathrm{O}_{2} 5 \%$ de $\mathrm{CO}_{2}$ e incubados por 120 minutos em banhomaria, a $37^{\circ} \mathrm{C}$. Ao término da incubação, $0,2 \mathrm{~mL}$ de $\mathrm{H}_{2} \mathrm{SO}_{4}(8 \mathrm{~N})$ foi pipetado sobre a mistura de reação e um flaconete com papel de filtro $(2 \times 4 \mathrm{~cm}$ embebido com $0,2 \mathrm{~mL}$ de etanolamina) foi emborcado (para adsorver o ${ }^{14} \mathrm{CO}_{2}$ liberado da reação). Incubouse por mais 30 minutos, após isso, o flaconete foi preenchido com coquetel de cintilação biodegradável (Universol, ICN) para contagem da radioatividade beta incorporada (Fine e Girolamo, 1997; Lima et al., 1994).

Em seguida, foi realizada a extração dos lipídios mediante a adição de $2,5 \mathrm{~mL}$ de reativo de DOLE (isopropanol:n-heptano: $\mathrm{H}_{2} \mathrm{SO}_{4} 8 \mathrm{~N}, 4: 1: 0.25 \mathrm{v}: \mathrm{v}: \mathrm{v}$ ) no meio de incubação. Agitou-se a mistura por 4 a 5 vezes (sessões de 10 segundos) em vórtex durante 30 minutos. Ao final do período, foram adicionados 1,5 $\mathrm{mL}$ de $\mathrm{n}$-heptano e $1,5 \mathrm{~mL}$ de água deionizada. Após a agitação em vórtex, deixou-se a mistura decantar e alíquotas de $0,5 \mathrm{~mL}$ da fase superior (contendo os lipídios extraídos no nheptano) foram transferidas para flaconetes contendo $2,5 \mathrm{~mL}$ de coquetel de cintilação biodegradável (EcoLume ${ }^{\mathrm{TM}}$, ICN Pharmaceuticals, Costa Mesa, CA, EUA) para contagem da radioatividade beta incorporada. Os resultados foram expressos em nmol. $10^{-6}$ células. $\mathrm{h}^{-1}$.

\subsection{Incorporação de D-[U- $\left.{ }^{14} \mathrm{C}\right]-$ Glicose em AG de TAG}

Uma fração da glicose incorporada em lipídios é resultante da síntese de AG a partir de substratos glicídicos, processo denominado lipogênese de novo. A partir disso, este teste objetiva avaliar a fração de glicose incorporada em AG de TAG. Da mistura composta por TAG previamente obtida no teste de incorporação de D-[U- $\left.{ }^{14} \mathrm{C}\right]-$ Glicose em lipídios, foram retirados $500 \mu \mathrm{L}$, seguidos por evaporação completa, utilizando-se $\mathrm{N}_{2}$ gasoso. Após este processo, adicionaram-se $1 \mathrm{~mL}$ de etanol (95\%) e $250 \mu \mathrm{L}$ de $\mathrm{KOH}$ (40\%); os tubos de ensaio foram frouxamente tampados e colocados em banho-maria, a $60{ }^{\circ} \mathrm{C}$, por 1 hora. Em seguida, o material foi resfriado à temperatura ambiente por aproximadamente 10 minutos e, logo após, adicionaramse $2 \mathrm{~mL}$ de $\mathrm{HCL}(3 \mathrm{~N})$ e $2 \mathrm{~mL}$ de $\mathrm{n}$-heptano. Esta mistura foi homogeneizada em vórtex e deixada em repouso por 10 minutos. Uma amostra de $500 \mu \mathrm{L}$ da fase superior desta mistura foi retirada e transferida para um vial contendo $2,5 \mathrm{~mL}$ de líquido de cintilação, que foi finalmente levado ao contador beta por 5 minutos. 


\subsubsection{Determinação da atividade de enzimas lipogênicas}

Brevemente, as amostras de TA foram submetidas à extração em tampão sacarose $(250 \mathrm{mM})$, EDTA (1 mM), DTT (1 mM), leupeptina $(50 \mu \mathrm{M})$ e aprotinina (5 $\mu \mathrm{M})$ com $\mathrm{pH}$ 7,4 - as amostras foram homogeneizadas por 30 segundos em Polytron e centrifugadas a $20.000 \mathrm{~g} \mathrm{a} 4^{\circ} \mathrm{C}$. No homogenato livre de gordura (fat cake free), as atividades foram determinadas a $340 \mathrm{~nm}$, sendo o coeficiente de extinção para este comprimento de onda igual a 6,22, durante tempo e temperatura específicos para cada enzima. A atividade máxima enzimática foi obtida através da inclinação da curva de absorbância $x$ tempo. As proteínas foram quantificadas pelo kit de ensaio proteico BCA $^{\text {TM }}$ (PIERCE Biotechnology, Rockford, IL, Estados Unidos). Os resultados foram expressos em $\mathrm{nmol} /$ minuto por $\mathrm{mg}$ de proteína presente no extrato.

\subsection{Atividade da glicose-6-fosfato-desidrogenase (G6PDH)}

A atividade da G6PDH foi determinada segundo metodologia aplicada conforme Bergmeyer et al. (1974). O tampão de ensaio utilizado $(270 \mu \mathrm{l})$ consistiu de Tris-HCL (8,6 mM) e $\mathrm{MgCl}_{2}(6,9 \mathrm{mM})$, NADP (0,4 mM) e Triton X-100 (0,05\% (v/v), $\mathrm{pH} 7,6)$. A reação foi iniciada com a adição de $15 \mu$ de glicose-6-fosfato $(1,2 \mathrm{mM})$ ao extrato enzimático, sendo acompanhada por 10 minutos de leitura $\left(25^{\circ} \mathrm{C}\right)$.

\subsection{Atividade da ácido graxo sintase (FAS)}

A atividade da FAS foi determinada segundo metodologia aplicada conforme Bazin e Ferré (2001). O tampão de ensaio utilizado $(260 \mu \mathrm{L})$ consistiu de $\mathrm{KH}_{2} \mathrm{PO}_{4}$ (100 mM), acetil-CoA $(100 \mu \mathrm{M})$ e NADPH $(200 \mu \mathrm{M}), \mathrm{pH}=6,5$. A reação foi iniciada com a adição de $10 \mu \mathrm{L}$ da solução de malonilCoA $(600 \mu \mathrm{M})$ e $\mathrm{KH}_{2} \mathrm{PO}_{4}(100 \mathrm{mM})$ ao extrato enzimático, sendo acompanhada por 10 minutos de leitura $\left(37^{\circ} \mathrm{C}\right)$.

\subsection{Atividade da enzima málica (ME)}

Para a determinação da atividade máxima da ME foi utilizada a metodologia aplicada conforme Bazin e Ferré (2001), utilizando-se tampão de ensaio (270 $\mu \mathrm{L})$ contendo, Tris-HCL (200 mM), $\mathrm{MgCl}_{2} 6 \mathrm{H}_{2} \mathrm{O}$ (20 mM) e NADP (2 mM), pH 7,4. A 
reação foi iniciada com a adição de $15 \mu \mathrm{L}$ da solução de malato (100 mM), Tris-HCL (200 mM) e $\mathrm{MgCl}_{2} \quad 6 \mathrm{H}_{2} \mathrm{O}(20 \mathrm{mM}), \mathrm{pH}$ 7,4 ao extrato enzimático, sendo acompanhada por 10 minutos de leitura $\left(37^{\circ} \mathrm{C}\right)$.

\subsection{ATP Citrato liase}

A atividade da ATP Citrato liase foi determinada segundo metodologia aplicada conforme Bazin e Ferré (2001). Para a determinação da atividade máxima da enzima ATP Citrato liase, utilizou-se tampão de ensaio $(270 \mu \mathrm{L})$ contendo, Tris$\mathrm{HCL}(200 \mathrm{mM}), \mathrm{MgCl}_{2} 6 \mathrm{H}_{2} \mathrm{O}(20 \mathrm{mM})$, Citrato de Potássio (20 mM), DTT (1 mM), Malato desidrogenase $(1 \mathrm{U} / \mathrm{mL})$, CoA $(0,5 \mathrm{mM})$ e NADP $(0,2 \mathrm{mM})$. A reação foi iniciada com a adição de $15 \mu \mathrm{L}$ da solução de ATP (60 mM), Tris-HCL (200 mM) e $\mathrm{MgCl}_{2} 6 \mathrm{H}_{2} \mathrm{O}(20 \mathrm{mM})$ ao extrato enzimático, sendo acompanhada por 10 minutos de leitura $\left(37^{\circ} \mathrm{C}\right)$.

\subsection{Experimento II}

O EXPERIMENTO II teve como objetivo avaliar os efeitos da suplementação com leucina em duas condições metabólicas distintas. E, para tal, avaliamos qual a participação deste aminoácido no metabolismo do tecido adiposo branco.

\subsubsection{Animais}

O EXPERIMENTO II foi realizado com 20 Rattus norvergicus da linhagem Wistar, machos e desmamados no $21^{\circ}$ dia de vida. Os animais foram fornecidos pelo Biotério Central do Instituto de Ciências Biomédicas I da Universidade de São Paulo. Os animais desmamados foram mantidos em caixas individuais (46x24x20 cm), sob condições ambientais controladas, temperatura de $22 \pm 2{ }^{\circ} \mathrm{C}$, umidade relativa de 55 $\pm 10 \%$ e ciclo de iluminação $12 \mathrm{~h}$ claro/escuro (luz acesa às $6 \mathrm{~h}$ ).

Todos os procedimentos realizados com os animais foram aprovados pela Comissão de Ética no Uso de Animais (CEUA) do Instituto de Ciências Biomédicas da Universidade de São Paulo, de acordo com as normas da Sociedade Brasileira de Ciências em Animais de Laboratório (SBCAL). 


\subsubsection{Ração e suplementação com leucina}

As dietas foram compradas à empresa PRAG Soluções, formuladas de acordo com as recomendações do American Institute of Nutrition (AIN-93M) (Reeves, 1997), para a manutenção de roedores, conforme descrito no EXPERIMENTO I (Tabela 1).

A leucina foi adicionada na água de consumo dos animais, na dose de 1,5\% peso/volume (Ajinomoto Interamericana Indústria e Comércio Ltda., São Paulo, Brasil), sendo esta uma dosagem bastante utilizada por importantes grupos de pesquisa (Guo et al., 2010; Macotela et al., 2011; Nairizi et al., 2009; Zhang et al., 2007).

Para a manutenção do mesmo teor de nitrogênio (suplementações isonitrogenadas) dos grupos suplementados com leucina, os demais grupos receberam o acréscimo de uma mistura de aminoácidos não essenciais (alanina, glicina e serina), fornecidos pela Ajinomoto Interamericana Indústria e Comércio Ltda. (São Paulo, Brasil).

Para o estabelecimento da quantidade de cada aminoácido a ser adicionado na água de consumo, inicialmente o peso molecular do nitrogênio foi dividido pelo peso molecular da leucina, permitindo, assim, o cálculo da quantidade de nitrogênio por grama deste aminoácido $(0,11 \mathrm{~N} / \mathrm{g}$ de leucina). Em seguida, multiplicamos o resultado encontrado pela quantidade em gramas do aminoácido leucina (15 g/L) $[0,11 \times 15=1,6]$ e, posteriormente, dividimos o valor obtido pelo número de aminoácidos não essenciais a serem adicionados na água de consumo. Por fim, a partir da multiplicação do resultado encontrado pelo peso molecular de cada aminoácido adicionado e sua respectiva divisão pelo peso molecular do nitrogênio, foi obtido o valor equivalente em gramas de cada aminoácido a ser adicionado em 1 litro de água. Com base nessas informações, a quantidade de aminoácidos adicionados na suplementação controle foi da ordem de 10,26 g (3,40 g de alanina; 2,86 $\mathrm{g}$ de glicina; e 4,01 $\mathrm{g}$ de serina).

Os lotes de L-leucina, alanina, glicina e serina, fornecidos pela empresa Ajinomoto Interamericana Indústria e Comércio Ltda. (São Paulo, Brasil), apresentavam graus de pureza de 99,50 a 100,60\%, segundo certificado de análise de cada lote, realizada pela própria Ajinomoto, que adota valores entre 98,5 e 101\% como níveis adequados. As dietas oferecidas apresentaram as quantidades de 
minerais e vitaminas (Tabela 1) recomendadas para roedores (AIN-93M) (Reeves, 1997).

\subsubsection{Grupos experimentais}

a) Grupo Controle Mix (CON+MIX): ração AIN-93M e água com a mistura de aminoácidos não essenciais. Animais com livre acesso à ração e à água durante todo o experimento $(n=5)$;

b) Grupo Controle Leucina (CON+LEU): ração AIN-93M e água com leucina. Animais com livre acesso à ração e à água durante todo o experimento $(n=5)$;

c) Grupo Hiperlipíica Mix $(H L+M I X)$ : ração $\mathrm{HL}$ e água com a mistura de aminoácidos não essenciais. Animais com livre acesso à ração e à água durante todo o experimento $(n=5)$;

d) Grupo Hiperlipídica Leucina (HL+LEU): ração HL e água com leucina. Animais com livre acesso à ração e à água durante todo o experimento $(n=5)$.

\subsubsection{Desenho experimental}

Os animais, inicialmente, receberam dietas controle $(n=10)$ e $H L(n=10)$ durante 10 semanas. Posteriormente, cada grupo foi distribuído em dois grupos de 5 animais cada, formando o total de 4 grupos. Os grupos foram compostos objetivando a homogeneidade na idade e conforme o peso corporal atingido após o período de 10 semanas, semelhantemente ao EXPERIMENTO I. Além disso, adotou-se, para o peso corporal, uma distribuição aleatória, sendo que cada grupo de animais apresentava um coeficiente de variação do peso corporal inferior a 10\%. Ao final desta conduta, os animais foram distribuídos em quatro grupos: $\mathrm{CON}+\mathrm{MIX}(n=5)$; CON+LEU ( $n=5) ; H L+M I X(n=5) ; H L+L E U(n=5)$, conforme o peso corporal atingido após o período de 15 semanas, e semelhante ao EXPERIMENTO I. Posteriormente, cada grupo teve livre acesso às suas respectivas rações (ração AIN-93M ou Hiperlipídica) e água (mistura de aminoácidos essenciais ou leucina) pelo período de intervenção adicional, com duração de 6 semanas. 
Figura 2 - Desenho experimental do EXPERIMENTO II.

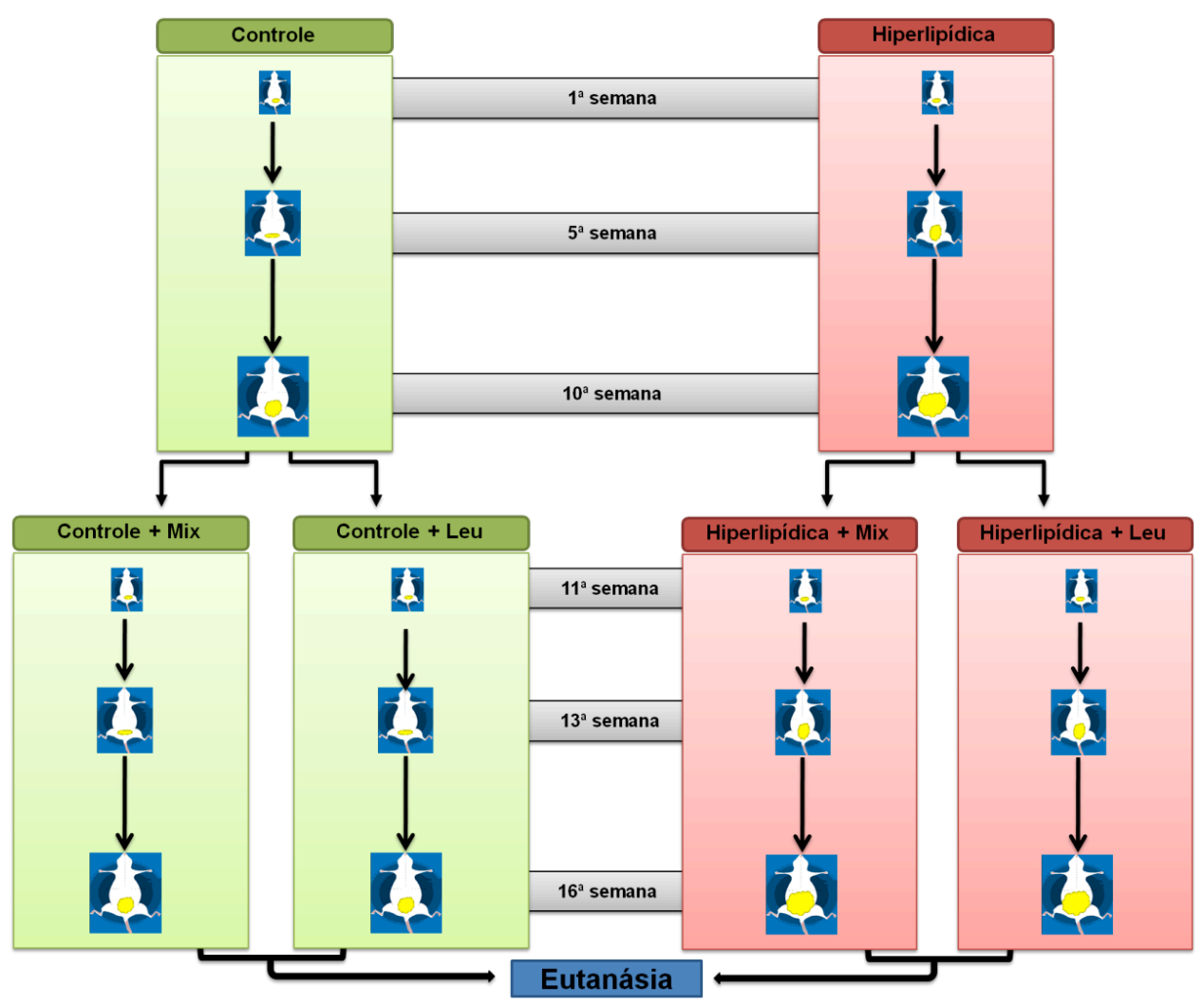

Fonte: Torres-Leal (2012).

3.2.5 Manipulação dos animais e determinação do peso corporal e do consumo de ração e água

A manipulação dos animais e a determinação do peso corporal e do consumo de ração e água foram realizadas conforme descrito no EXPERIMENTO I.

\subsubsection{Parâmetros avaliados durante o EXPERIMENTO II}

3.2.6.1 Teste de tolerância à glicose oral (GTT oral)

O teste de tolerância à glicose oral foi realizado conforme descrito no EXPERIMENTO I. 
3.2.6.2 Teste intravenoso de tolerância à insulina (ITT)

O teste intravenoso de tolerância à insulina foi realizado conforme descrito no EXPERIMENTO I.

\subsubsection{Eutanásia dos animais e coleta de sangue e tecidos}

A eutanásia dos animais e a coleta de sangue e tecidos foram realizadas conforme descrito no EXPERIMENTO I.

\subsubsection{Isolamento dos adipócitos e análise morfométrica dos adipócitos}

O isolamento dos adipócitos e a análise morfométrica foram realizadas conforme descrito no EXPERIMENTO I.

\subsubsection{Ensaios biológicos em adipócitos isolados}

Os ensaios biológicos em adipócitos isolados foram realizados conforme descrito no EXPERIMENTO I.

3.2.6.5.1 Teste de incorporação de D-[U- $\left.{ }^{14} \mathrm{C}\right]$-Palmitato e $\left[{ }^{3} \mathrm{H}\right]$-Oleico em lipídios em adipócitos isolados

Adipócitos (concentração final 30-40\%) em tampão Krebs/Ringer/Fosfato /BSA/glicose $1 \mathrm{mM}, \mathrm{pH}=7,4$ a $37^{\circ} \mathrm{C}$, saturados de uma mistura gasosa de carbogênio $5 \%$, foram pipetados em tubos de ensaio de polipropileno $17 \times 100 \mathrm{~mm}$ contendo D-[U$\left.{ }^{14} \mathrm{C}\right]$-palmitato e $\left[{ }^{3} \mathrm{H}\right]$-Oleico $(0,05 \mu \mathrm{Ci} /$ tubo $)(500 \mu \mathrm{L}$ de volume final). Estes tubos foram vedados com tampas de borracha. A seguir, os tubos foram enriquecidos de uma atmosfera com $95 \%$ de $\mathrm{O}_{2} 5 \%$ de $\mathrm{CO}_{2}$ e incubados por 120 minutos em banho-maria, a $37^{\circ} \mathrm{C}$. Em seguida, foi adicionada a mistura $800 \mu \mathrm{L}$ de silicone $(D=0,98)$, sendo centrifugados a $2.000 \mathrm{~g}$ por $3 \mathrm{~min}$, para separação dos adipócitos do meio de incubação, que foi descartado. Foi realizada a extração dos lipídios mediante a adição de 2,5 mL de reativo de DOLE (isopropanol:n-heptano: $\mathrm{H}_{2} \mathrm{SO}_{4}$ 8N, 4:1:0.25 v:v:v) nos adipócitos. Agitou-se a mistura em vórtex durante 10 segundos e, subsequentemente, 
foram adicionados $1,5 \mathrm{~mL}$ de $\mathrm{n}$-heptano e 1,5 mL de água deionizada. Após a agitação em vórtex, deixou-se a mistura decantar por 15 minutos e alíquotas de $1 \mathrm{~mL}$ da fase superior (contendo os lipídios extraídos no n-heptano) foram transferidas para flaconetes. Após a evaporação do n-heptano, $2,5 \mathrm{~mL}$ de coquetel de cintilação biodegradável (EcoLume ${ }^{\mathrm{TM}}$, ICN Pharmaceuticals, Costa Mesa, CA, EUA) foram adicionados para contagem da radioatividade em contador beta por $5 \mathrm{~min}$. Os resultados foram expressos em nmol. $10^{-6}$ células. $\mathrm{h}^{-1}$.

3.2.6.5.2 Teste de avaliação da atividade lipolítica frente a estímulo com isoproterenol (ISO)

Adipócitos isolados foram incubados em tampão Earle/Hepes contendo 20 $\mathrm{mM} / \mathrm{BSA} 1 \%$ de glicose (5 mM), pH 7,4 na presença ou na ausência de isoproterenol $1 \mu \mathrm{M}$ (agente lipolítico). As células foram previamente tratadas por 30 minutos com adenosina $(0,05 \mu \mathrm{g} / \mathrm{mL})$, a $37{ }^{\circ} \mathrm{C}$. Em seguida, acrescentou-se adenosina desaminase nos tubos basais (ADA, Sigma, 0,2 U/mL em tampão EHB, pH 7,45) e incubou-se por mais 30 minutos, a $37{ }^{\circ} \mathrm{C}$ (para possibilitar a degradação da adenosina liberada pelos adipócitos, pois esta tem ação antilipolítica e pode mascarar os resultados). Em seguida, foi adicionado isoproterenol $\left(2 \times 10^{-6} \mathrm{M}\right)$. O tempo de incubação foi de 30 minutos a $37^{\circ} \mathrm{C}$ e, ao final, a mistura de incubação (volume total $=200 \mu \mathrm{l}$ ) foi centrifugada em microcentrífuga refrigerada a $0{ }^{\circ} \mathrm{C}$ por 5 minutos a $7.000 \mathrm{rpm}$. Alíquotas $(120 \mu \mathrm{L})$ do infranadante foram coletadas para a determinação da concentração de glicerol liberado pelas células, pelo método enzimático-colorimétrico. Utilizou-se kit de determinação de glicerol livre (SigmaAldrich, St. Louis, Estados Unidos). Procurando diminuir ainda mais qualquer influência nos resultados, foi feita uma incubação, a qual seguiu todos os procedimentos até os primeiros 30 minutos de ensaio. $O$ valor obtido nesta determinação (considerado como liberação não específica de glicerol) foi descontado das leituras basal e estimulada por isoproterenol. 


\subsubsection{Determinação da atividade de enzimas lipogênicas}

A determinação da atividade de enzimas lipogênicas foi realizada conforme descrito no EXPERIMENTO I.

\subsubsection{Expressão gênica por PCR tempo real}

\subsection{Extração de RNA total}

Fragmentos de $0,2 \mathrm{~g}$ de tecido adiposo subcutâneo e periepididimal foram

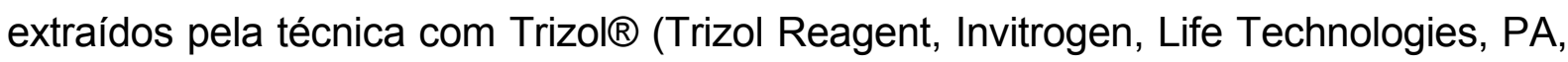
Estados Unidos) para obtenção do RNA total das amostras. Para isso, acrescentou-se às amostras $2 \mathrm{ml}$ de solução de Trizol $\circledast$ (Trizol Reagent, Invitrogen, Life Technologies, PA, Estados Unidos) e foi feita a homogeneização em homogeneizador Polytron® (PT 3100 , Kinematica $A G$ ). Após essa etapa, foram adicionados $0,2 \mathrm{ml}$ de clorofórmio ao homogeneizado e, posteriormente realizada uma centrifugação a $12.000 \mathrm{~g}$ para recuperação da fase aquosa superior. A esta, foi adicionado $0,5 \mathrm{ml}$ de isopropanol e feita nova centrifugação a $12.000 \mathrm{~g}$ para obtenção do precipitado. Descartou-se o sobrenadante e, ao pellet, foi adicionado $1 \mathrm{ml}$ de etanol $75 \%$ seguido de centrifugação a 7500 g. O sobrenadante foi novamente descartado e o procedimento de lavagem com etanol foi repetido. O precipitado final, sem resíduo de etanol, foi ressuspenso em 100 a $200 \mu l$ de água ultrapura (Sigma).

A leitura da concentração de RNA foi realizada a $260 \mathrm{~nm}$ em espectrofotômetro nanodrop (Thermo), utilizando-se $1 \mu \mathrm{l}$ da solução. Para averiguação da pureza da solução de ácido nucleico, foram feitas leituras adicionais a 230 e a $280 \mathrm{~nm}$ para cálculo das razões 260/230 e 260/280.

\subsection{Transcrição reversa}

As amostras contendo $2 \mu \mathrm{g}$ de RNA total foram submetidas à reação de transcrição reversa com primers randômicos. Para tanto, foram adicionados em cada amostra: tampão de enzima ( $50 \mathrm{mM}$ de Tris- $\mathrm{HCl} \mathrm{pH}$ 8,3; $75 \mathrm{mM}$ de $\mathrm{KCl} ; 3 \mathrm{mM}$ e $\mathrm{MgCl}_{2}$ ), mistura de dNTPs (0,5 mM cada), primers randômicos (150 ng) e a enzima Impron II (200U; Promega, EUA), em volume final de $20 \mu \mathrm{l}$. As reações foram 
incubadas por 60 minutos a $42^{\circ} \mathrm{C}$, seguida de aquecimento à $70{ }^{\circ} \mathrm{C}$ por 15 minutos para desnaturação da enzima.

\subsection{PCR em tempo real}

Seguindo criteriosamente as recomendações do fabricante, foram realizados os experimentos de PCR em tempo real nas amostras de cada grupo experimental. A análise dos resultados foi feita utilizando o software disponibilizado pelo fabricante. Resumidamente, para cada condição acima descrita, foram calculados os valores de $\Delta \mathrm{Ct}$ para cada gene de interesse $\left(\Delta \mathrm{Ct}=\mathrm{Ct}\right.$ gene de interesse $\left.-\mathrm{Ct}{ }^{\text {gene constitutivo }}\right)$. Em seguida, tomando-se como referência os valores de $\Delta \mathrm{Ct}{ }^{\mathrm{CTL}}$, calculou-se os valores de $\Delta \Delta \mathrm{Ct}$, resultados da subtração $\Delta \mathrm{Ct}{ }^{\mathrm{CTL}}-\Delta \mathrm{Ct}{ }^{\mathrm{P} 19}$. Os primers utilizados estão listados na tabela abaixo (Tabela 1). Além disso, utilizamos dois constitutivos como normalizadores ( $\beta 2 \mathrm{M}$ e HPRT) que apresentaram menor variabilidade entre amostras, a partir, de teste inicial realizado com cinco genes. Todos os pares de primers foram desenhados a partir da sequência disponível no GenBank.

Tabela 2 - Sequências sense e antisense dos primers utilizados no PCR tempo-real.

\begin{tabular}{|c|c|c|}
\hline Gene & Sense / Antisense & $\begin{array}{c}\text { Número de acesso } \\
\text { GenBank }\end{array}$ \\
\hline PEPCK & $\begin{array}{l}\text { TGGTCTGGACTTCTCTGCCAAG } \\
\text { AATGATGACCGTCTTGCTTTCG }\end{array}$ & BC081900 \\
\hline PPAR $\gamma$ & $\begin{array}{l}\text { GAACGTGAAGCCCATCGAGG } \\
\text { GGAACACTTTGTCAGCGACTGG }\end{array}$ & NW047696.2 \\
\hline DGAT-1 & $\begin{array}{c}\text { CAGACCAGCGTGGGCG } \\
\text { GAACAAAGAGTCTTGCAGACGATG }\end{array}$ & NM053437.1 \\
\hline GPAT & $\begin{array}{l}\text { CAGCGTGATTGCTACCTGAA } \\
\text { СTCTCCGTCCTGGTGAGAAG }\end{array}$ & NM017274.1 \\
\hline LPL & $\begin{array}{c}\text { ACAGTCTTGGAGCCCATGCT } \\
\text { AGCCAGTAATTCTATTGACCTTCTTGT }\end{array}$ & NM012598.2 \\
\hline FABP4 & $\begin{array}{l}\text { ATGTGTGATGCCTTTGTGGG } \\
\text { CCCAGTTTGAAGGAAATCTC }\end{array}$ & NM053365 \\
\hline
\end{tabular}




\section{ANÁLISE ESTATÍSTICA}

\subsection{Experimento I}

Os dados dos EXPERIMENTOS I e II foram primeiramente submetidos aos testes de normalidade e de homogeneidade das variâncias (Bartlett).

$\mathrm{Na}$ comparação entre apenas 2 grupos utilizou-se o teste de $t$-Student ( $T$-test) não pareado e two-tailed. A análise estatística foi realizada no software GraphPad Prism versão 5.0 (GraphPad Software Inc., San Diego, CA, EUA).

\subsection{Experimento II}

Os efeitos da dieta, da suplementação com leucina e da interação destes fatores foram analisados por ANOVA fatorial $\left(2^{2}\right)$.

Onde:

a) Fator dieta ( $\mathrm{HL}+\mathrm{MIX}$ e $\mathrm{HL}+\mathrm{LEU}$ vs $\mathrm{CON}+\mathrm{MIX}$ e $\mathrm{CON}+\mathrm{LEU})$;

b) Fator suplementação (CON+LEU e HL+LEU vs CON+MIX e $\mathrm{HL}+\mathrm{MIX})$;

c) Interação (fator dieta vs fator suplementação).

A análise estatística foi realizada no software GraphPad Prism versão 5.0 (GraphPad Software Inc., San Diego, CA, EUA). Nas análises dos EXPERIMENTOS I e $\mathrm{Il}$, foi considerado o valor de alfa de 0,05 . Todos os resultados estão expressos como a média \pm erro-padrão da média. 


\section{RESULTADOS}

Durante a eutanásia dos animais do presente estudo (somente do EXPERIMENTO II), pode-se observar a presença nefrolitíase na grande maioria ( $90 \%)$ dos animais de ambos os grupos. Após estas observações, consideramos prudente avaliar as concentrações séricas de ureia (avaliação da função renal), afim de afastar possíveis repercussões sistêmicas deste achado. $E$ a partir das avaliações podemos verificar a ausência de efeitos significativos $(P>0,05)$

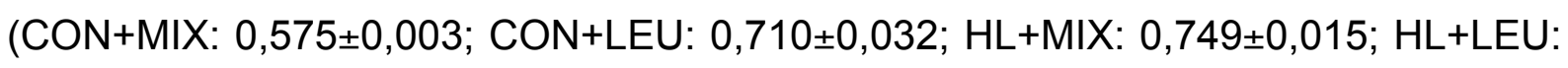
$0,721 \pm 0,076)$ destas variáveis. Após, as observações fomos investigar quais os constituintes da ração que poderiam estar envolvidos com o desenvolvimento de nefrolitíase e podemos observar que a alta presença de caseinato de cálcio pode desenvolver este quadro.

\subsection{Experimento I}

\subsubsection{Consumo de ração}

Ao longo do período experimental, o consumo alimentar foi acompanhado e a quantidade consumida de energia diária foi calculada. A figura $3 \mathrm{~A}$ apresenta $\mathrm{O}$ consumo de quilocalorias diário dos grupos experimentais. Pode-se observar que o grupo HL apresentou curvas de consumo calórico distintas das do grupo CON durante todo período experimental, o que foi corroborado pela análise das áreas totais sob as curvas de consumo, que também se apresentaram significativamente maiores que as do grupo CON $(P=0,0002)$ (Figura 3B). 
Figura 3 - Consumo calórico apresentado durante o EXPERIMENTO I.
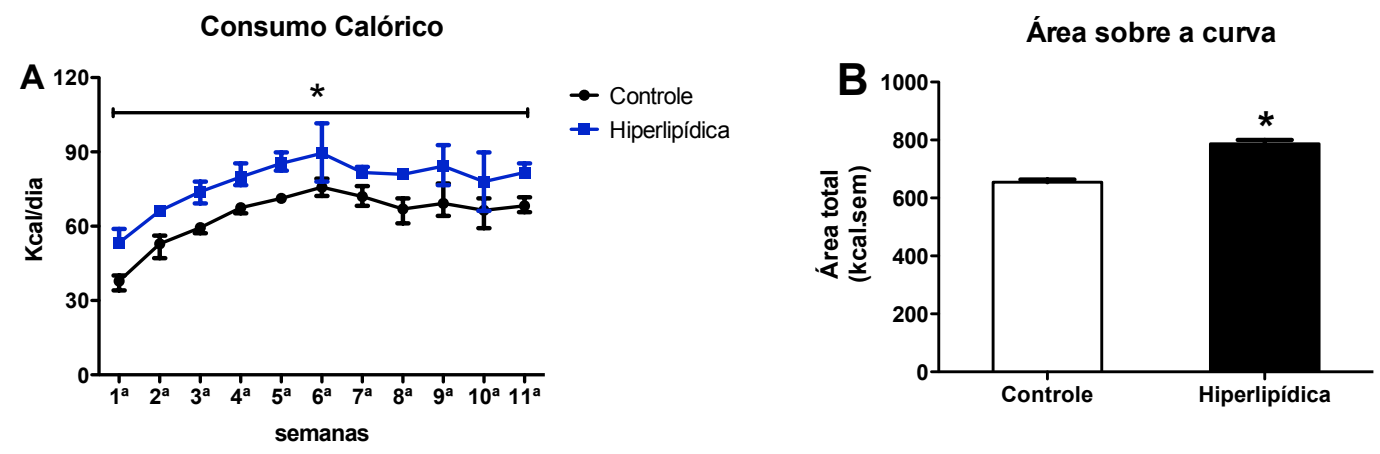

(A) Consumo calórico semanal $(P<0,05)$; (B) Área total sob a curva obtida a partir do consumo inicial e final do experimento $(P=0,0002)$. Os pontos apresentam a média semanal do consumo individual \pm EPM, $\mathrm{n}=5$. Valores expressos em quilocalorias/dia. ${ }^{*} P<0,05$ em relação ao grupo controle.

Fonte: Torres-Leal (2012).

\subsubsection{Peso corporal e ganho de peso}

As figuras 4 ( $A$ e B) apresentam os pesos corporais, inicial e final, além do ganho de peso dos grupos durante o experimento, respectivamente. A partir dos resultados observados, destaca-se que o grupo HL apresentou peso corporal final $(P=0,0422)$ e ganho de peso $(P=0,0146)$ significativamente maiores do que o grupo CON.

Figura 4 - Efeito da dieta hiperlipídica sobre o peso final e o ganho de peso durante o EXPERIMENTO I.
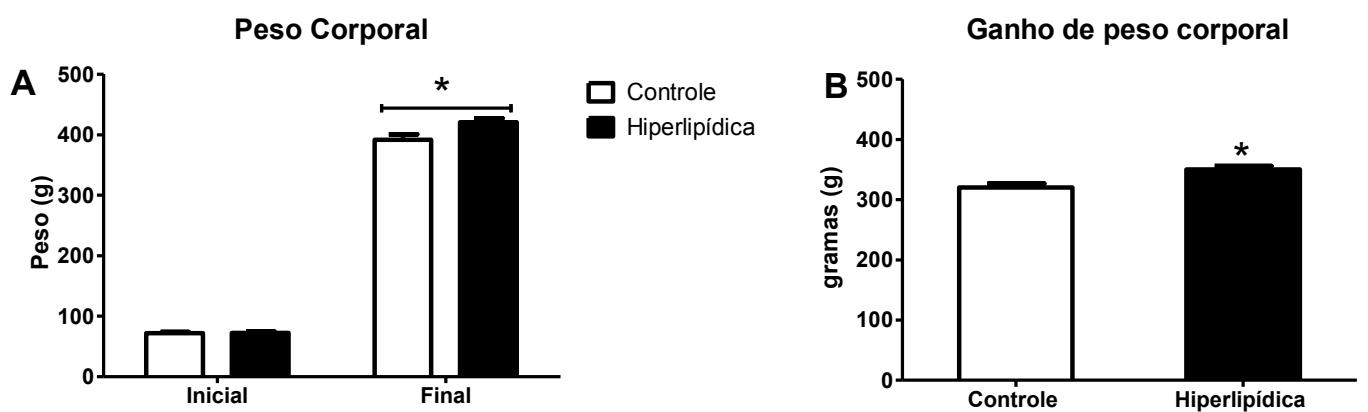

(A) Peso corporal final e inicial $(P=0,0422)$; (B) Variação do peso corporal, $(P=0,0146)$. Valores representam média $\pm E P M, n=5 .{ }^{*} P<0,05$ em relação ao grupo controle.

Fonte: Torres-Leal (2012). 
5.1.3 Efeitos da dieta hiperlipídica sobre a adiposidade, a hipertrofia adiposa e o número de adipócitos

Após a eutanásia dos animais, as gorduras - SC, PE e RP - foram retiradas e quantificou-se o peso relativo (\%). Pode-se notar que houve aumento significativo na massa de todos os depósitos de gordura do grupo $\mathrm{HL}$, quando comparado com o grupo CON $(P<0,05)$ (Figura $5 \mathrm{~A})$. Em relação ao diâmetro dos adipócitos isolados dos tecidos SC e PE, observou-se que o grupo que consumiu a dieta $\mathrm{HL}$ apresentou hipertrofia significativa das células adiposas do coxim SC $(P=0,0169)$, quando comparado com o grupo CON. No entanto, o mesmo não foi observado para o coxim adiposo $\mathrm{PE}(P=0,1547)$ (Figura $3 \mathrm{~B}$ ). Na figura $5 \mathrm{C}$, verifica-se que os grupos CON e $\mathrm{HL}$ apresentaram semelhante celularidade nos coxins SC e PE $(P>0,05)$ (Figura 5C).

Figura 5 - Efeitos da dieta hiperlipídica sobre a adiposidade e a celularidade durante o EXPERIMENTO I.
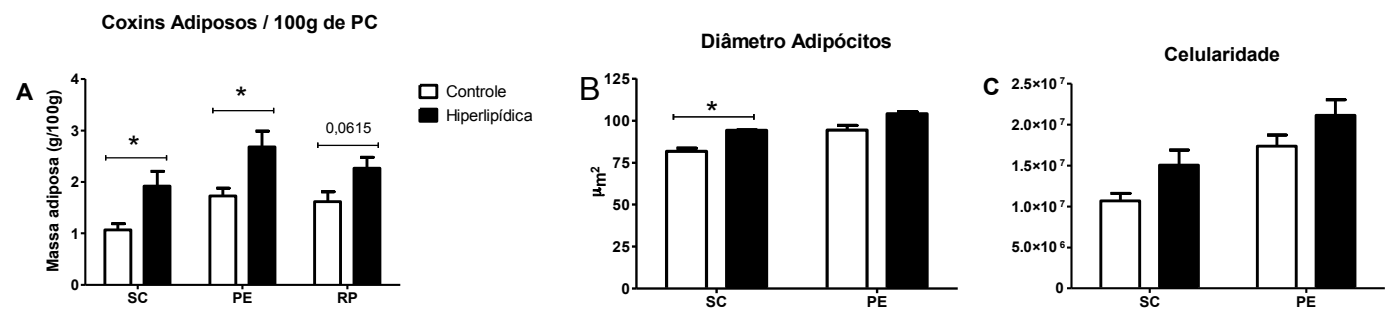

(A) Peso dos coxins adiposos subcutâneo (SC), $(P=0,0352)$, periepididimal (PE), $(P=0,0329)$ e retroperitoneal (RP), $(P=0,0615)$; (B) Diâmetro dos adipócitos SC, $(P=0,0169)$ e $P E,(P=0,1547)$; (C) Celularidade de adipócitos SC, $(P=0,0758)$ e PE, $(P=0,1605)$ e PE. As barras representam média \pm EPM, $n=5 .{ }^{*} P<0,05$ em relação ao grupo controle.

Fonte: Torres-Leal (2012). 


\subsubsection{Avaliação clínica e metabólica sistêmica}

\subsubsection{Teste oral de tolerância à glicose (GTT oral)}

$\mathrm{Na} 10^{\mathrm{a}}$ semana de dieta, os animais foram submetidos ao GTT oral. A curva glicêmica foi obtida em amostras de sangue caudal, utilizando-se glicosímetro (One Touch Ultra, Johnson \& Johnson) nos tempos definidos anteriormente ( 0 - basal; 5 ; 15; 20 e 60 minutos). Verifica-se que a curva glicêmica do grupo HL foi signifivamente maior $(P<0,05)$ em todos os tempos, indicando intolerância à glicose (Figura 6A).

Figura 6 - Teste oral de tolerância à glicose oral (GTTo) durante o EXPERIMENTO I.

\section{GTT oral}

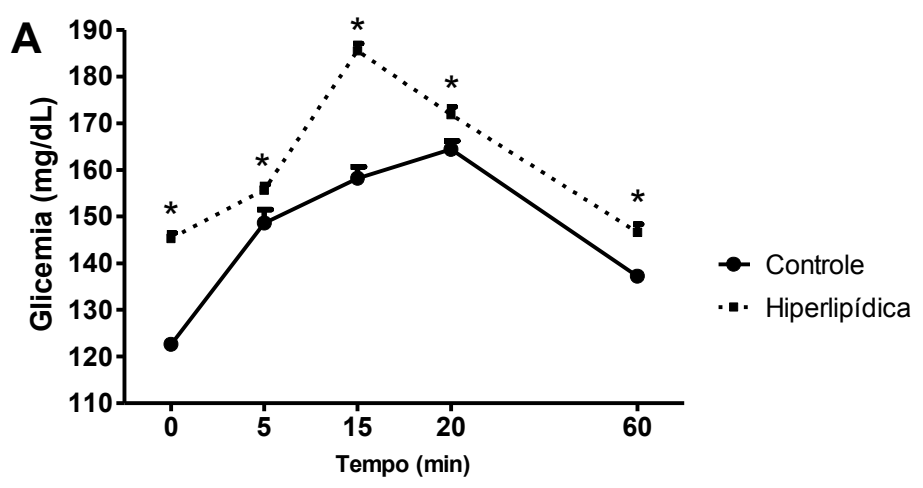

Os animais foram submetidos ao teste com uma carga de glicose $(75 \mathrm{mg} / 100 \mathrm{~g}$ p.c.) infundida por gavagem. Os ratos estavam em jejum prévio de $12 \mathrm{~h}$. (A) Curva glicêmica obtida durante o teste. As linhas representam a curva da glicemia entre os grupos controle $(C O N)$ e hiperlipídica $(H L)$. $(n=12-$ 14). ${ }^{*} P<0,05$ em relação ao grupo controle.

Fonte: Torres-Leal (2012). 
A figura 7 mostra o decaimento da glicemia durante o ITT. A constante de desaparecimento da glicose $\left(\mathrm{K}_{\mathrm{ITT}}\right)$, calculada como previamente descrito por Bonora et al. (1989). Na figura 7A, é possível observar padrões distintos de curvas glicêmicas entre os grupos CON e HL. O grupo $\mathrm{HL}$ apresentou valores significativamente inferiores $(P=0.0001)$ de $\mathrm{K}_{\mathrm{ITT}}$, indicando baixa responsividade à ação da insulina (Figura 7B).

Figura 7 - Responsividade à ação da insulina exógena durante o teste de tolerância à insulina (ITT).

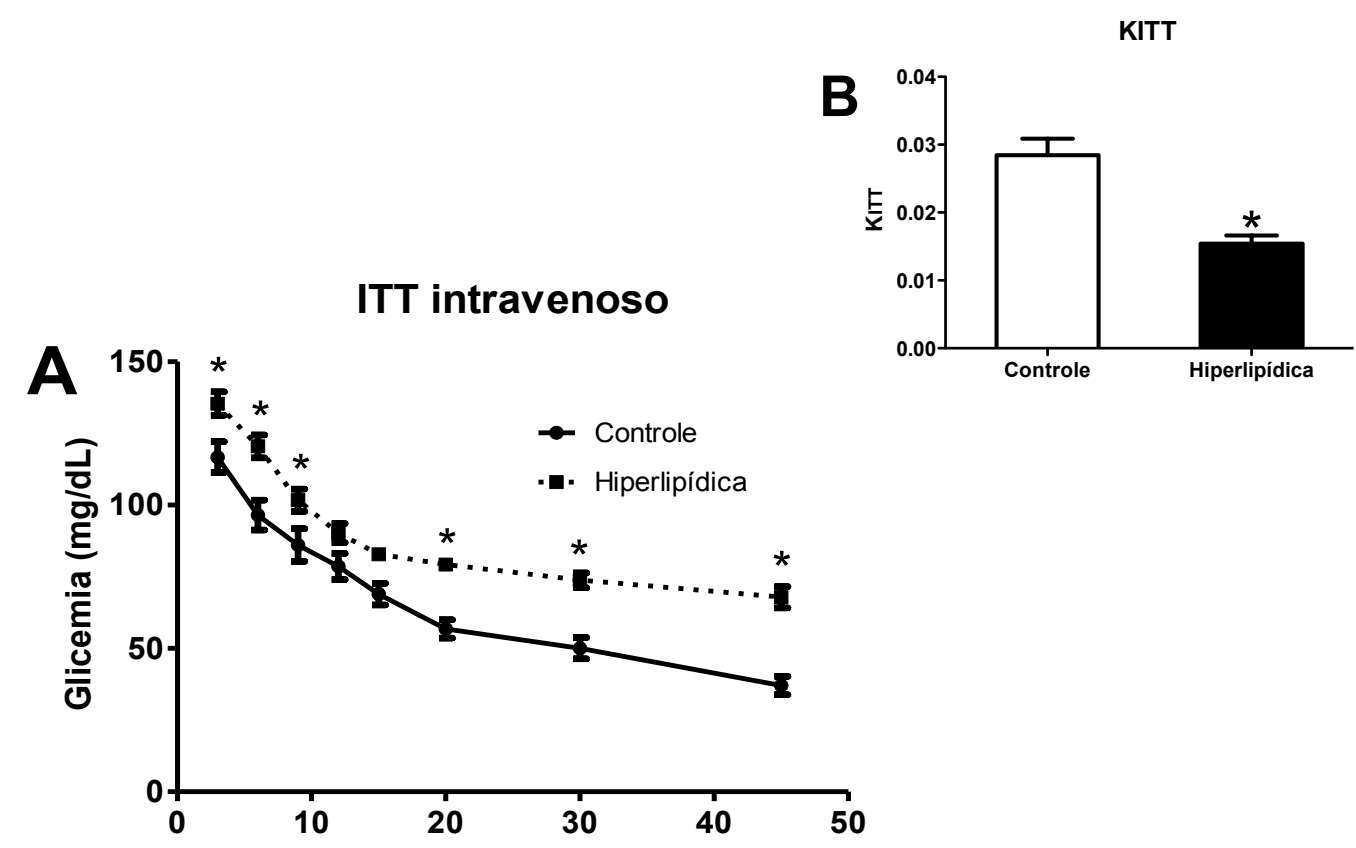

(A) Glicemias obtidas durante o teste de tolerância à insulina (ITT). Após jejum prévio de $12 \mathrm{~h}$, os animais anestesiados receberam uma carga de insulina $(1,12 \mathrm{U} / \mathrm{kg})$ infundida na veia peniana. Valores estão expressos em $\mathrm{mg} / \mathrm{dL}$ e representam média $\pm E P M, n=12-14)$. (B) Efeito da dieta hiperlipídica sobre a taxa de decaimento da glicose plasmática $\left(K_{I T T}\right),(P=0.0001)$. A glicemia foi determinada por meio de glicosímetro em amostras de sangue retiradas da cauda nos tempos 0 (basal), 3, 6, 9, 12, 15, 20, 30 e 45 minutos após a administração de insulina. As barras representam média $\pm \mathrm{EPM}, \mathrm{n}=12-14$. ${ }^{*} P<0,05$ em relação ao grupo controle.

Fonte: Torres-Leal (2012). 


\subsubsection{Ensaios com adipócitos isolados}

\subsubsection{Teste de Captação de [3]H-2-Desoxi-D-Glicose em Adipócitos Isolados}

$\mathrm{Na}$ ausência de insulina, as células do coxim adiposo PE e SC apresentaram incrementos significativos no transporte de glicose $P=0,0024$ e $P=0,0001$, respectivamente (Figura $8 \mathrm{~A}$ ). Quando estimulados maximamente com insulina, somente encontramos diferenças significativas na gordura $P E(P=0,0393)$, que apresentou menor capacidade resposta quando foi comparado com o grupo CON. Por outro lado, a gordura SC do grupo $\mathrm{HL}$ apresentou obteve respostas semelhantes ao grupo $\operatorname{CON}(P=0,7986)$, frente ao mesmo estímulo (Figuras $8 \mathrm{~A}$ e 8B).

Figura 8 - Avaliação da captação de glicose em adipócitos durante o EXPERIMENTO I.
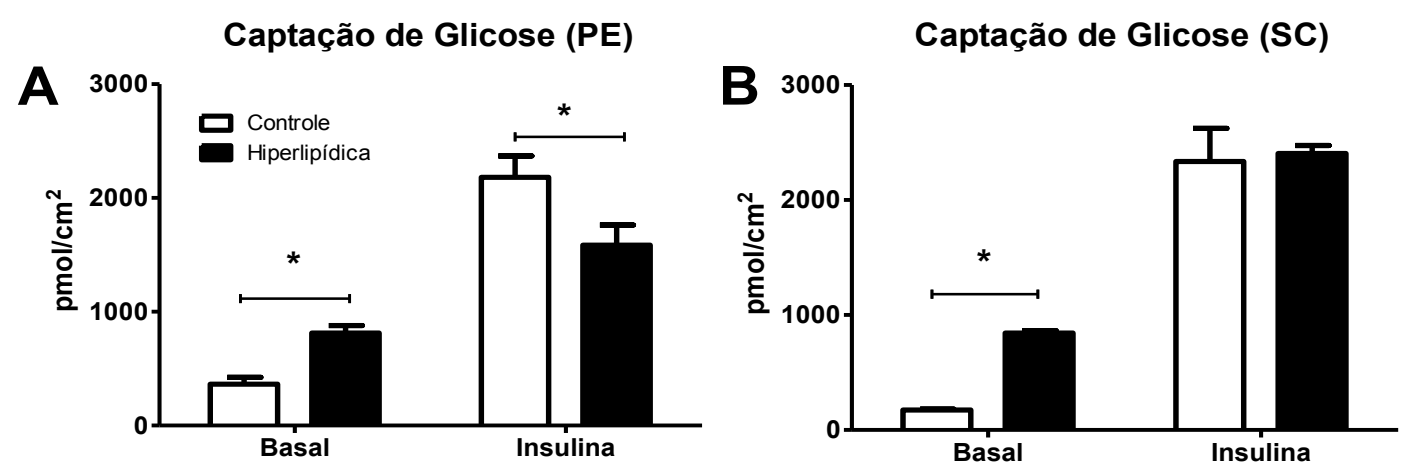

As células isoladas foram incubadas sem ou com insulina $10 \mathrm{nM}$ por 30 minutos a $37{ }^{\circ} \mathrm{C}$ e, em seguida, alíquotas deste meio de incubação foram adicionadas a microtubos contendo [ $\left.{ }^{3} \mathrm{H}\right]-2-\mathrm{DG}$. Após 3 minutos, a reação foi interrompida com o acréscimo de Phloretin. (A) Captação de glicose em adipócitos periepididimais, basal $(P=0,0024)$ e estimulado $(P=0,0393)$; (B) Subcutâneos, basal $(P=0,0001)$ e estimulado $(P=0,7986)$. As barras representam média \pm EPM. $\mathrm{n}=4 .{ }^{*} P<0,05$ em relação ao grupo controle.

Fonte: Torres-Leal (2012). 
5.1.5.2 Incorporação de $D-\left[U-{ }^{14} \mathrm{C}\right]$-Glicose em lipídios de adipócitos isolados

A taxa de incorporação de glicose em lipídios na ausência de insulina foi semelhante entre os grupos $\mathrm{CON}$ e $\mathrm{HL}$ nos adipócitos $\mathrm{PE}(P=0,6655)$. Já nos adipócitos da gordura SC do grupo HL a incorporação basal foi significativamente maior $(P=0,0289)$. Quando estimulados com insulina (10 nM), os adipócitos do grupo $\mathrm{HL}$ apresentaram respostas significativamente reduzidas tanto na gordura PE $(P=0,0029)$ quanto SC $(P=0,0090)$ (Figuras 9A e 9B).

Figura 9 - Avaliação da incorporação de glicose em triacilgliceróis em adipócitos durante o EXPERIMENTO I.
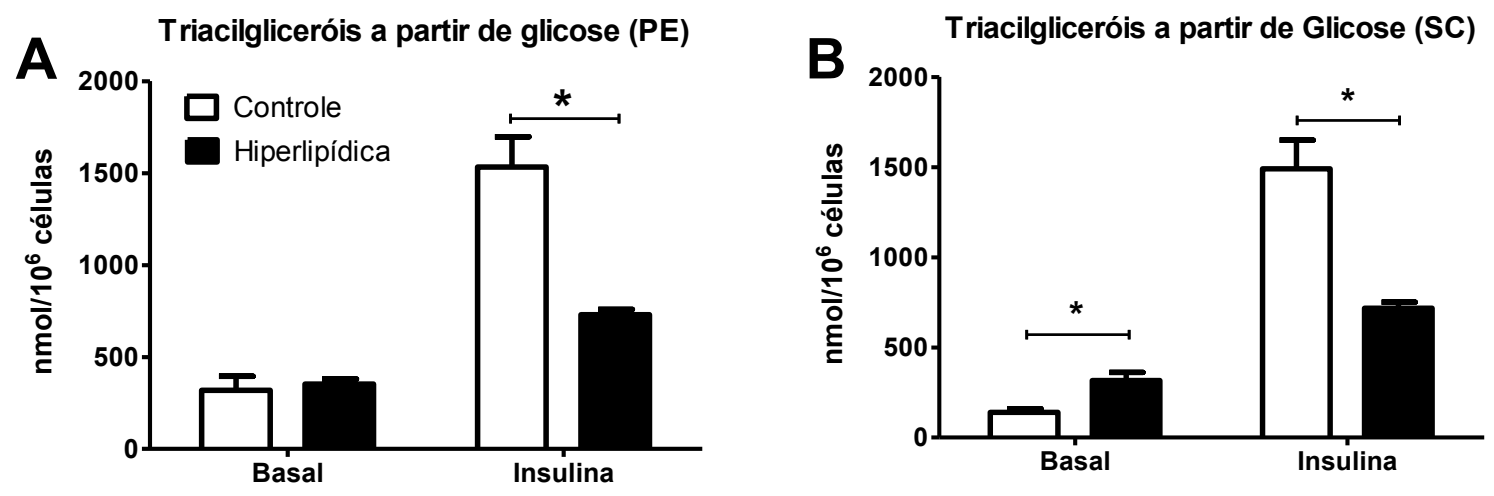

Respostas obtidas na ausência (basal) e na presença de insulina em adipócitos isolados. (A) Adipócitos periepididimais, basal $(P=0,6655)$ e estimulado $(P=0,0029)$; (B) Adipócitos subcutâneos, basal $(P=0,0289)$ e estimulado $(P=0,0090)$. A extração das gorduras dos adipócitos pré-incubados com ${ }^{14} \mathrm{C}$-glicose foi feita com reagente de Dole. $\mathrm{n}=4 .{ }^{*} P<0,05$ em relação ao grupo controle.

Fonte: Torres-Leal (2012). 
5.1.5.3 Incorporação de $D-\left[U-{ }^{14} C\right]$-Glicose em AG de TAG

Durante a situação basal (ausência de insulina) os grupos CON e HL apresentaram respostas semelhantes nos adipócitos da região PE $(P=0,6652)$ e SC $(P=0,6606)$. No entanto, quando estimulados com insulina, observou-se redução significativa na via de conversão de glicose em AG do TAG, nas gorduras PE $(P=0,0001)$ e SC $(P=0,0135)$ do grupo HL (Figuras 10A e 10B).

Figura 10 - Avaliação da incorporação de D-[U- $\left.{ }^{14} \mathrm{C}\right]$-Glicose em AG de TAG em adipócitos durante o EXPERIMENTO I.
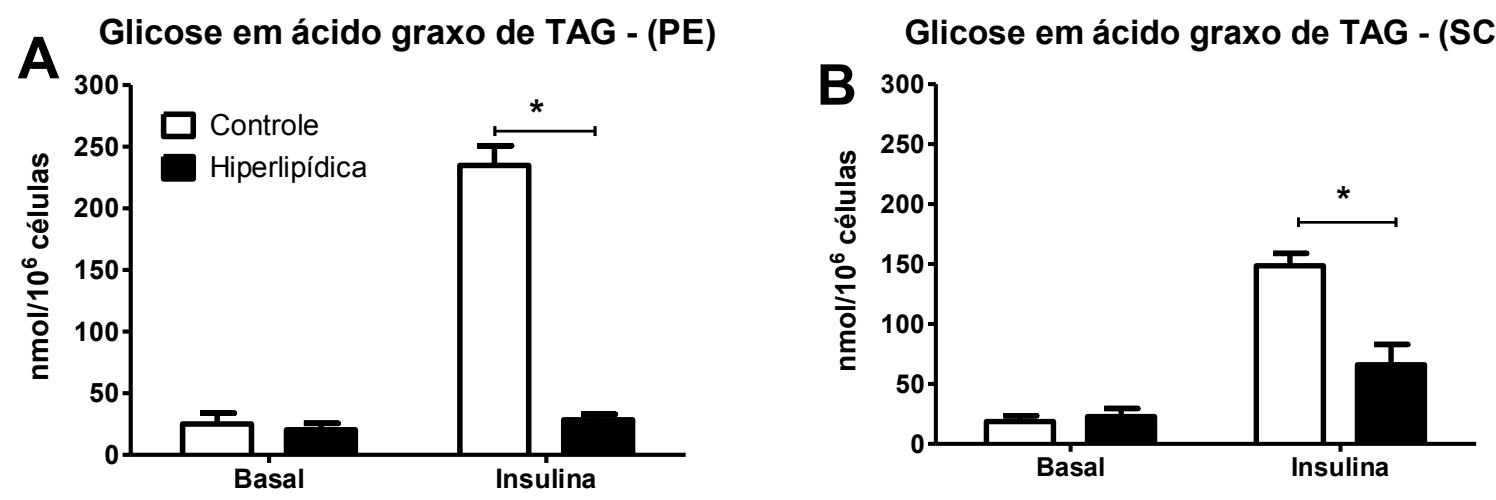

As células isoladas foram incubadas com $5 \mu \mathrm{l}$ de $\mathrm{D}$-[U- $\left.{ }^{14} \mathrm{C}\right]$-glicose $[0,05 \mu \mathrm{Ci} /$ tubo), acrescido de insulina $(10 \mathrm{nM})$ por 120 minutos a $37^{\circ} \mathrm{C}$. (A) Adipócitos periepididimais, basal $(P=0,6652)$ e estimulado $(P=0,0001)$; (B) Adipócitos subcutâneos, basal $(P=0,6606)$ e estimulado $(P=0,0135)$. As barras representam média \pm EPM. $n=4$. ${ }^{*} P<0,05$ em relação ao grupo controle.

Fonte: Torres-Leal (2012). 
5.1.5.4 Incorporação de $D-\left[U-{ }^{14} C\right]$-Glicose em glicerol do TAG

Descontando-se da radioatividade incorporada em lipídios totais dos adipócitos os resultados obtidos com a incorporação de glicose no resíduo AG de TAG, obtém-se o montante da radioatividade da ${ }^{14} \mathrm{C}$-glicose incorporada no resíduo glicerol. Assim, observamos que os adipócitos da gordura SC de ratos do grupo HL incorporaram mais glicose em glicerol na ausência de insulina $(P=0,0244)$ (Figura 9B). Além disso, verificou-se que, na presença estimulante de insulina, ambas as células ( $P E, P=0,0001$ e SC, $P=0,0390$ ) de ratos do grupo $\mathrm{HL}$ apresentaram respostas significativamente reduzidas em comparação aos do grupo controle (Figuras 11A e 11B).

Figura 11 - Incorporação de glicose em glicerol de triacilgliceróis em adipócitos durante o EXPERIMENTO I.
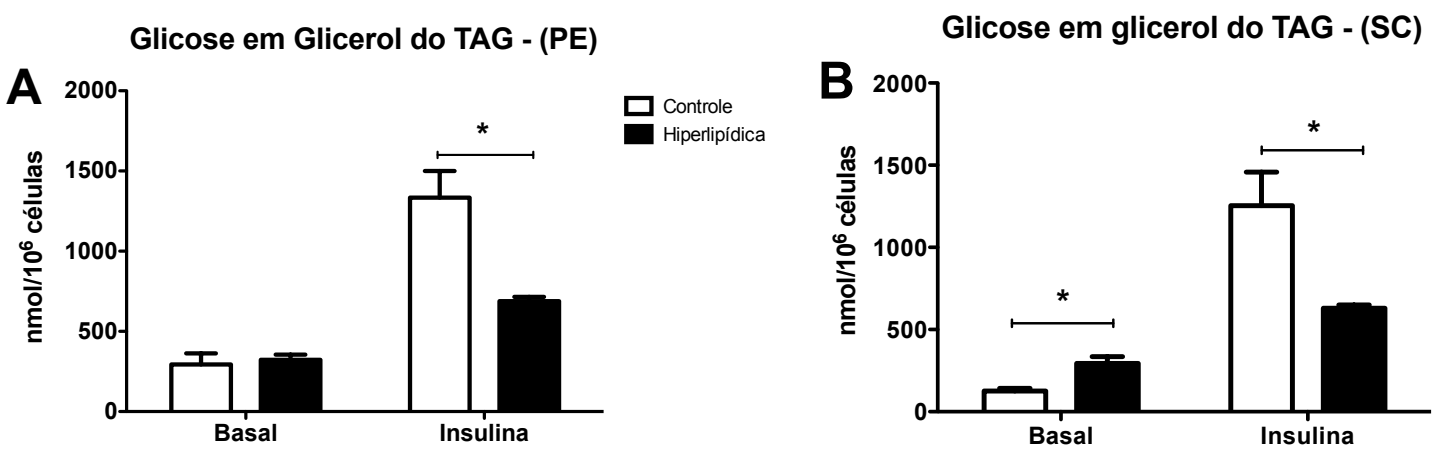

(A) Adipócitos periepididimais, basal $(P=0,6652)$ e estimulado $(P=0,0001)$; (B) Adipócitos subcutâneos, basal $(P=0,0244)$ e estimulado $(P=0,0390)$. As barras representam média \pm EPM. $\mathrm{n}=4$. ${ }^{*} P<0,05$ em relação ao grupo controle.

Fonte: Torres-Leal (2012). 


\subsubsection{Atividade máxima das enzimas envolvidas na lipogênese de novo}

A figura 12, a seguir, demonstra que todas as enzimas avaliadas dos animais alimentados com dieta HL apresentaram expressiva redução em suas atividades máximas quando avaliada em diferentes coxins adiposos; G6PDH, PE $(P=0,0380)$, SC $(P=0,0003)$ e RP $(P=0,0148)$; málica, PE $(P=0,0002)$, SC $(P=0,0007)$ e RP $(P=0,0033) ; \quad$ ATP-citrato liase, PE $(P=0,0375)$, SC $(P=0,0007) ;$ e, FAS, PE $(P=0,0071)$, SC $(P=0,0045)$ e RP $(P=0,0010)$, com excessão da enzima ATP-citrato liase no coxim adiposo $\mathrm{RP}(P=0,2548)$.

Figura 12 - Efeito da dieta hiperlipídica sobre a atividade das enzimas G6PDH, málica, ATPcitrato liase e FAS do EXPERIMENTO I.
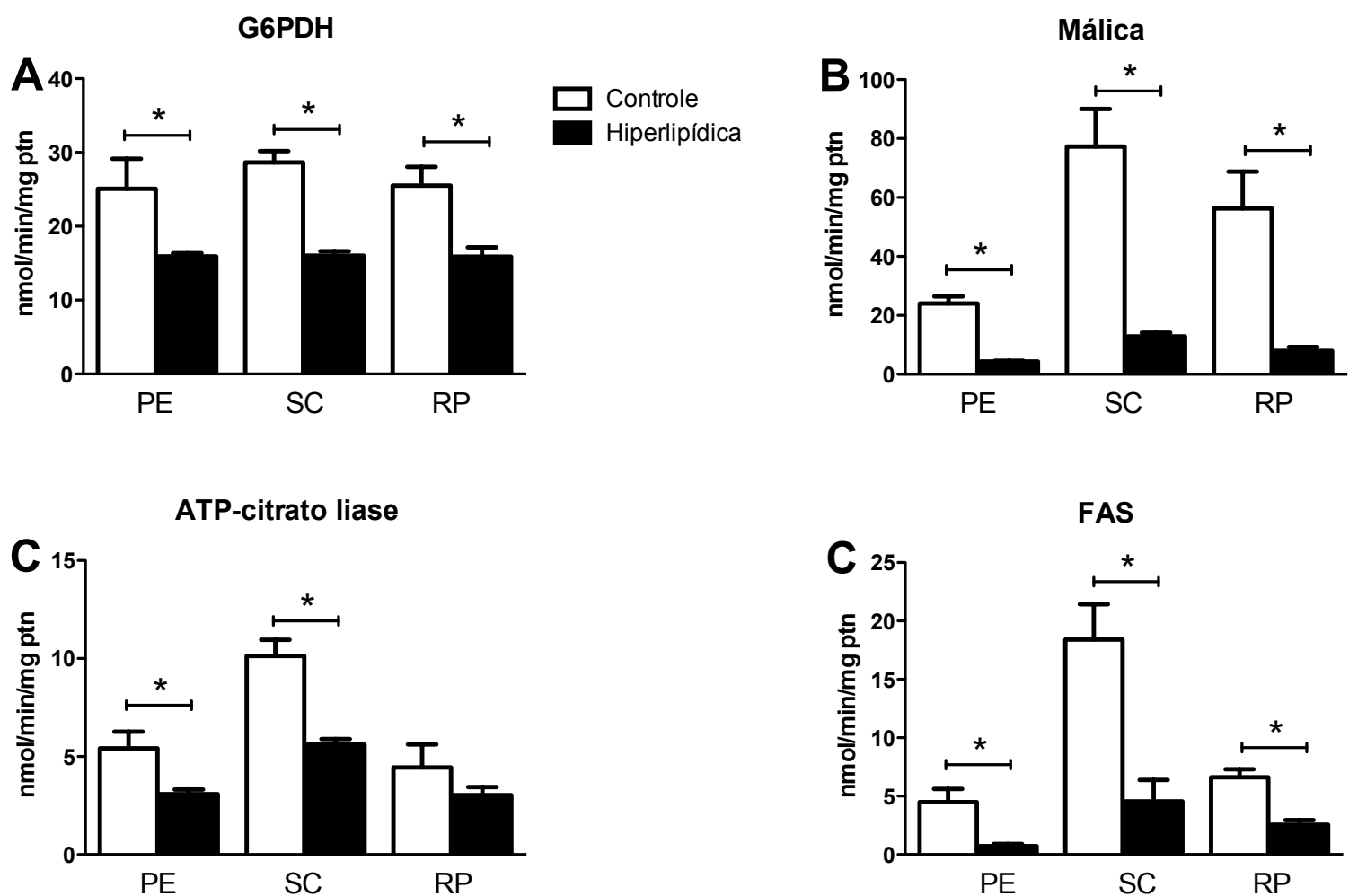

Atividade máxima das enzimas nas gorduras periepididimal ( $P E)$, subcutânea (SC) e retroperitoneal (RP): (A) G6PDH, PE $(P=0,0380)$, SC $(P=0,0003)$ e RP $(P=0,0148) ;(B)$ málica, PE $(P=0,0002), S C$ $(P=0,0007)$ e RP $(P=0,0033)$; (C) ATP-citrato liase, $P E(P=0,0375)$, SC $(P=0,0007)$ e $\operatorname{RP}(P=0,2548)$ e (D) FAS, PE $(P=0,0071)$, SC $(P=0,0045)$ e RP $(P=0,0010)$; As barras representam média \pm EPM. $\mathrm{n}=4$. ${ }^{*} P<0,05$ em relação ao grupo controle.

Fonte: Torres-Leal (2012). 


\subsection{Experimento II}

\subsubsection{Consumo de ração}

Ao longo das 16 semanas experimentais, o consumo alimentar foi monitorado semanalmente, porém, somente apresentaremos os resultados das 6 semanas de tratamento com leucina. Observa-se que os grupos de animais que consumiram dieta HL (fator dieta) apresentaram maior consumo de calorias ao longo do período de tratamento, quando comparados com os grupos que consumiram dieta CON (Figura 13). A suplementação com leucina (fator suplementação), não exerceu efeitos significativos sobre o padrão alimentar, independetemente do tipo de dieta consumida (Hiperlipídica ou Controle) (Figura 13). Após 6 semanas de suplementação com leucina, os grupos CON+LEU e HL+LEU apresentaram o mesmo consumo diário de leucina (dieta+bebida): $\operatorname{CON}+\operatorname{LEU}(0,3240 \pm 0,0478)$ e HL+LEU $(0,4054 \pm 0,0587)(P=0,2983)$.

Figura 13 - Consumo calórico diário apresentado pelos grupos durante o período de tratamento no EXPERIMENTO II.

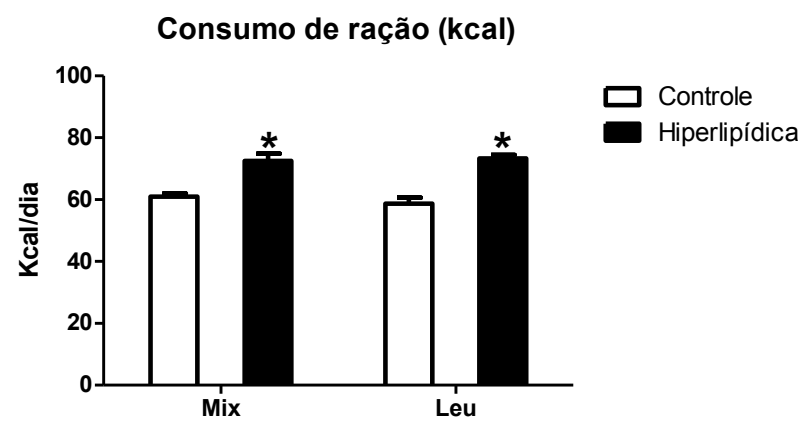

Efeito do fator dieta $(P=0,0001)$; Efeito do fator suplementação $(P=0,6813)$ e Interação $(P=0,3843)$. As barras representam média diária de calorias consumidas $\pm \mathrm{EPM}, \mathrm{n}=5$. ${ }^{*} P<0,05$ em relação ao grupo controle. MIX: mistura de aminoácidos não essenciais; LEU: leucina.

Fonte: Torres-Leal (2012). 


\subsubsection{Peso corporal e ganho de peso}

Na figura 14 (painel A e B), apresentamos a média ponderal semanal. Com tal procedimento, avaliamos o ritmo semanal de ganho de peso ao longo do estudo. Os quatro grupos (CON+MIX, CON+LEU, HL+MIX e HL+LEU) apresentaram ritmo de crescimento significativo durante o período de suplementação, porém, não observamos efeitos significativos quando comparamos os grupos experimentais. Nessa perspectiva, os resultados de ganho de peso (Figura 14C) apresentaram comportamento semelhante entre os fatores dieta $(P=0,1595)$, suplementação $(P=0,7376)$ e interação $(P=0,8569)$.

Figura 14 - Influência dos tratamentos sobre o peso corporal durante o EXPERIMENTO II.

\section{Evolução do peso corporal}
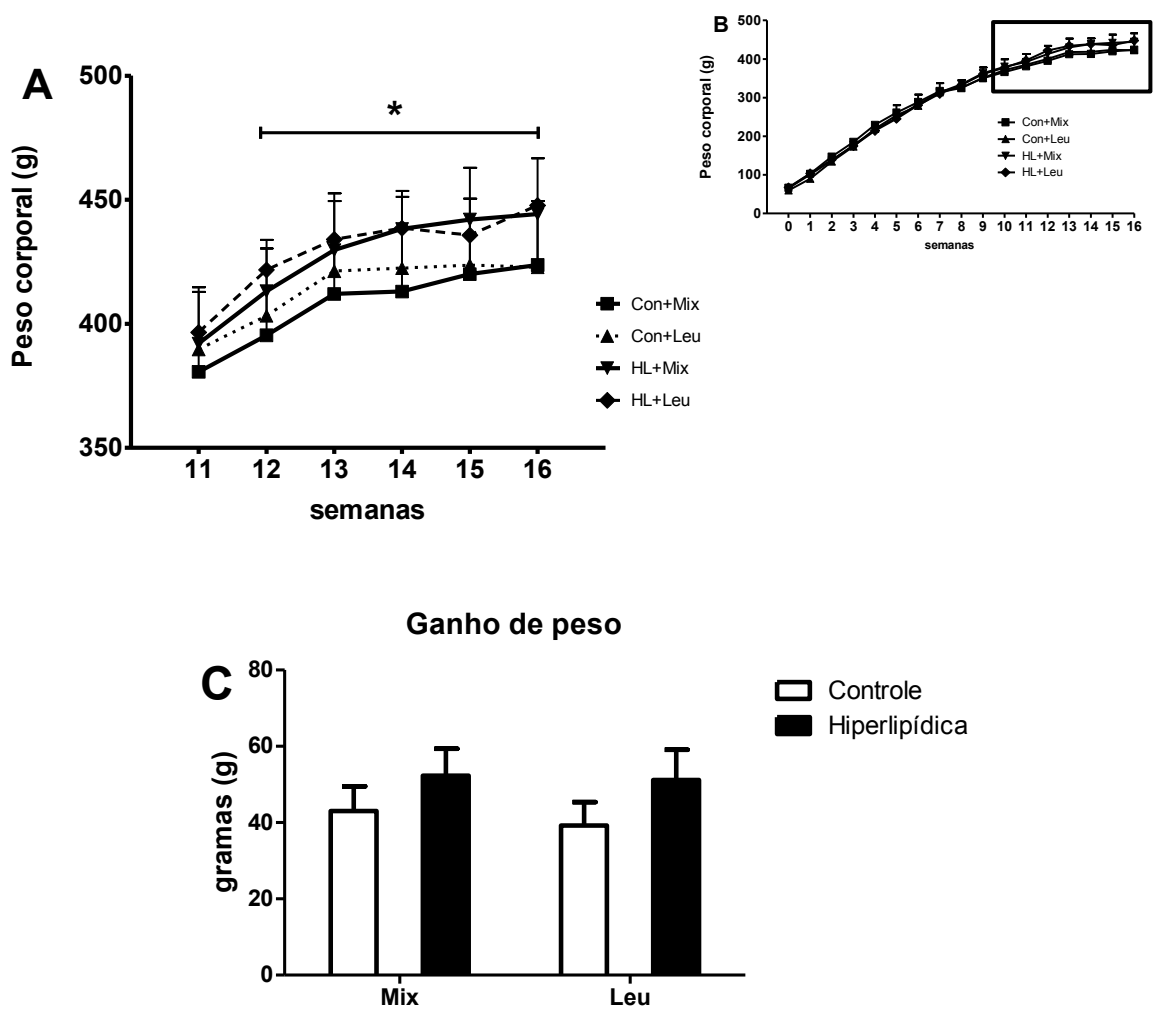

(A) Evolução do peso semanal durante 6 semanas de suplementação; $(P=0,0001)$; (B) Evolução do peso semanal durante as 10 semanas de experimento; (C) Ganho de peso ao longo do período de suplementação com leucina, fator dieta $(P=0,1595)$, fator suplementação $(P=0,7376)$ e Interação, $(P=0,8569)$. As barras e pontos representam média $\pm \mathrm{EPM}, \mathrm{n}=5 .{ }^{*} v s$ semana 1 . MIX: mistura de aminoácidos não essenciais; LEU: leucina.

Fonte: Torres-Leal (2012). 


\subsubsection{Efeitos da suplementação com leucina sobre a adiposidade e o volume de adipócitos}

Após a eutanásia dos animais, as gorduras periepididimal (PE), subcutânea (SC) (região abdominal e inguinal) e mesentérica (MS) foram retiradas e quantificadas em peso relativo $(\mathrm{g} / 100 \mathrm{~g})$. Os grupos que consumiram dieta $\mathrm{HL}$ ou leucina isoladamente (Figura 15A) não apresentaram maior adiposidade na região $\mathrm{PE}$, [fator dieta $(P=0,0971)$ e fator suplementação $(P=0,5579)]$. Em contraste, verifica-se significativa interação $(P=0,0014)$ destes fatores na região $P E$.

Em relação à massa do coxim adiposo SC, pode-se observar (Figura 15B) aumento significativo na adiposidade dos animais que consumiram dieta $\mathrm{HL}$ $(P=0,0015)$, além disso, observou-se significativa interação para os animais alimentados com dieta $\mathrm{HL}$ e suplementados com leucina $(P=0,0432)$, sendo que 0 mesmo não é observado para os fatores suplementação $(P=0,1650)$.

A adiposidade da região MS pode ser verificada na figura 15C. Nota-se que a dieta HL $(P=0,3151)$ ou a suplementação com leucina $(P=0,4196)$ isoladamente não alteraram a adiposidade do coxim. No entanto, observa-se significativa interação dos fatores testados $(P=0,0487)$.

$\mathrm{Na}$ soma dos três coxins adiposos, pode-se notar que o fator dieta exerceu efeitos significativos (Figura 15D) sobre a adiposidade ( $P=0,0115)$, o mesmo não ocorrendo para o fator suplementação $(P=0,3811)$. Na mesma figura 15D, nota-se que a suplementação com leucina influenciou de maneira oposta esta variável, caracterizando significativa interação entre os fatores avaliados $(P=0,0040)$. 
Figura 15 - Avaliação da adiposidade das regiões periepididimal (PE), subcutânea (SC), mesentérica (MS) e soma dos três coxins durante o EXPERIMENTO II.

\section{Adiposidade região $\mathrm{PE}$}

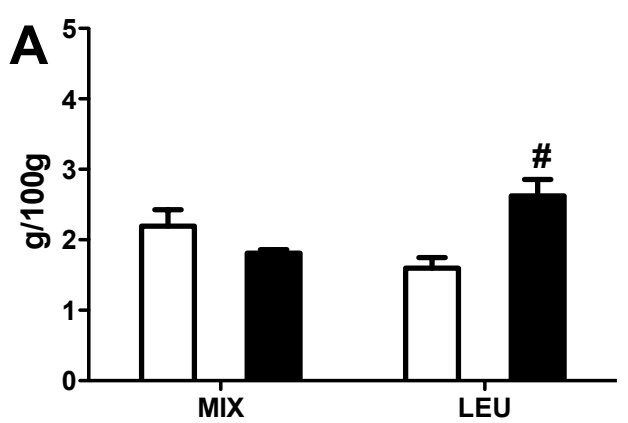

Adiposidade região MS

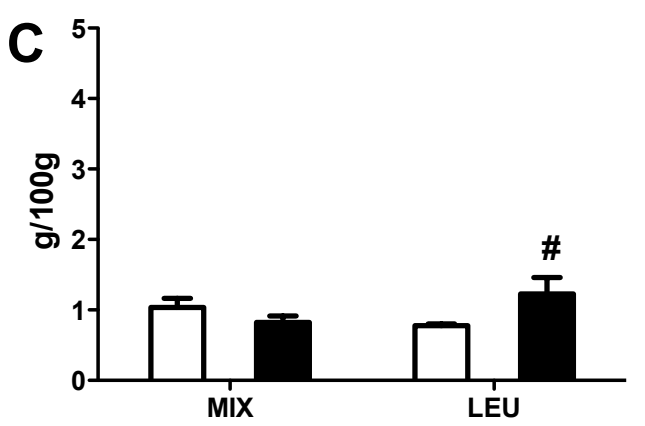

Adiposidade região SC

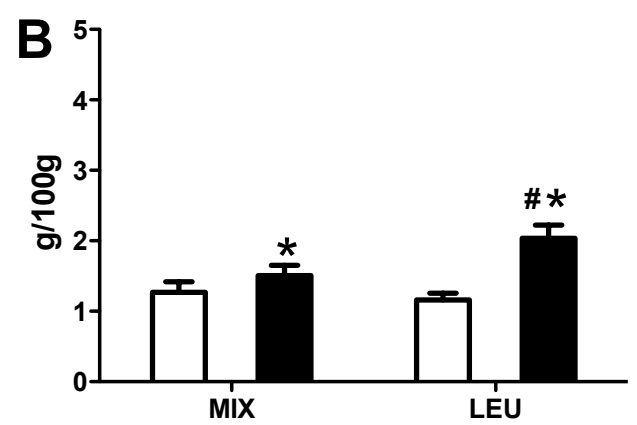

Soma dos coxins adiposos

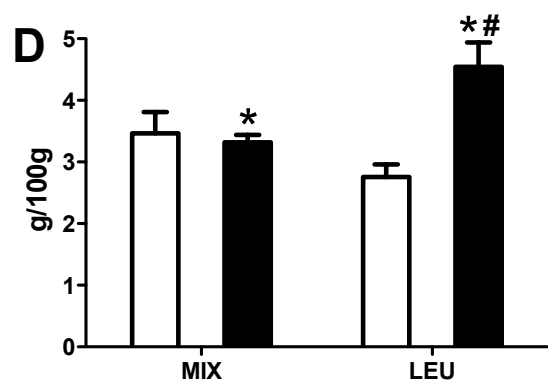

(A) Adiposidade da região $\mathrm{PE}$; fator dieta $(P=0,0971)$, fator suplementação $(P=0,5579)$, interação $(P=0,0014)$; (B) Adiposidade da região SC; fator dieta $(P=0,0015)$, fator suplementação $(P=0,1650)$, interação $(P=0,0432)$; (C) Adiposidade da região MS; fator dieta $(P=0,4201)$, fator suplementação $(P=0,6205)$, interação $(P=0,0343)$; (D) Soma dos coxins adiposos (PE+SC+MS); fator dieta $(P=0,0115)$, fator suplementação $(P=0,3811)$, interação $(P=0,0040)$; As barras e pontos representam média \pm EPM, $n=5 .{ }^{*} P<0,05$ em relação ao grupo controle; ${ }^{\#} P<0,05$ em relação ao grupo CON+LEU. MIX: mistura de aminoácidos não essenciais; LEU: leucina.

Fonte: Torres-Leal (2012). 
Em relação ao diâmetro dos adipócitos, não observamos diferenças significativas no fator dieta das gorduras PE $(P=0,4115)$ e SC $(P=0,0947)$ (Figuras $16 \mathrm{~A}$ e 16B). Semelhantemente, as mesmas respostas foram observadas para os grupos suplementados, nas gorduras PE $(P=0,5067)$ e SC $(P=0,3311)$. Além disso, pode-se verificar a ausência de interação dos fatores em adipócitos $P E(P=0,3160)$ (Figura 16A). Por outro lado, observou-se, em adipócitos da gordura SC, significativa (Figura 16B) interação entre os grupos suplementados com leucina $(P=0,0128)$.

Figura 16 - Avaliação do diâmetro dos adipócitos periepididimais (PE) e subcutâneos (SC) durante o EXPERIMENTO II.

Diâmetros dos adipócitos PE

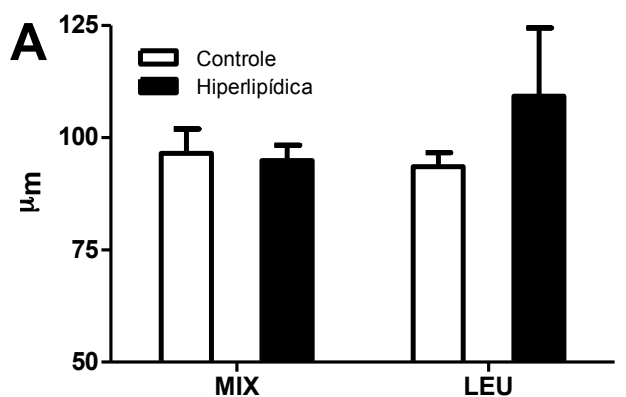

Diâmetros dos adipócitos SC

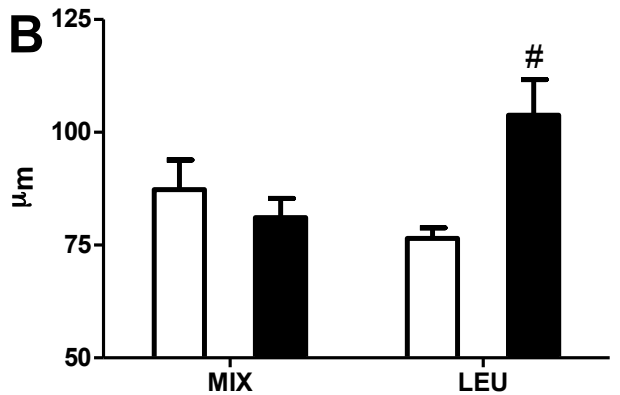

(A) Diâmetro dos adipócitos $P E$; fator dieta $(P=0,3160)$, fator suplementação $(P=0,4115)$, interação $(P=0,5067)$; (B) Diâmetro dos adipócitos SC; fator dieta $(P=0,0128)$, fator suplementação $(P=0,0947)$, interação $(P=0,3311)$; As barras e pontos representam média $\pm \mathrm{EPM}, \mathrm{n}=5$. ${ }^{\#} P<0,05$ em relação ao grupo CON+LEU. MIX: mistura de aminoácidos não essenciais; LEU: leucina.

Fonte: Torres-Leal (2012). 


\subsubsection{Avaliação clínica e metabólica sistêmica}

\subsubsection{Curva de tolerância à insulina (ITT)}

A figura 17A mostra a constante de desaparecimento da glicose (K $\left.\mathrm{K}_{\mathrm{ITT}}\right)$, calculada como previamente descrito por Bonora et al. (1989). Observaram-se, na figura 17A, padrões distintos na taxa de desaparecimento entre os grupos alimentados com dieta HL vs $\operatorname{CON}(P=0,0002)$, indicando baixa responsividade à ação da insulina para os animais que consumiram ração HL. De forma contrária, não constatamos diferença significativa após a suplementação com leucina $(P=0,4084)$ e na interação dos fatores $(P=0,1020)$, para o $\mathrm{K}_{\mathrm{ITT}}$ (Figura 17A).

\subsubsection{Teste oral de tolerância à glicose (GTT oral)}

Pela análise das áreas sob as curvas dos animais durante o período de suplementação, verifica-se a inexistência de intolerância à glicose durante o teste de GTT oral em todos os fatores avaliados, apesar de termos observado forte tendência, nos animais suplementados com leucina $(P=0,0609)$ de intolerância à glicose (Figura 17B).

Figura 17 - Efeito do tratamento sobre a taxa de desaparecimento da glicose plasmática ( $\left.\mathrm{K}_{\mathrm{ITT}}\right)$ durante o teste de tolerância à insulina (ITT) e o teste oral de tolerância à glicose (GTT oral) durante o EXPERIMENTO II.
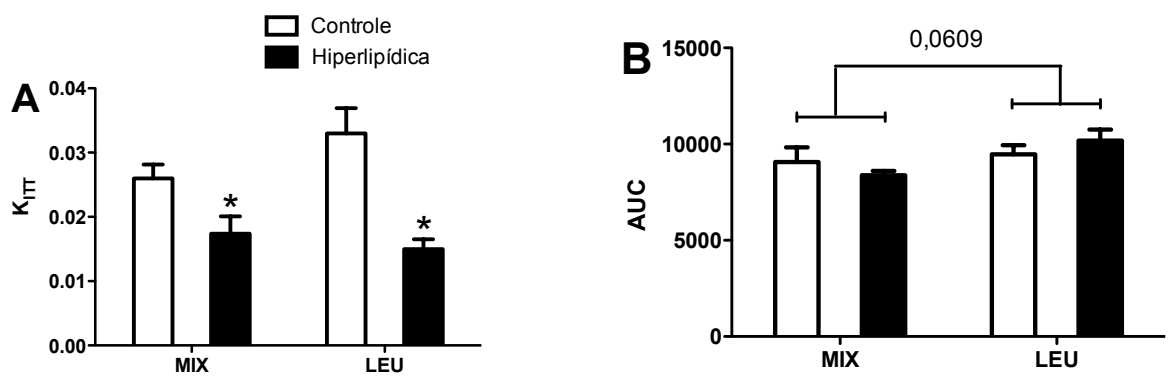

(A) Taxa de desaparecimento da glicose durante o teste de tolerância à insulina $\left(\mathrm{K}_{\mathrm{ITT}}\right)$; fator dieta $(P=0,0002)$, fator suplementação $(P=0,4084)$, interação $(P=0,1020)$; (B) Área sob a curva do teste de tolerância à glicose oral (AUC); fator dieta $(P=0,9825)$, fator suplementação $(P=0,0609)$, interação $(P=0,2152)$; As barras e pontos representam média $\pm E P M, n=5 .{ }^{*} P<0,05$ em relação ao grupo controle. MIX: mistura de aminoácidos não essenciais; LEU: leucina.

Fonte: Torres-Leal (2012). 
5.2.8.3 Secreção estática de insulina pela ilhota pancreática isolada e insulina de jejum

As ilhotas dos animais que consumiram dieta $\mathrm{HL}$ apresentaram maior capacidade de secreção de insulina estimulada por glicose nas duas concentrações testadas $(5,6$ e $16,7 \mathrm{mM})(P=0,0019)$ e $(P=0,0190)$, respectivamente. O tratamento a longo prazo com leucina incrementou a secreção de insulina quando as ilhotas foram incubadas na maior concentração de glicose [16,7 mM] $(P=0,0314)$ (Figura 18). Além disso, verificamos que a dieta $\mathrm{HL}$ aumentou significativamente a insulina de jejum $(P=0,0071)$ que foi acompanhada pelo efeito significativo do fator suplementação $(P=0,0310)$. 
Figura 18 - Efeito do tratamento com leucina na secreção de insulina pela ilhota pancreática isolada em meio com 5,6 ou 16,7 mM de glicose durante o EXPERIMENTO II.
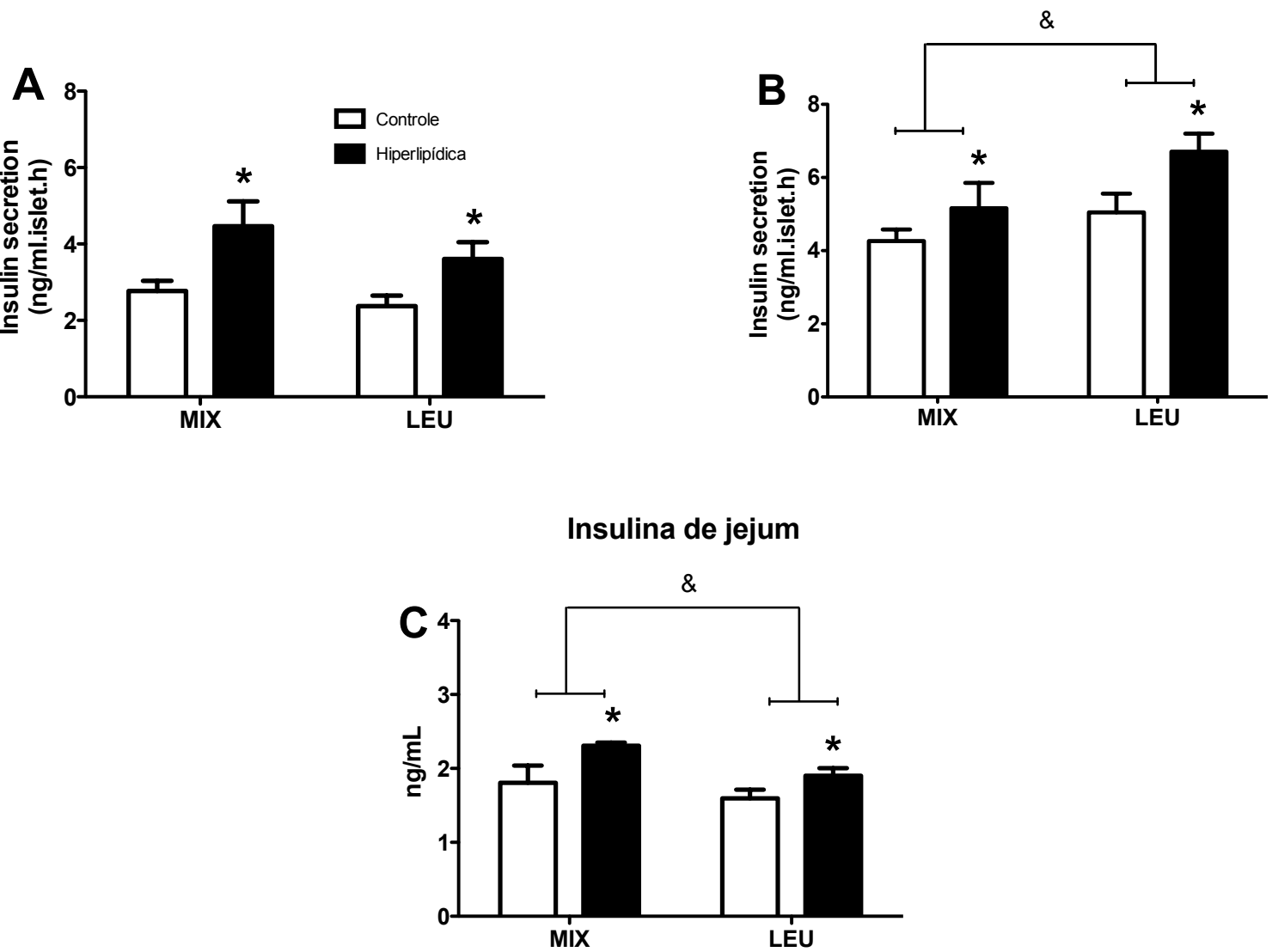

As ilhotas foram isoladas e incubadas na presença de glicose por 1 hora. Após esse tempo foi dosado a insulina no meio de incubação. (A) Concentração de $5,6 \mathrm{mM}$ de glicose; fator dieta $(P=0,0019)$, fator suplementação $(P=0,1650)$, interação $(P=0,6066)$; (B) Concentração de $16,7 \mathrm{mM}$ de glicose; fator dieta $(P=0,0190)$, fator suplementação $(P=0,0314)$, interação $(P=0,4734) ;(C)$ Insulina de jejum; fator dieta $(P=0,0071)$, fator suplementação $(P=0,0310)$, interação $(P=0,4636)$. As barras representam média \pm EPM, $n=5$. ${ }^{*} P<0,05$ em relação ao grupo controle; ${ }^{\circledR} P<0,05$ entre os grupos $\mathrm{MIX}$ vs LEU. MIX: mistura de aminoácidos não essenciais; LEU: leucina.

Fonte: Torres-Leal (2012).

\subsubsection{Ensaios com adipócitos isolados}

5.2.9.1 Avaliação da capacidade de adipócitos isolados em captar [ $\left.{ }^{3} H\right]-2-D e s o x i-D-$ glicose

Observou-se que somente os adipócitos SC dos animais alimentados com dieta HL na condição basal apresentaram aumento significativo na sua capacidade de transportar a $\left[{ }^{3} \mathrm{H}\right]-2 \mathrm{DG}(P=0,0091)$ em relação aos animais alimentados com dieta 
controle (fator dieta) (Figuras 19C). Já, em relação aos animais suplementados e à interação dos fatores avaliados, não observamos respostas significativas $(P>0,05)$ nos adipócitos PE e SC em ambas as condições (basal e estimulado).

Figura 19 - Avaliação da capacidade de adipócitos isolados em captar [ $\left.{ }^{3} \mathrm{H}\right]-2-D e s o x i-D-$ Glicose durante o EXPERIMENTO II.

Transporte por área PE - Basal

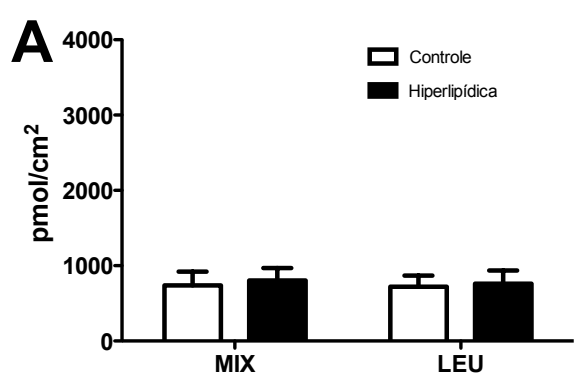

Transporte por área SC - Basal

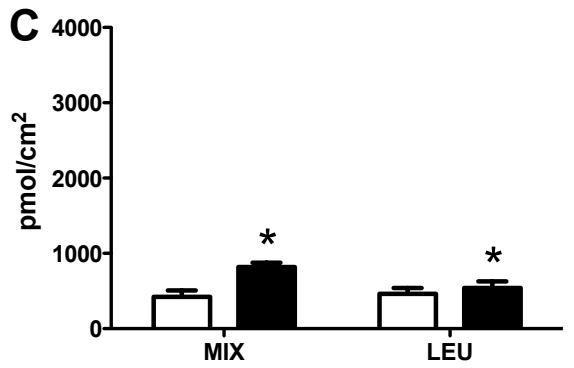

Transporte por área PE - Máximo

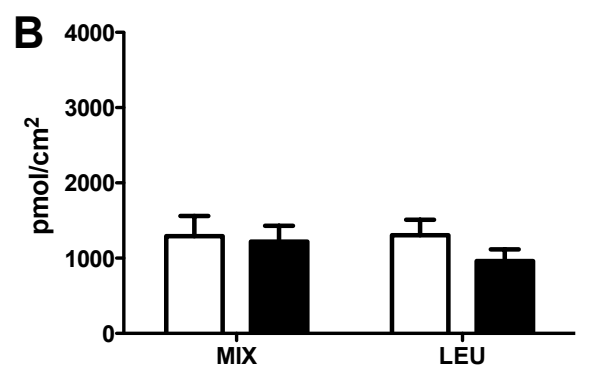

Transporte por área SC - Máximo

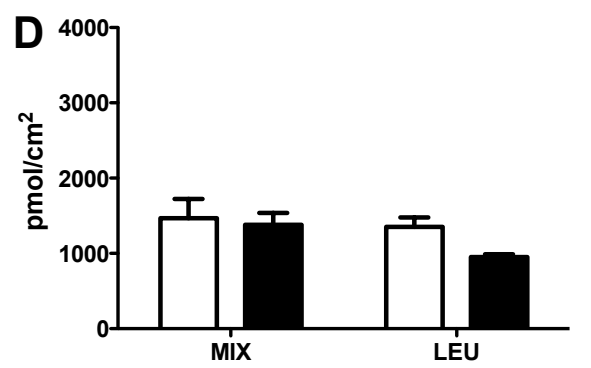

As células isoladas foram incubadas sem ou com insulina $10 \mathrm{nM}$ (estímulo máximo) por 30 minutos a $37^{\circ} \mathrm{C}$ e, em seguida, alíquotas deste meio de incubação foram adicionadas a microtubos contendo $\left[{ }^{3} \mathrm{H}\right]-2-D G$. Após 3 minutos, a reação foi interrompida com o acréscimo de Phloretin (Material e Métodos). Capacidade dos adipócitos (A) PE basal; fator dieta $(P=0,7655)$, fator suplementação $(P=0,8615)$, interação $(P=0,9408)$; (B) $P E$ máximo; fator dieta $(P=0,3480)$, fator suplementação $(P=0,5734)$, interação $(P=0,5345)$; (C) $S C$ basal; fator dieta $(P=0,0091)$, fator suplementação $(P=0,1538)$, interação $(P=0,0638)$; (D) $S C$ máximo; fator dieta $(P=0,1588)$, fator suplementação $(P=0,1171)$, interação $(P=0,3534)$; As barras representam média $\pm \mathrm{EPM}, \mathrm{n}=5 .{ }^{*} P<0,05$ em relação ao grupo controle. MIX: mistura de aminoácidos não essenciais; LEU: leucina.

Fonte: Torres-Leal (2012). 


\subsubsection{Avaliação da capacidade de oxidação}

Na figura 20, verifica-se a capacidade de conversão de D-[U- $\left.{ }^{14} \mathrm{C}\right]$-Glicose em ${ }^{14} \mathrm{CO}_{2}$ em adipócitos isolados das regiões PE e SC. Os resultados deste ensaio são apresentados na condição basal e na maximamente estimulada pela insulina (10nM). Nessa perspectiva, pode-se observar que os adipócitos da gordura PE e SC não apresentaram diferenças significativas $(P>0,05)$, nos fatores avaliados (dieta, suplementação e interação) (Figura 20). Porém, salienta-se que os adipócitos SC dos animais alimentados com dieta HL parecem ser mais responsivos à ação da leucina, mesmo na ausência de significância. Em especial, na condição basal o grupo HL+LEU apresentou incremento de 157,72\% (fator interação, $P=0,0696$ ) e estimulada com insulina de $63,75 \%$ (fator interação, $P=0,1008$ ) em relação ao grupo CON+LEU (Figura 20C e D).

Figura 20 - Capacidade de adipócitos isolados em oxidar glicose em $\mathrm{CO}_{2}$ durante $\mathrm{o}$ EXPERIMENTO II.
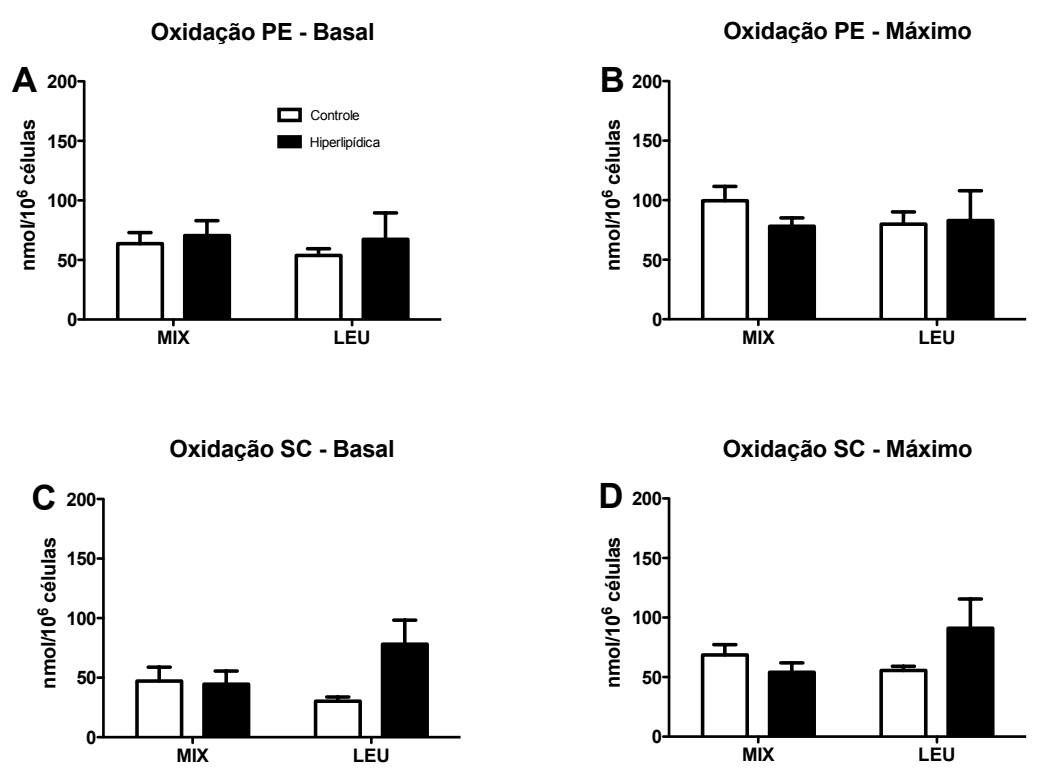

Os adipócitos foram isolados e incubados com $5 \mu \mathrm{l}$ de D-[U- $\left.{ }^{14} \mathrm{C}\right]$-glicose $[0,05 \mu \mathrm{Ci} /$ tubo, $2 \mathrm{mM}]$, acrescido de insulina (10nM) por 120 minutos a $37^{\circ} \mathrm{C}$. $\mathrm{O}^{14} \mathrm{CO}_{2}$ liberado pela reação com o $\mathrm{H}_{2} \mathrm{SO}_{4}$ foi adsorvido em um papel de filtro previamente banhado em etanolamina. Capacidade oxidativa de adipócitos (A) PE-basal; fator dieta $(P=0,4378)$, fator suplementação $(P=0,6139)$, interação

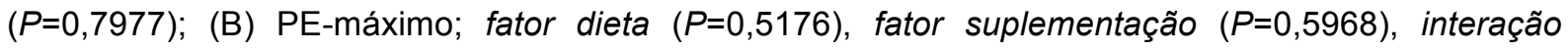
$(P=0,3885) ;$ (C) SC-basal; fator dieta $(P=0,1009)$, fator suplementação $(P=0,5307)$, interação $(P=0,0696) ;(D)$ SC-máximo; fator dieta $(P=0,4767)$, fator suplementação $(P=0,4137)$, interação $(P=0,1008)$. As barras representam média $\pm E P M, n=5$. MIX: mistura de aminoácidos não essenciais; LEU: leucina.

Fonte: Torres-Leal (2012). 


\subsubsection{Avaliação da capacidade de incorporação de $D-\left[U-{ }^{14} C\right]$-Glicose em lipídios}

Após o término do ensaio de oxidação de glicose, demos continuidade à avaliação da capacidade de adipócitos em incorporar glicose em lipídios destes animais. A figura 21 A, B e D indica ausência de significância para este ensaio nos adipócitos da região PE e SC em todos os fatores avaliados $(P>0,05)$; por outro lado, na figura $21 \mathrm{C}$, a incorporação de glicose em lipídios nos adipócitos SC dos animais alimentados com dieta $\mathrm{HL}$ foi significativamente maior, fator dieta $(P=0,0331)$.

Figura 21 - Capacidade de adipócitos isolados em incorporar glicose em lipídios durante o EXPERIMENTO II.
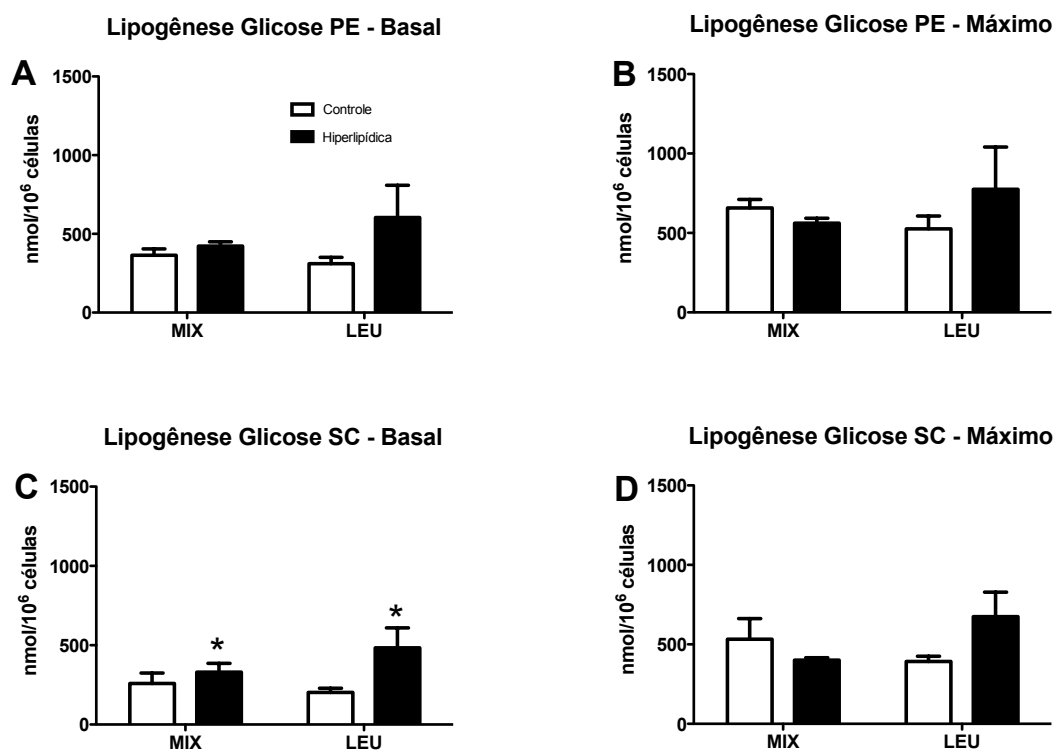

Após a coleta de $\mathrm{CO}_{2}$ para determinação da capacidade de oxidação da glicose, a sua incorporação em lipídios foi realizada. A extração das gorduras dos adipócitos pré-incubados com ${ }^{14} \mathrm{C}$-glicose foi feita com reagente de Dole. Capacidade de adipócitos em incorporar glicose em lipídios (A) PE basal; fator dieta $(P=0,1226)$, fator suplementação $(P=0,5610)$, interação $(P=0,2908)$; (B) $P E$ máximo; fator dieta $(P=0,5975)$, fator suplementação $(P=0,7773)$, interação $(P=0,2434)$; (C) SC basal; fator dieta $(P=0,0331)$, fator suplementação $(P=0,5262)$, interação $(P=0,1857)$; (D) SC máximo; fator dieta $(P=0,4715)$, fator suplementação $(P=0,5232)$, interação $(P=0,0602)$. As barras representam média \pm EPM, $\mathrm{n}=5$. ${ }^{*} P<0,05$ em relação ao grupo controle. MIX: mistura de aminoácidos não essenciais; LEU: leucina.

Fonte: Torres-Leal (2012). 


\subsubsection{Avaliação da incorporação de $D-\left[U-{ }^{14} C\right]$-Glicose em ácidos graxos de TAG}

Ao analisarmos a capacidade de incorporação de glicose no resíduo AG de TAG em células adiposas, podemos avaliar a síntese de AG de novo. Na figura 22A, observa-se que não houve diferença estatística entre os grupos nos fatores avaliados na condição basal em adipócitos $P E(P>0,05)$. Por outro lado, observa-se em adipócitos PE (estimulado) e SC (basal e estimulado) significativa interação (PE, estimulado, $P=0,0415$ ) e SC (basal, $P=0,0225$; e estimulado, $P=0,0162$ ). Os demais fatores (dieta e suplementação) não apresentaram diferença significativa para adipócitos PE e SC (Figura $22 \mathrm{~B}, \mathrm{C}, \mathrm{D})(P>0,05)$.

Figura 22 - Incorporação de glicose em ácido graxo de adipócitos isolados durante o EXPERIMENTO II.
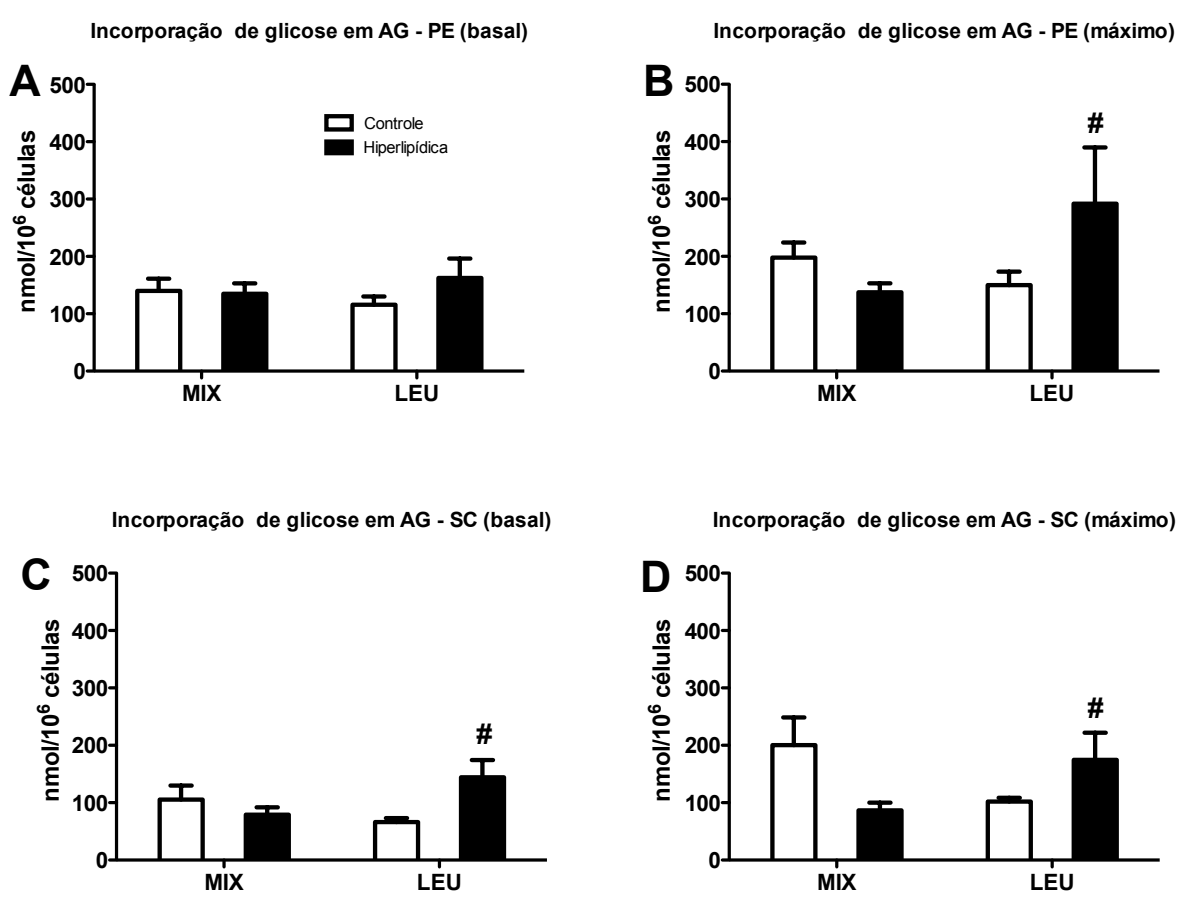

Incorporação de glicose em ácido graxo de adipócitos; (A) PE basal; fator dieta $(P=0,3529)$, fator suplementação $(P=0,9362)$, interação $(P=0,2488)$; (B) $P E$ máxima; fator dieta $(P=0,3833)$, fator suplementação $(P=0,2589)$, interação $(P=0,0415)$; (C) SC basal; fator dieta $(P=0,2266)$, fator suplementação $(P=0,5347)$, interação $(P=0,0225)$; (D) SC máxima; fator dieta $(P=0,5652)$, fator suplementação $(P=0,8819)$, interação $(P=0,0162)$. As barras e os pontos representam média \pm EPM, $\mathrm{n}=5$. ${ }^{*} P<0,05$ em relação ao grupo CON+LEU. MIX: mistura de aminoácidos não essenciais; LEU: leucina.

Fonte: Torres-Leal (2012). 


\subsubsection{Incorporação de AG em TAG}

Tendo em vista que os animais do grupo HL consumiram quantidade maior de ácidos graxos o que significa um maior aporte de ácidos graxos para os adipócitos, optamos por investigar a incorporação dos ácidos graxos majoritários (ácido palmítico e ácido oléico) da dieta utilizada no presente estudo, em TAG em adipócitos PE e SC. Nessa perspectiva, as figuras 23A e 23B indicam um incremento significativo na incorporação de palmitato $(P=0,0031)$ e oléico $(P=0,0398)$ em adipócitos PE de animais alimentados com dieta HL (fator dieta) refletindo uma maior capacidade de re-esterificação dos adipócitos destes animais. Por outro lado, observa-se a ausência de efeitos significativos da suplementação com leucina (fator suplementação) e de interação dos fatores, quando testados os dois traçadores $(P>0,05)$.

Figura 23 - Incorporação de AG em TAG de adipócitos PE isolados durante o EXPERIMENTO II.

Incorporação de palmitato em TAG - PE

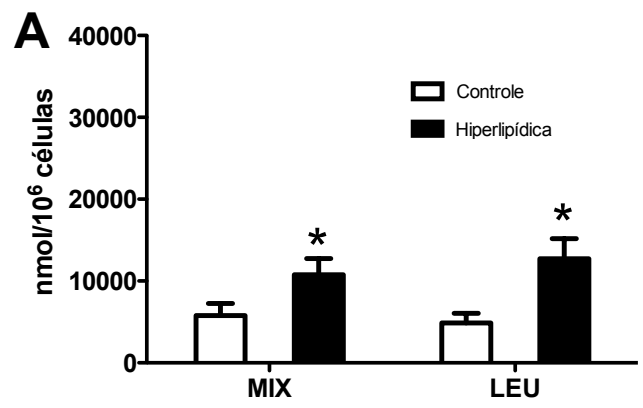

Incorporação de oléico em TAG - PE

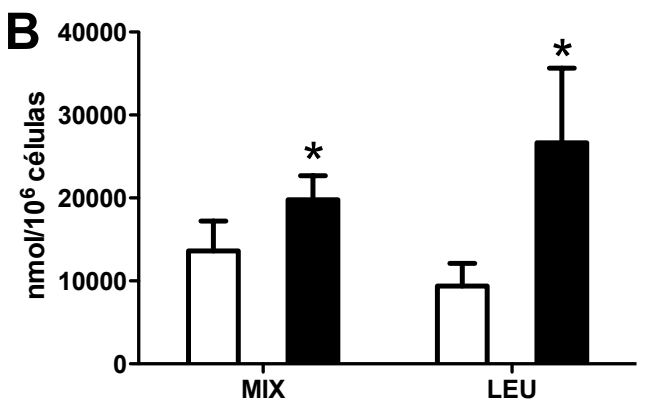

Incorporação em triacilgliceróis em adipócitos $\mathrm{PE}$ de $(\mathrm{A})$ ácido palmitico; fator dieta $(P=0,0031)$, fator suplementação $(P=0,7727)$, interação $(P=0,4488)$; e $(B)$ ácido oleico em triacilgliceróis de adipócitos $\mathrm{PE}$; fator dieta $(P=0,0398)$, fator suplementação $(P=0,8048)$, interação $(P=0,3050)$; As barras representam média \pm EPM, $n=5 .{ }^{*} P<0,05$ em relação ao grupo controle. MIX: mistura de aminoácidos não essenciais; LEU: leucina.

Fonte: Torres-Leal (2012). 
Dando continuidade aos ensaios de incorporação de AG em TAG, avaliou-se a incorporação de palmitato e oleico em adipócitos da região SC. Nas figuras 24A e 24B, pode-se observar incremento significativo na formação de TAG, a partir de palmitato $(P=0,0001)$ e oleico $(P=0,0266)$ nos animais alimentados com dieta $\mathrm{HL}$ (fator dieta). Além disso, verifica-se diferença significativa na interação dos fatores avaliados $(P<0,05)$. Entretanto, não foi observada diferença significativa para o fator suplementação $(P>0,05)$ em relação à incorporação de ácido palmítico e oleico em adipócitos da região SC.

Figura 24 - Incorporação de AG em TAG de adipócitos SC isolados durante o EXPERIMENTO II.

Incorporação de palmitato em TAG - SC

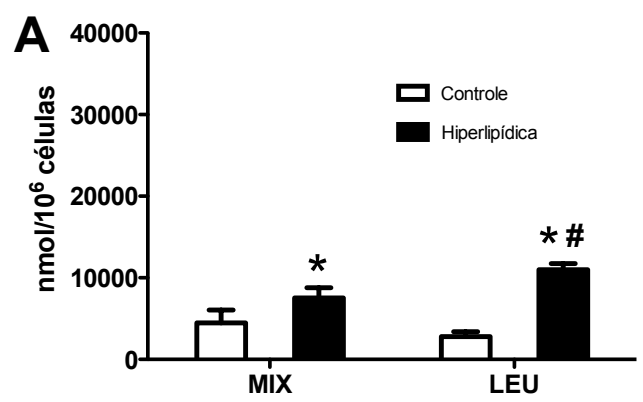

Incorporação de oléico em TAG - SC

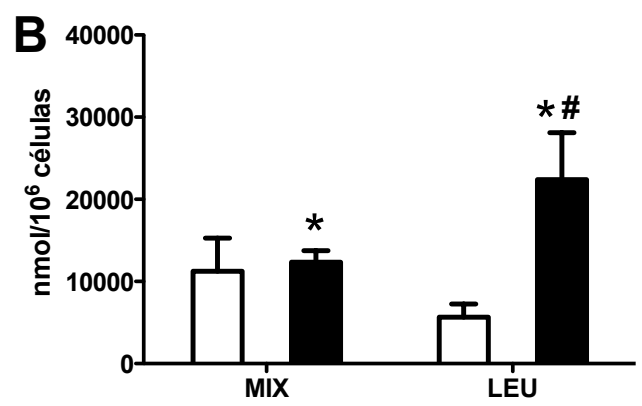

Incorporação em triacilgliceróis em adipócitos $S C$ de $(A)$ ácido palmitico; fator dieta $(P=0,0001)$, fator suplementação $(P=0,4397)$, interação $(P=0,0339)$; $(\mathrm{B})$ ácido oleico; fator dieta $(P=0,0266)$, fator suplementação $(P=0,5489)$, interação $(P=0,0481)$; As barras representam média $\pm \mathrm{EPM}, \mathrm{n}=5$. ${ }^{*}<<0,05$ em relação ao grupo controle; ${ }^{\#} P<0,05$ em relação ao grupo CON+LEU. MIX: mistura de aminoácidos não essenciais; LEU: leucina.

Fonte: Torres-Leal (2012). 


\subsubsection{Avaliação da capacidade lipolítica em adipócitos isolados}

As atividades lipolíticas na ausência e na presença do agonista $\beta$-adrenérgico isoproterenol (ISO) foram determinadas por meio da liberação de glicerol em adipócitos isolados. Na figuras $25 \mathrm{~A}$ e 25D verifica-se que o fator dieta aumentou significativamente a capacidade lipolítica em adipócitos das regiões $P E(P=0,0001)$ e SC $(P=0,0071)$, na ausência e na presença de isoproterenol, respectivamente. Além disso, observam-se efeitos significativos, recorrente, da suplementação com leucina (fator suplementação) em adipócitos SC tanto na ausência $(P=0,0029)$ quanto na presença do agonista $\beta$-adrenérgico $(P=0,0132)$ (Figura 25C e 25D). Ademais, houve uma significativa interação quando animais suplementados com leucina apresentam condições metabólicas distintas $(P=0,0193)$, uma vez que, animais alimentados com dieta HL apresentam um aumento expressivo de $116,24 \%$ na taxa lipolítica quando comparado com os animais controles (Figura 25D). Contrariamente ao observado com os adipócitos SC, as células da região PE dos animais suplementados com leucina e alimentados com dieta HL, apresentaram reduções significativas de $82 \%$ (interação, $P=0,0010$ ), quando comparado com os animais alimentados com dieta controle e suplementados com leucina (Figura 25A). 
Figura 25 - Respostas lipolíticas de adipócitos isolados durante o EXPERIMENTO II.

Lipólise PE - Basal

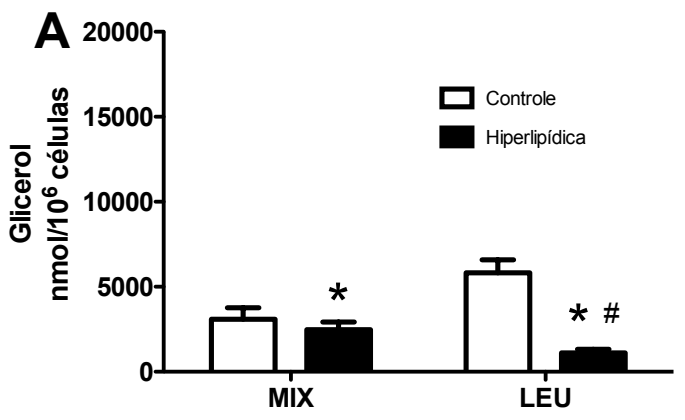

Lipólise SC - Basal

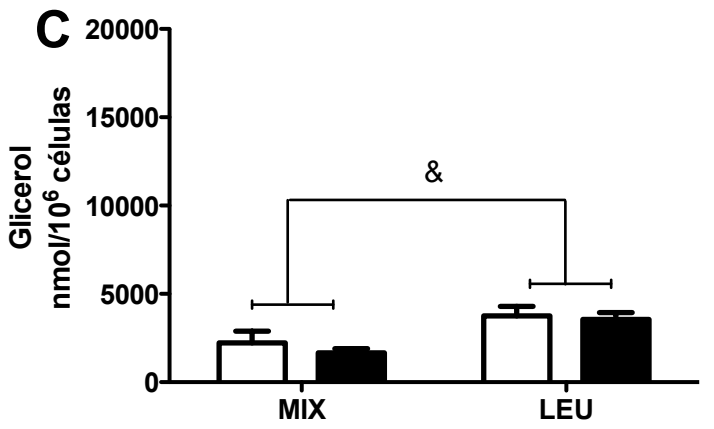

Lipólise PE - ISO

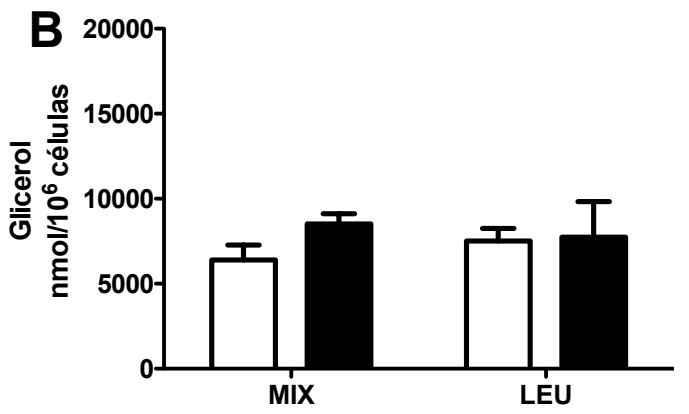

Lipólise SC - ISO

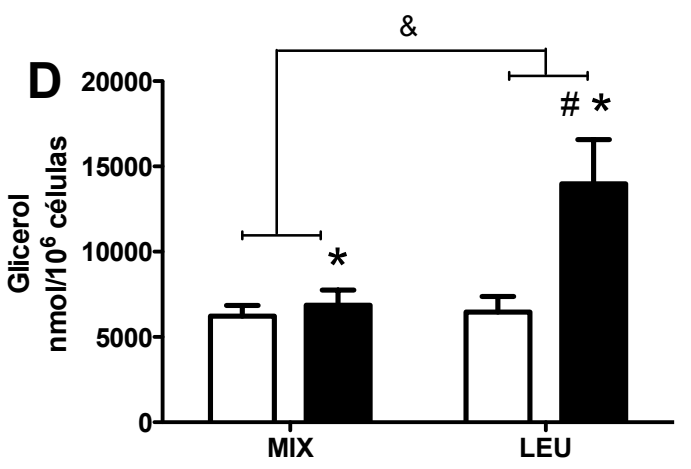

Capacidade lipolítica de adipócitos (A) PE basal; fator dieta $(P=0,0001)$, fator suplementação $(P=0,2022)$, interação $(P=0,0010)$; (B) $P E$ estimulada; fator dieta $(P=0,3565)$, fator suplementação $(P=0,8963)$, interação $(P=0,4547) ;(C)$ SC basal; fator dieta $(P=0,4478)$, fator suplementação $(P=0,0029)$, interação $(P=0,7069)$; (D) SC estimulada; fator dieta $(P=0,0071)$, fator suplementação $(P=0,0132)$, interação $(P=0,0193)$. As barras representam média $\pm \mathrm{EPM}, \mathrm{n}=5$. ${ }^{*} P<0,05$ em relação ao grupo controle; ${ }^{\#} P<0,05$ em relação ao grupo CON+LEU; ${ }^{\circledR} P<0,05$ entre os grupos MIX vs LEU. MIX: mistura de aminoácidos não essenciais; LEU: leucina.

Fonte: Torres-Leal (2012). 


\subsubsection{Avaliação da atividade máxima de enzimas envolvidas na lipogênese de} novo

A figura 26, demonstra que as enzimas ATP-citrato liase (coxim SC, $P=0,0327$ ), FAS (coxim PE, $P=0,0216$; SC, $P=0,0259$;MS, $P=0,0005$ ), G6PDH (coxim SC, $P=0,0052$ ), málica (coxim PE, $P=0,0239$;SC, $P=0,0110 ; \mathrm{MS}, P=0,0001$ ) dos animais alimentados com dieta HL apresentaram expressiva redução em suas atividades máximas quando comparados com os animais controle, sendo que o mesmo não foi observado nos outros o coxins adiposos. 
Figura 26 - Efeito do tratamento sobre a atividade das enzimas ATP-citrato liase, FAS, G6PDH e málica, do EXPERIMENTO II.
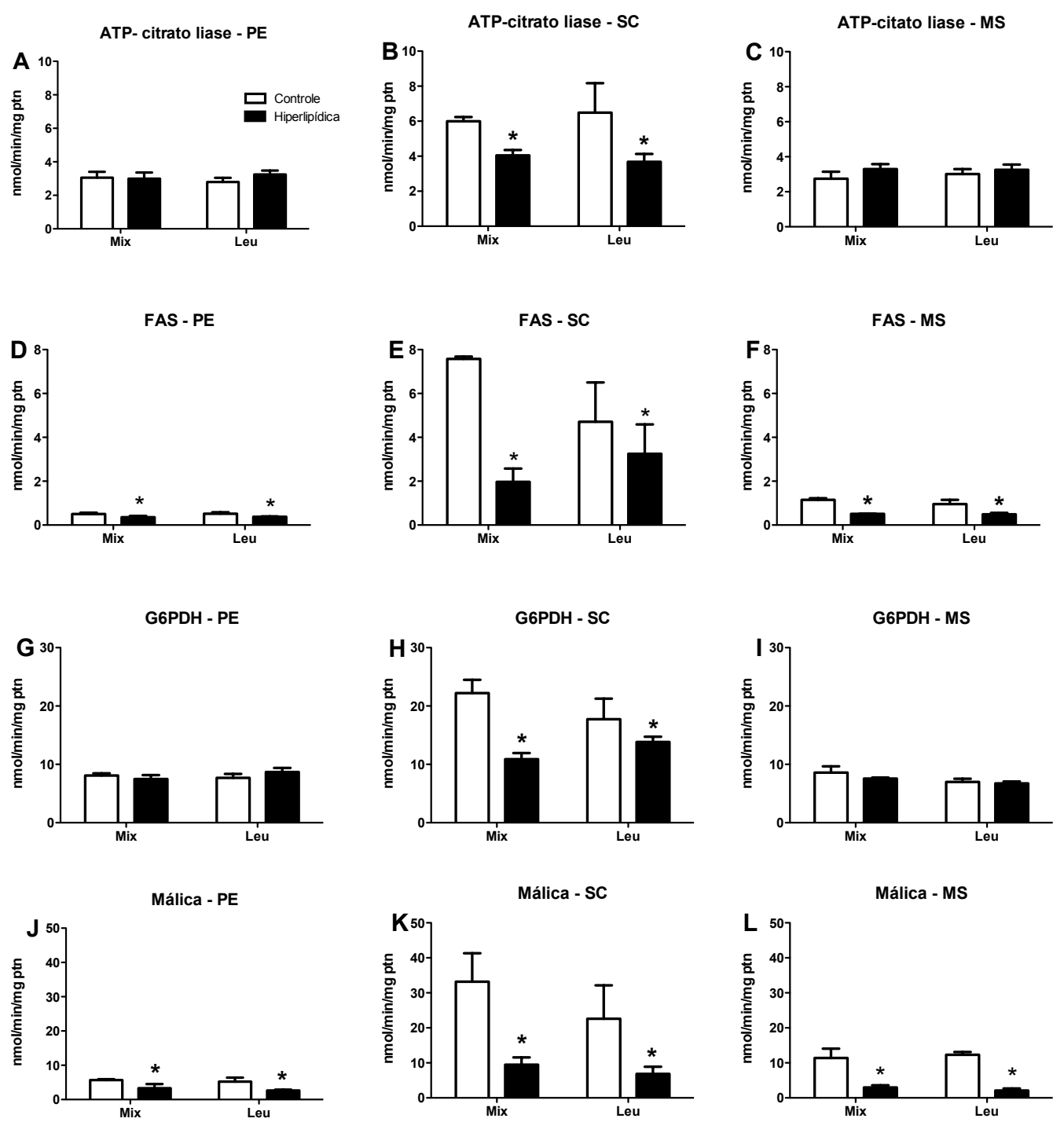

( $A, B$ e C) Atividade máxima da enzima ATP-citrato liase; (D, E e F) Atividade máxima da enzima FAS; ( $\mathrm{G}, \mathrm{H}$ e I) Atividade máxima da enzima G6PDH e (J, K e L) Atividade máxima da enzima málica. Todos os ensaios foram realizados nas gorduras periepididimal (PE), subcutânea (SC) e mesenterica (MS); As barras representam média \pm EPM. $n=4$. ${ }^{*}<0,05$ em relação ao grupo controle. MIX: mistura de aminoácidos não essenciais; LEU: leucina.

Fonte: Torres-Leal (2012). 


\subsubsection{Expressão gênica por $P C R$ em tempo real (qPCR) no tecido periepididimal (PE) e subcutâneo (SC)}

Os resultados relacionados às expressões gênicas de tecido adiposo PE apontam para a ausência de efeitos significativos em todos os fatores avaliados (dieta, suplementação e interação). Nessa perspectiva, algo que foi bem frequente em nossos achado é que a suplementação com leucina praticamente não exerceu efeitos sobre o metabolismo e na expressão gênica do tecido adiposo PE (Figura 27).

Figura 27 - Efeito do tratamento sobre a expressão gênica por qPCR de PPAR $\gamma$, LPL, GPAT e DGAT no tecido adiposo periepididimal (PE).

PPAR $\gamma$-PE

A

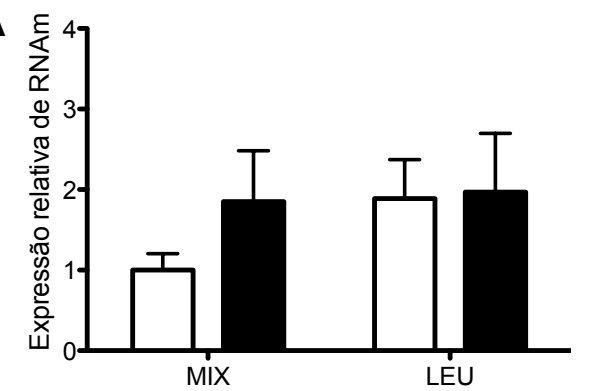

GPAT-PE

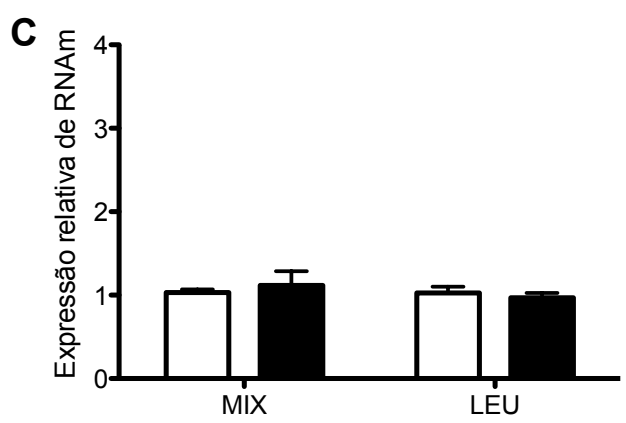

LPL-PE

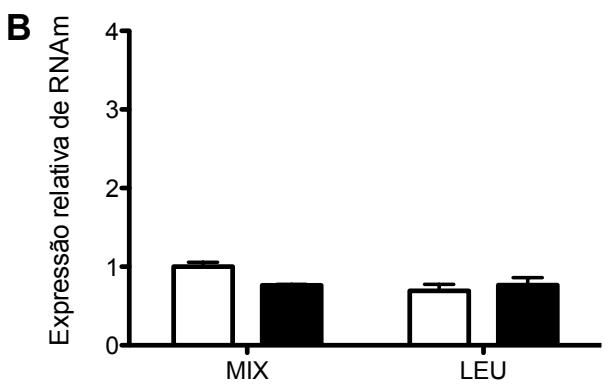

DGAT-PE

D

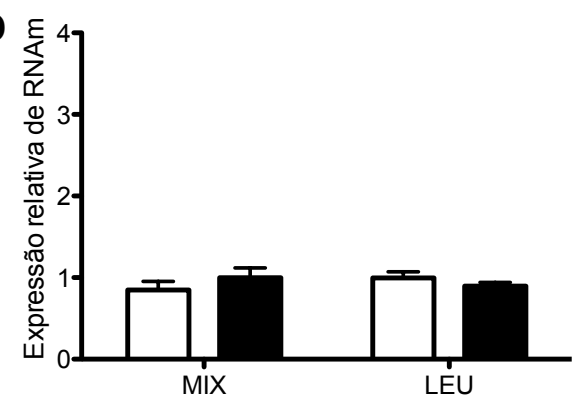

(A) PPAR $\gamma$, fator dieta $(P=0,4514)$, fator suplementação $(P=0,4178)$ e interação $(P=0,5307)$; $(B) L P L$, fator dieta $(P=0,2993)$, fator suplementação $(P=0,0672)$ e interação $(P=0,0647)$; (C) GPAT, fator dieta $(P=0,9150)$, fator suplementação $(P=0,5515)$ e interação $(P=0,5853)$; (D) DGAT, fator dieta $(P=0,8062)$, fator suplementação $(P=0,8313)$ e interação $(P=0,2453)$. As barras representam média \pm EPM, $n=4$. MIX: mistura de aminoácidos não essenciais; LEU: leucina.

Fonte: Torres-Leal (2012). 
Os resultados relacionados às expressões gênicas de tecido adiposo SC apontam para o incremento na expressão de PPAR $\gamma(P=0,0007)$, GPAT $(P=0,0089)$, $\operatorname{FABP}(P=0,0077)$ e PEPCK $(P=0,0331)$ para os animais suplementados com leucina (fator suplementação). Os demais efeitos observados foram verificados somente para os animais alimentados com dieta HL (fator dieta) para os genes da LPL $(P=0,0500)$ e DGAT $(P=0,0147)$, estes, por sua vez, apresentaram reduções significativas. Por outro lado, neste mesmo fator (dieta) observamos um incremento significativo para o gene da GPAT $(P=0,0279)$ no tecido adiposo SC. Além disso, observamos uma significativa interação na expressão gênica da FABP, onde o grupo alimentado por dieta HL apresentou redução significativa expressiva, frente a estas condições experiemntais (Figura 28). 
Figura 28 - Efeito do tratamento sobre a expressão gênica por qPCR de PPAR $\gamma, \mathrm{LPL}$, GPAT, DGAT, FABP e PEPCK no tecido adiposo subcutâneo (SC).

PPARY-SC

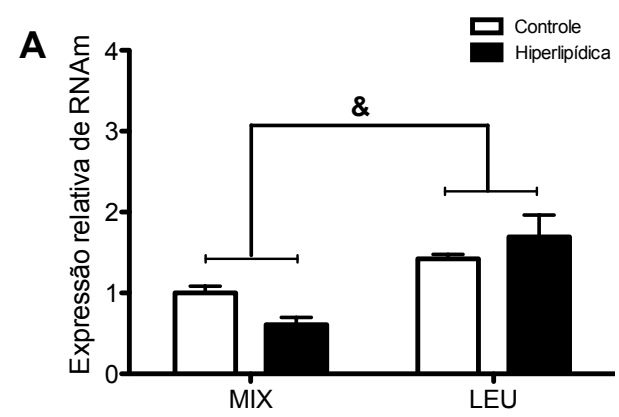

GPAT-SC

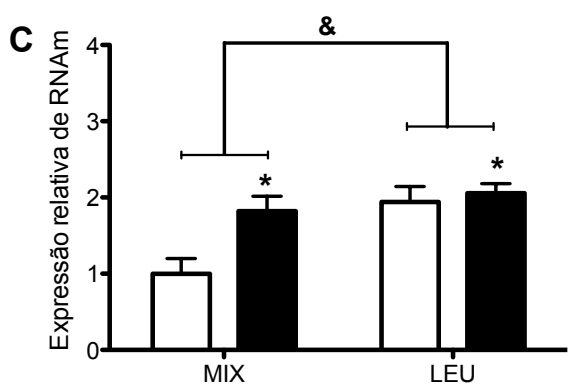

FABP-SC

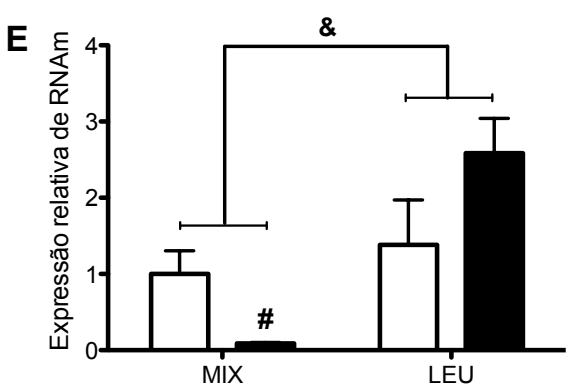

LPL-SC

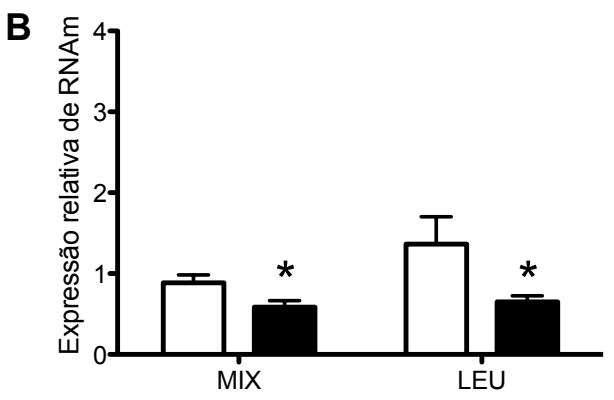

DGAT-SC

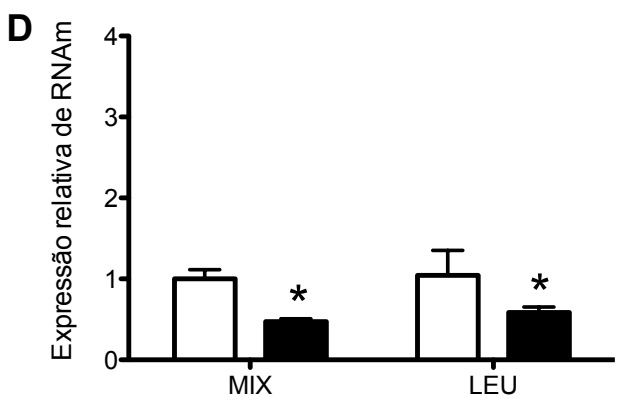

PEPCK-SC

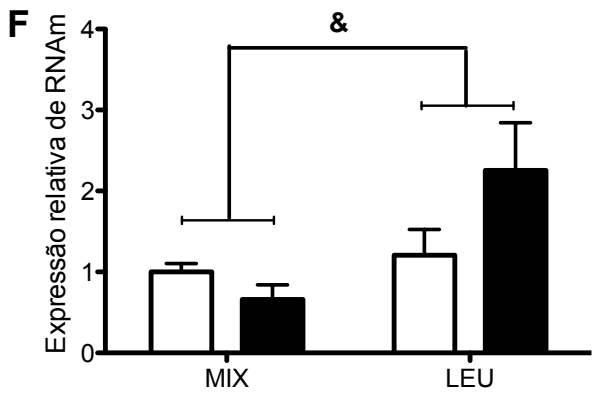

(A) PPAR $\gamma$, fator dieta $(P=0,7141)$, fator suplementação $(P=0,0007)$ e interação $(P=0,0648) ;(B) L P L$, fator dieta $(P=0,0500)$, fator suplementação $(P=0,2689)$ e interação $(P=0,3984)$; (C) GPAT, fator dieta $(P=0,0279)$, fator suplementação $(P=0,0089)$ e interação $(P=0,0839)$; $(D)$ DGAT, fator dieta $(P=0,0147)$, fator suplementação $(P=0,6563)$ e interação $(P=0,8461) ;(E) \quad F A B P$, fator dieta $(P=0,7370)$, fator suplementação $(P=0,0077)$ e interação $(P=0,0336)$. ( $F)$ PEPCK, fator dieta $(P=0,3403)$, fator suplementação $(P=0,0331)$ e interação $(P=0,0828)$. As barras representam média \pm EPM, $n=4$. * $P<0,05$ em relação ao grupo controle; ${ }^{\#} P<0,05$ em relação ao grupo $C O N+L E U ;{ }^{\&} P<0,05$ entre os grupos MIX vs LEU. Símbolos MIX: mistura de aminoácidos não essenciais; LEU: leucina. Fonte: Torres-Leal (2012). 


\section{DISCUSSÃO}

No presente estudo, usando a combinação do modelo experimental de obesidade+resistência à insulina induzido por dieta HL e a suplementação com leucina, fomos capazes de elucidar alguns aspectos da complexa relação entre a participação da leucina sobre a adiposidade e alguns genes que participam da lipogênese e da esterificação de ácidos graxos. Os nossos resultados demonstram que animais com diferentes condições metabólicas apresentam respostas distintas quando submetidos à suplementação com leucina, principalmente, no que diz respeito à adiposidade corporal, incorporação de ácidos graxos em TAG e em alguns genes relacionados ao transporte de lipídios e na participação direta sobre a lipogênese. Mais especificamente, a suplementação com leucina exerce seus efeitos sobre o PPAR $\gamma$, (via ativação do $\operatorname{mTORC1}$, como já descrito na literatura) que age como um mediador chave deste processo em animais obesos e resistentes à insulina, proporcionando ações sobre o metabolismo lipídico. Tomados em conjunto, nossos resultados estabelecem que a leucina é um nutriente capaz de exercer efeitos sobre a expressão gênica de PPAR (mesmo que via mTORC1), sobre a incorporação de ácidos graxos ex vivo e sobre adiposidade in vivo. Além disso, destacamos que os efeitos da leucina sobre a adiposidade são depósito-especifico, uma vez que, os nossos resultados foram sempre observados em adipócitos particularmente do tecido adiposo SC. Nesse sentido, o conhecimento específico de determinadas condições metabólicas frente à administração de leucina é considerado importante, haja vista que, este nutriente tem sido amplamente proposto como uma ferramenta importante no controle e perda de peso corporal.

\subsection{Caracterização do modelo de obesidade e resistência à insulina no EXPERIMENTO I}

A administração de dieta HL por 10 semanas favoreceu maior acúmulo de gordura corporal em dois dos três coxins adiposos avaliados, a saber, SC e PE, acompanhado do aumento no consumo calórico, do maior peso corporal e da hipertrofia do adipócito SC. Apesar da maior deposição de gordura corporal, observamos a ausência de efeitos da dieta HL sobre a massa adiposa no coxim RP e sobre o tamanho dos adipócitos PE. Assim, nossos resultados corroboram com 
estudo anterior onde destacamos que o consumo de dieta HL por 15 semanas desencadeou maior adiposidade nos dois coxins adiposos (SC e PE) e sobre o tamanho de adipócitos SC (Torres-Leal et al., 2011). Por outro lado, a ausência de maiores repercussões sobre a gordura RP e o tamanho de adipócitos da gordura PE podem ser devidos ao tempo (relativamente curto) de exposição a este tipo de dieta (Torres-Leal et al., 2011). Independente das respostas observadas, já está bem consolidado o uso de dieta $\mathrm{HL}$ em modelos animais para indução de obesidade (Cani et al., 2008; Tsukumo et al., 2007).

Dentre os distúrbios metabólicos associados à obesidade, destaca-se a tolerância diminuída à glicose, que, por sua vez, tem sido relacionada à resistência à insulina. Os resultados do EXPERIMENTO I apontam para hiperglicemia e resistência à insulina. Nos últimos anos, foi dada considerável atenção para a possibilidade de que o tipo de gordura consumida na dieta representasse riscos ao metabolismo, com destaque para o possível prejuízo ao metabolismo dos carboidratos. A dieta $\mathrm{HL}$ em questão apresenta grande quantidade de gordura monoinsaturada (oleico) e saturada (palmítico) quando comparada com a dieta controle (AIN-93M), sendo que o último constituinte é considerado prejudicial à ação da insulina, o que pode favorecer a resistência a este hormônio no músculo esquelético, fígado e TAB (Reynoso et al., 2003; Shi et al., 2006).

Destacamos em nossos resultados que os animais que consumiram dieta $\mathrm{HL}$ apresentaram significativa intolerância à glicose e resistência à ação da insulina sistêmica. Estudos publicados, que utilizaram a mesma dieta para indução da obesidade, sugerem que o modelo experimental em questão esteja associado com a resistência à insulina sistêmica, bem como, no fígado e no músculo (Cintra et al., 2012; Torres-Leal et al., 2011). Estas respostas podem estar relacionadas a um processo inflamatório decorrente do excesso de gordura corporal, uma vez que, a obesidade parece apresentar forte relação com um maior estado inflamatório basal e o acúmulo de gordura em outros tecidos além do adiposo, como fígado, músculo e em células $\beta$, o que agrava este estado crônico de inflamação, favorecendo a disfunção metabólica (Arruda et al. 2011; Calegari et al., 2011; Hotamisligil, 2006; Moraes et al., 2009; Velloso et al., 2008).

Anteriormente, realizamos a avaliação clínica e metabólica sistêmica através do GTT oral e KITT. Dando continuidade a mesma linha, avaliamos em adipócitos PE e SC a captação (taxas - basal e maximamente estimulada pela insulina) de 2- 
Desoxi-D-Glicose. Nossos resultados indicam que, na ausência de insulina (condição basal), os adipócitos PE e SC dos animais HL apresentaram maior captação de glicose. O interessante é que mesmo resistentes à ação da insulina estes apresentaram maior captação deste substrato. Já, quando maximamente estimulados por insulina, os adipócitos PE (grupo $\mathrm{HL}$ ) foram menos responsivos e o mesmo não foi observado para adipócitos SC. Em adipócitos, o transporte de glicose é realizado por dois tipos de transportadores (GLUT 1 e 4). O GLUT1 é muito menos abundante nos adipócitos que o GLUT-4, e a insulina estimula a translocação de GLUT1 para a superfície celular em cerca de1-2 vezes, contra cerca de 10 vezes para o GLUT4 (Kahn e Flier, 1990). Partindo dessa premissa, o GLUT1 em células adiposas é, portanto, considerado primariamente um transportador de glicose constitutivo com uma pequena contribuição quando estimulado pela insulina. Coerentemente, Pedersen et al. (1992) verificaram uma correlação positiva entre a captação de glicose basal e expressão proteica de GLUT1 por célula adiposa. Seguindo a mesma vertente, os mesmos pesquisadores observaram a existência de um aumento de 3 a 4 quatro vezes no conteúdo de RNAm e de proteína de GLUT1 quando comparou adipócitos de ratos obesos que apresentaram aumento na captação de glicose basal quando comparados aos controles (Pedersen et al., 1992). O efeito fisiológico do aumento na expressão de GLUT1 em adipócitos de ratos obesos não é claro, mas este transportador pode contribuir para o aumento contínuo na taxa de captação de glicose. Este aumento na captação de glicose é especialmente verificado em adipócitos de ratos obesos e resistentes à ação da insulina, nos quais há infrarregulação do GLUT4 (Pedersen et al., 1992). A menor captação de glicose estimulada por insulina na gordura PE pode estar relacionada à menor translocação ou atividade de GLUT4 com o compensatório incremento na expressão e função de GLUT1.

Os nossos resultados relacionados à incorporação de glicose em ácido graxo e à atividade máxima das enzimas que participam da síntese de novo de ácidos graxos foram expressivamente reduzidos nos grupos que consumiram dieta HL. A principal resposta para este efeito está diretamente relacionada com a sensibilidade à ação da insulina que foi significativamente comprometida nestes animais. Além disso, a quantidade reduzida de carboidratos e a elevada de lipídios na dieta contribuíram substancialmente para que este efeito se agravasse. Os dois fatores podem estar envolvidos nestas respostas. O primeiro, pela menor disponibilidade da 
cadeia de dois carbonos doada pela glicose, e o segundo, pelos efeitos deletérios da dieta HL na resposta à insulina. Estudos clássicos destacam os efeitos prejudiciais atribuídos a alta quantidade de ácidos graxos presente na dieta sobre a atividade máxima das enzimas que participam desse processo, bem como, de suas expressões gênicas (Foufelle et al., 1992, 1996; Girard et al., 1994). Ademais, em indivíduos obesos com DM2, a lipogênese de novo é significativamente mais agravada do que a observada em indivíduos apenas com sobrepeso (Ortega et al., 2010).

\subsection{EXPERIMENTO II}

Atualmente, grande importância tem sido dada para o uso da suplementação com leucina na prevenção da adiposidade corporal e homeostase glicêmica. Exemplo disso são os estudos que buscaram avaliar os efeitos da leucina na prevenção da obesidade, utilizando modelos animais (Macotela et al., 2011; Nairizi et al., 2009; Zhang et al., 2007) e ratos idosos (Viana et al., 2012) que consumiam leucina e dieta HL. Nesse sentido, o presente estudo buscou avaliar uma condição que se aproxima mais da realidade mundial, em que o quadro de obesidade vem se acentuando, com inúmeros gastos públicos e alta taxa de mortalidade e agravando o dispêndio de recursos e gastos públicos com saúde. Nós avaliamos o efeito da leucina em uma condição já instalada de obesidade e resistência à insulina. Além disso, a partir de estudo anterior (Torres-Leal et al., 2011), apoiamos a nossa hipótese de que a condição metabólica adversa (obesidade e resistência à insulina) quando associada à suplementação com leucina potencialmente favoreça os eventos lipogênicos.

Nessa perspectiva, no presente trabalho, ao avaliarmos a influência da dieta hiperlipídica e da leucina sobre o consumo alimentar, verificamos que a dieta $\mathrm{HL}$ isoladamente contribuiu significativamente para o maior consumo calórico diário (kcal/dia), resposta esta semelhante a observada no EXPERIMENTO I. Apesar de algumas evidências destacarem que a leucina seja capaz de exercer efeitos sobre o controle alimentar via ativação central do mTORC1 (Cota et al., 2006; Ropelle et al., 2008), isto não se confirmou neste trabalho. Estudos anteriores demonstram que a leucina não exerce qualquer efeito sobre o consumo alimentar (Donato et al., 2006; 2007; Teodoro et al., 2012; Torres-Leal et al., 2011; Vianna et al., 2012). 
Acreditamos que este nutriente exerça efeitos periféricos e não centrais como destacados por Cota et al. (2006) e Ropelle et al. (2008), já que a barreira hematoencefálica é estritamente seletiva quanto à passagem de nutrientes. Ademais, os estudos que creditam entre os efeitos da leucina, ações sobre comportamento alimentar, utilizaram doses suprafisiológicas deste nutriente, além de sua infusão ter sido direta na região hipotalâmica estudada (Cota et al., 2006; Ropelle et al., 2008).

Em relação ao peso corporal e ganho de peso não observamos quaisquer efeitos sobre estas variáveis que, por muitas vezes, podem não representar efeitos sobre a adiposidade corporal que constituiria um fator de maior impacto sobre as respostas relacionas a disfunções metabólicas. Desse modo, ao analisar a massa de determinados coxins adiposos (PE, SC e MS) bem como a somatória dessas massas, podemos verificar que a dieta HL exerceu seus efeitos indutores de maior acúmulo de gordura corporal. Destacam-se também os efeitos significativos da interação da suplementação com leucina, que favoreceu maior adiposidade aos animais alimentados por dieta $\mathrm{HL}$, que, no caso da gordura SC, foi acompanhada de maior hipertrofia de seus adipócitos. Em estudos anteriores, foi observado que a suplementação com leucina pode exercer efeitos lipogênicos em diferentes condições experimentais, como na obesidade (Torres-Leal et al., 2011), na senescência (Zeanandin et al., 2012) e na desnutrição proteica (Teodoro et al., 2012).

Frente a condições de excesso de gordura corporal, os animais alimentados com dieta HL por 16 semanas continuam a apresentar um quadro característico de resistência à ação da insulina, semelhante ao observado no EXPERIMENTO I. Por outro lado, em resposta ao GTT oral, observou-se a ausência de efeitos da dieta HL frente à sobrecarga de glicose, resposta esta justificada pela maior secreção de insulina desempenhada pelas ilhotas pancreáticas isoladas (baixa e alta concentração de glicose) nos animais alimentados com dieta HL. O DM2 resulta da complexa combinação entre a resistência à insulina e o defeito funcional das células $\beta$-pancreáticas (Muoio e Newgard, 2008). A maioria dos indivíduos com DM2 apresentam sobrepeso e os fatores relacionados à obesidade atualmente propostos são considerados importantes determinantes para piora da homeostase glicêmica. Adipocinas produzidas por adipócitos hipertrofiados, como TNF- $\alpha$ e IL-6, ativam quinases em resíduos de treonina e serina em células sensíveis à insulina, prejudicando a transdução e a propagação da sinalização da insulina, resultando em 
resistência ao hormônio (Hotamisligil, 2006). Com o agravamento da resistência, as células $\beta$-pancreáticas aumentam a secreção de insulina para compensar a demanda periférica (Arruda et al., 2011). Esta compensação pode falhar dependendo da carga genética e da presença de fatores prejudiciais, tais como as adipocinas, ácidos graxos e glicose circulante (Muoio e Newgard, 2008).

Os efeitos da leucina em aumentar a secreção de insulina foram somente observados em meio com altas concentrações de glicose [16,7 mM]. Foi relatado que, em células $\beta$-pancreáticas, a leucina tem muitas funções, como a de estimular a secreção de insulina, e de regular a sua expressão gênica e síntese proteica (McDaniel et al., 2002). Entretanto, as funções deste nutriente no desenvolvimento das células pancreáticas não estão totalmente compreendidas, uma vez que pesquisadores destacam que o mTORC1 tem papel fundamental na proliferação de células adultas (Rachdi et al., 2012). Sendo assim, é nossa suposição de que leucina possa ter influenciado o crescimento de células- $\beta$ e consequentemente esta resposta aumentada na produção de insulina.

Quanto à captação de 2-Desoxi-D-Glicose, não se observaram efeitos adicionais frente à suplementação com leucina, tanto na ausência com na presença de concentrações maximamente estimulantes de insulina. Inesperadamente, observamos somente efeitos da dieta HL sobre a captação de glicose na ausência de insulina (condição basal) em adipócitos SC. Esta resposta apesar de semelhantes ao EXPERIMENTO I, demonstra, mais uma vez, que adipócitos desta região SC apresentam maiores adaptações no que diz respeito à participação do GLUT1 na captação basal de glicose. Quando estimulados por insulina, nem dieta $H L$, nem suplementação com leucina e nem a interação destes dois fatores provocou alteração na resposta de adipócitos SC e PE. Algumas evidências destacam que a leucina quando utilizada em condições de resistência à insulina por dieta HL ou wortmannin é capaz de melhorar a fosforilação da Akt no TAB pela quinase dependente de fosfoinositol-1 (PDK1), e, assim, recuperar a capacidade de transporte de glicose, estimular a lipogênese, bem como, a ativação do mTORC1 (Hinault et al., 2004, 2006). Entretanto, estas hipóteses não puderam ser comprovadas.

Nesse contexto, os mecanismos de ação da leucina na via de sinalização da insulina em adipócitos, durante a condição de resistência à insulina induzida por alimentos, permanecem pouco elucidados. Porém, há evidências de que a leucina pode revelar-se promissora para o tratamento e/ou prevenção das doenças 
metabólicas associadas com disfunção do TAB e da resistência à insulina (Hinault et al., 2004, 2006).

Quanto à incorporação de glicose em lipídios, observa-se que a suplementação com leucina pode exercer efeitos diretos favoráveis sobre o metabolismo de adipócitos, principalmente na formação de ácidos graxos em células do coxim adiposo SC. Hinault et al. (2004) verificaram que adipócitos tratados com wortmannin + leucina, apresentaram incremento significativo na lipogênese e que seus mecanismos são desconhecidos, mas que possivelmente esta resposta esteja associada a melhora na captação de glicose. Recentemente, Chakrabarti et al. (2010) verificaram que o $\mathrm{mTORC1}$ exerce efeitos sobre a síntese de novo de ácido graxo em adipócitos. Além das evidências em adipócitos, outros pesquisadores demonstraram claramente que a participação do mTORC1 na síntese de novo de ácido graxo hepático é via SREBP1c (Li et al., 2010). Apesar da maior síntese de ácidos graxos observada para os animais alimentados com dieta $\mathrm{HL}$ e suplementados com leucina, a determinação da atividade máxima das enzimas lipogênicas não mostrou nenhum efeito em relação à interação da dieta HL com a suplementação com leucina, como havia sido observado na síntese de novo de ácidos graxos. Possíveis respostas podem estar associadas aos nossos achados, que vão desde a longa exposição à dieta $\mathrm{HL}$ (16 semanas), que é rica em ácidos graxos de cadeia longa, e pelo jejum de $12 \mathrm{~h}$ que os animais foram submetidos. Estas duas condições influenciam diretamente tanto a expressão gênica quanto a atividade destas enzimas. A exposição à dieta $\mathrm{HL}$ reduz drasticamente a atividade enzimática e o jejum de $8 \mathrm{~h}$ reduz em pelo menos 50\% expressão gênica (Foufelle et al., 1992, 1996; Girard et al., 1994; Palou et al., 2010).

Outro aspecto oportuno que merece destaque são as divergências nas respostas dos adipócitos e a atividade enzimática. Os nossos ensaios com células isoladas são realizados em duas condições, basal e maximamente estimulado com insulina [10 nM]; ademais, o meio para a manutenção das células durante o experimento contém uma certa quantidade de glicose [2,5 mM]. Já a atividade das enzimas é realizada em homogenatos de tecidos adiposos de animais submetidos a $12 \mathrm{~h}$ de jejum. Possivelmente, esta condição interfira diretamente resultando nas divergências em nossas respostas. Nesse sentido, foi demonstrado anteriormente (Foufelle et al., 1996; Iritani et al., 1996) que a glicose isoladamente consegue recuperar a expressão gênica das enzimas lipogênicas em questão, e que esta 
resposta é ainda mais intensa quando se associam glicose e insulina e, ainda, que estes efeitos parecem ser potencializados na condição de resistência à insulina, como uma estratégia metabólica para compensar esta condição desfavorável. Frente a estas observações, as células adiposas de todos os grupos encontravamse expostas às mesmas condições experimentais, e o único diferencial entre os mesmos seriam seus respectivos tratamentos. Nesse sentindo, estudos têm destacado o potencial lipogênico da leucina (Teodoro et al. 2012; Torres-Leal et al., 2011; Zeanandin et al., 2012). Também foram relatados estudos nos quais mTORC1 apresenta ação direta na formação do ácido graxo tanto em adipócitos como em hepatócitos (Chakrabarti et al., 2010; Li et al., 2010).

Ao final do EXPERIMENTO I verificou-se que os animais alimentados com dieta HL apresentaram maior adiposidade e adipócitos maiores, caracterizando um modelo de obesidade. Porém, a lipogênese de novo, (síntese nova de ácidos graxos) e a atividade máxima das enzimas lipogênicas encontravam-se expressivamente reduzidas. A partir destas evidências fizemos o seguinte questionamento: como explicar que animais alimentados com dieta $\mathrm{HL}$, a despeito da reduzida biossíntese de ácidos graxos nos seus adipócitos, apresentaram maior adiposidade? No EXPERIMENTO II procuramos investigar a lipogênese a partir da incorporação de ácidos graxos livres em TAG, o que, por sua vez, é a forma mais representativa para o incremento da massa adiposa tanto em animais alimentados com dieta controle ou HL. Pela incorporação dos dois ácidos graxos majoritários da nossa dieta HL (ácido palmítico e oleico), verificamos que os animais alimentados com dieta $\mathrm{HL}$ apresentaram significativa incorporação destes em TAG nas duas regiões avaliadas (PE e SC). Além disso, somente em adipócitos SC, verificamos significativa interação entre dieta HL e leucina no fenômeno. Esta resposta nos possibilitou o entendimento dos efeitos distintos observados após a suplementação crônica com leucina, frente a duas condições metabólicas adversas, sobre a esterificação de ácidos graxos. Atualmente, não existem trabalhos que avaliaram estes efeitos em adipócitos. Desse modo, buscamos investigar quais seriam os mecanismos que permeavam a compreensão destas respostas relacionadas aos efeitos da leucina sobre duas condições metabólicas distintas (controle vs metabolicamente disfuncional). Curiosamente, após a avaliação de alguns genes relacionados à lipogênese e à esterificação de ácidos graxos, no tecido adiposo PE, não observamos quaisquer efeitos, sejam eles da dieta hiperlipídica, da suplementação com leucina e da interação destes fatores. Estas respostas se coadunam com nossos 
resultados, em que verificamos uma menor responsividade dos adipócitos PE. Por outro lado, o tecido adiposo SC apresentou aumento significativo (devido ao fator dieta $H L$ ) na expressão gênica da enzima glicerol-3-fosfato aciltransferase (GPAT) e redução na expressão dos genes, lipase lipoproteica (LPL) e diacilglicerol aciltranferase (DGAT), enzimas importantes para a esterificação de AGL com glicerol-fosfato. Além disso, destacamos que os genes PPAR $\gamma$, GPAT, proteína ligadora de ácidos graxos (FABP) e fosfoenolpiruvato carboxilase (PEPCK) foram reguladas após a suplementação com leucina por 6 semanas. Destacamos ainda que boa parte destes efeitos pode ser atribuída ao grupo alimentado com dieta HL e suplementado com leucina em especial para o gene PPAR que é um regulador positivo das demais enzimas participantes da lipogênese avaliadas no presente estudo.

Está bem estabelecido que a leucina é um regulador direto da atividade do mTORC1, e, por conseguinte, de seus substratos (4E-BP1 e S6K) em adipócitos. Desse modo, Kim e Chem (2004) verificaram que o mTORC1 e aminoácidos são capazes de regular a atividade de PPAR $\gamma$ na adipogênese. Recentemente, Blanchard et al. (2012) observaram que o mTORC1 é o maior regulador da captação de lipídios via LPL e atua como um mediador chave na incorporação de ácidos graxos. Os autores ainda destacam que estas respostas do mTORC1 sobre o metabolismo do TAB são intercedidas pelo PPAR $\gamma$. Como mencionado anteriormente, as nossas evidências são mais intensas no tecido SC, e que os animais alimentados com dieta $\mathrm{HL} e$ suplementado com leucina apresentaram maior adiposidade, incorporação de ácidos graxos e expressão de PPAR $\gamma$, assim como de outras enzimas que participam da esterificação de ácidos graxos. Podemos hipotetizar que, nas condições experimentais de obesidade associada com resistência à insulina, a suplementação com leucina favorece a maior adiposidade corporal via PPAR $\gamma$. Reforçando esta ideia, as respostas depósito-específicas em nossos experimentos encontram amparo em alguns estudos que reportam maior efeito do PPAR $\gamma$ sobre a regulação positiva de enzimas lipogênicas no TAB-SC (Festuccia et al., 2009; Laplante et al., 2003, 2006).

A literatura científica carece de relatos sobre os efeitos da suplementação com leucina e lipólise, porém, existem dados sobre repercussões da ausência de leucina sobre a taxa lipolítica no TAB. A deprivação deste nutriente na dieta provoca aumentos significativos sobre as concentrações séricas de glicerol pelo aumento na expressão de lipase hormônio sensível (HSL) e proteína quinase A (PKA) (Cheng et al., 2010). Além 
disso, quando avaliado a via do mTOC1, ativada por transfecção, sobre a lipólise Chakrabarti et al. (2010) observaram que ocorre diminuição da lipólise com uma redução das concentrações de glicerol, e queda da expressão gênica da lipase de triacilglicerol do adipócito (ATGL) e de HSL. Ao avaliar a inibição do mTORC1 pela rapamicina, Soliman et al. (2010) observaram significativos aumentos na lipólise e nas concentrações de ácidos graxos livres em adipócitos. Nossos resultados dão conta de um efeito interativo entre dieta HL e suplementação com leucina favorecendo uma redução na taxa lipolítica basal em adipócitos $\mathrm{PE}$ de animais obesos. Por outro lado, as taxas lipolíticas dos adipócitos SC foram maiores frente a suplementação com leucina tanto na condição basal quanto na estimulada. Nos adipócitos deste território, tanto a dieta quanto a suplementação interagiram aumentando a resposta lipolítica estimulada por isoproterenol. 


\section{CONCLUSÕES}

Frente ao exposto, os nossos resultados a partir de diversos experimentos indicam que:

\section{A exposição à dieta HL causa:}

a) Maior adiposidade corporal;

b) Maior hipertrofia dos adipócitos;

c) Intolerância à sobrecarga de glicose;

d) Resistência à insulina;

e) Maior captação basal de glicose;

f) Menor captação de glicose quando estimulada por insulina;

g) Expressiva redução na lipogênese, na biossíntese de ácidos graxos, bem como nas enzimas que participam deste processo.

A exposição à suplementação com leucina de ratos obesos e resistentes à insulina causa:

a) Maior adiposidade corporal nos coxins adiposos SC, PE e MS;

b) Maior hipertrofia dos adipócitos SC;

c) Nenhuma resposta sobre a tolerância à glicose e resistência à insulina;

d) Incremento na secreção de insulina em ilhotas pancreáticas colocadas em meio com altas concentrações de glicose;

e) Nenhum efeito sobre a captação de glicose;

f) Aumentos na biossíntese de ácidos graxos em adipócitos isolados da região PE e SC;

g) Maior incorporação de ácidos graxos palmítico e oleico somente nos adipócitos isolados SC;

h) Incremento na taxa lipolítica dos adipócitos SC quando estimulados com isoproterenol; 
i) Aumento na expressão de alguns genes (PPAR $\gamma$, GPAT, FABP4, PEPCK) relacionados à lipogênese, à esterificação e à incorporação de ácidos graxos que foram observados somente em adipócitos SC.

Desse modo, nossas evidências destacam que a suplementação com leucina em ratos obesos e resistentes à insulina exerce importantes efeitos sobre a adiposidade, por estimular a lipogênese de novo e incorporação de ácidos graxos, bem como, a maior expressão dos genes que estimulam estes processos metabólicos. Além disso, estas respostas são majoritariamente verificadas em adipócitos SC. Há, portanto um efeito sítio-específico na indução destas adaptações pela leucina associada à dieta $\mathrm{HL}$. 


\section{REFERÊNCIAS*}

Arruda AP, Milanski M, Coope A, Torsoni AS, Ropelle E, Carvalho DP, et al. Lowgrade hypothalamic inflammation leads to defective thermogenesis, insulin resistance, and impaired insulin secretion. Endocrinology. 2011;152(4):1314-26.

Bak JF, Møller N, Schmitz O, Saaek A, Pedersen O. In vivo insulin action and muscle glycogen synthase activity in type 2 (non-insulin-dependent) diabetes mellitus: effects of diet treatment. Diabetologia. 1992;35(8):777-84.

Balage M, Dupont J, Mothe-Satney I, Tesseraud S, Mosoni L, Dardevet D. Leucine supplementation in rats induced a delay in muscle IR/PI3K signaling pathway associated with overall impaired glucose tolerance. J Nutr Biochem. 2011;22(3):219-26.

Bazin R, Ferré P. Assays of lipogenic enzymes. Methods Mol Biol. 2001;155:121-7.

Bell A, Grunder L, Sorisky A. Rapamycin inhibits human adipocyte differentiation in primary culture. Obes Res. 2000;8(3):249-54.

Bergmeyer HU, Bernt E, Schmidt F, Stork H. Methods of enzymatic analysis. Orlando, FL: Academic Press; 1974.

Blanchard PG, Festuccia WT, Houde VP, St-Pierre P, Brule S, Turcotte V, et al. Major involvement of mTOR in the PPARy-induced stimulation of adipose tissue lipid uptake and fat accretion. J Lipid Res. 2012;53(6):1117-25.

Blaschke F, Takata Y, Caglayan E, Law RE, Hsueh WA. Obesity, peroxisome proliferator-activated receptor, and atherosclerosis in type 2 diabetes. Arterioscler Thromb Vasc Biol. 2006;26(1):28-40.

Bonora E, Moghetti P, Zancanaro C, Cigolini M, Querena M, Cacciatori V, et al. Estimates of in vivo insulin action in man: comparison of insulin tolerance tests with euglycemic and hyperglycemic glucose clamp studies. J Clin Endocrinol Metab. 1989;68(2):374-8.

Calegari VC, Torsoni AS, Vanzela EC, Araújo EP, Morari J, Zoppi CC, et al. Inflammation of the hypothalamus leads to defective pancreatic islet function. J Biol Chem. 2011;286(15):12870-80.

Cani PD, Bibiloni R, Knauf C, Waget A, Neyrinck AM, Delzenne NM, et al. Changes in gut microbiota control metabolic endotoxemia-induced inflammation in high-fat diet-induced obesity and diabetes in mice. Diabetes. 2008;57(6):1470-81.

Chakrabarti P, English T, Shi J, Smas CM, Kandror KV. Mammalian target of rapamycin complex 1 suppresses lipolysis, stimulates lipogenesis, and promotes fat storage. Diabetes. 2010;59(4):775-81. 
Cheng Y, Meng Q, Wang C, Li H, Huang Z, Chen S, et al. Leucine deprivation decreases fat mass by stimulation of lipolysis in white adipose tissue and upregulation of uncoupling protein 1 (UCP1) in brown adipose tissue. Diabetes. 2010;59(1):17-25.

Cho HJ, Park J, Lee HW, Lee YS, Kim JB. Regulation of adipocyte differentiation and insulin action with rapamycin. Biochem Biophys Res Commun. 2004;321(4):942-8.

Cintra DE, Ropelle ER, Moraes JC, Pauli JR, Morari J, Souza CT, et al. Unsaturated fatty acids revert diet-induced hypothalamic inflammation in obesity. PLoS One. 2012;7(1):e30571.

Cota D, Proulx K, Smith KA, Kozma SC, Thomas G, Woods SC, et al. Hypothalamic mTOR signaling regulates food intake. Science. 2006;312(5775):927-30.

Donato J, Pedrosa RG, Cruzat VF, Pires IS, Tirapegui J. Effects of leucine supplementation on the body composition and protein status of rats submitted to food restriction. Nutrition. 2006;22(5):520-7.

Donato J, Pedrosa RG, de Araújo JA, Pires IS, Tirapegui J. Effects of leucine and phenylalanine supplementation during intermittent periods of food restriction and refeeding in adult rats. Life Sci. 2007;81(1):31-9.

El-Chaâr D, Gagnon A, Sorisky A. Inhibition of insulin signaling and adipogenesis by rapamycin: effect on phosphorylation of p70 S6 kinase vs elF4E-BP1. Int J Obes Relat Metab Disord. 2004;28(2):191-8.

Festuccia WT, Blanchard PG, Turcotte V, Laplante M, Sariahmetoglu M, Brindley DN, et al. Depot-specific effects of the PPARgamma agonist rosiglitazone on adipose tissue glucose uptake and metabolism. J Lipid Res. 2009;50(6):1185-94.

Fine JB, DiGirolamo M. A simple method to predict cellular density in adipocyte metabolic incubations. Int J Obes Relat Metab Disord. 1997;21(9):764-8.

Foufelle F, Girard J, Ferré P. Regulation of lipogenic enzyme expression by glucose in liver and adipose tissue: a review of the potential cellular and molecular mechanisms. Adv Enzyme Regul. 1996;36:199-226.

Foufelle F, Perdereau D, Gouhot B, Ferre P, Girard J. Effect of diets rich in mediumchain and long-chain triglycerides on lipogenic-enzyme gene expression in liver and adipose tissue of the weaned rat. Eur J Biochem. 1992;208(2):381-7.

Fox HL, Kimball SR, Jefferson LS, Lynch CJ. Amino acids stimulate phosphorylation of p70S6k and organization of rat adipocytes into multicellular clusters. Am J Physiol. 1998;274(1 Pt 1):C206-13.

Freudenberg A, Petzke KJ, Klaus S. Comparison of high-protein diets and leucine supplementation in the prevention of metabolic syndrome and related disorders in mice. J Nutr Biochem. 2012.doi: http://dx.doi.org/10.1016/j.jnutbio.2011.10.005. 
Friedman JE, Dohm GL, Leggett-Frazier N, Elton CW, Tapscott EB, Pories WP, et al. Restoration of insulin responsiveness in skeletal muscle of morbidly obese patients after weight loss. Effect on muscle glucose transport and glucose transporter GLUT4. J Clin Invest. 1992;89(2):701-5.

Gagnon A, Lau S, Sorisky A. Rapamycin-sensitive phase of 3T3-L1 preadipocyte differentiation after clonal expansion. J Cell Physiol. 2001;189(1):14-22.

Girard J, Perdereau D, Foufelle F, Prip-Buus C, Ferré P. Regulation of lipogenic enzyme gene expression by nutrients and hormones. FASEB J. 1994;8(1):36-42.

Grundy SM. Obesity, metabolic syndrome, and coronary atherosclerosis. Circulation. 2002;105(23):2696-8.

Guo K, Yu YH, Hou J, Zhang Y. Chronic leucine supplementation improves glycemic control in etiologically distinct mouse models of obesity and diabetes mellitus. Nutr Metab (Lond). 2010;7:57.

Halton TL, Hu FB. The effects of high protein diets on thermogenesis, satiety and weight loss: a critical review. J Am Coll Nutr. 2004;23(5):373-85.

Hinault C, Mothe-Satney I, Gautier N, Lawrence JC, Van Obberghen E. Amino acids and leucine allow insulin activation of the PKB/mTOR pathway in normal adipocytes treated with wortmannin and in adipocytes from $\mathrm{db} / \mathrm{db}$ mice. FASEB $\mathrm{J}$. 2004;18(15):1894-6.

Hinault C, Mothe-Satney I, Gautier N, Van Obberghen E. Amino acids require glucose to enhance, through phosphoinositide-dependent protein kinase 1, the insulin-activated protein kinase B cascade in insulin-resistant rat adipocytes. Diabetologia. 2006;49(5):1017-26.

Hotamisligil GS. Inflammation and metabolic disorders. Nature. 2006;444(7121):860-7.

Houde VP, Brûlé S, Festuccia WT, Blanchard PG, Bellmann K, Deshaies Y, et al. Chronic rapamycin treatment causes glucose intolerance and hyperlipidemia by upregulating hepatic gluconeogenesis and impairing lipid deposition in adipose tissue. Diabetes. 2010;59(6):1338-48.

Hutson SM, Zapalowski C, Cree TC, Harper AE. Regulation of leucine and alphaketoisocaproic acid metabolism in skeletal muscle. Effects of starvation and insulin. $J$ Biol Chem. 1980;255(6):2418-26.

Iritani $\mathrm{N}$, Fukuda $\mathrm{H}$, Tada $\mathrm{K}$. Nutritional regulation of lipogenic enzyme gene expression in rat epididymal adipose tissue. J Biochem. 1996;120(2):242-8.

Kahn BB, Flier JS. Regulation of glucose-transporter gene expression in vitro and in vivo. Diabetes Care. 1990;13(6):548-64.

Kahn BB, Flier JS. Obesity and insulin resistance. J Clin Invest. 2000;106(4):473-81. 
Kim JE, Chen J. regulation of peroxisome proliferator-activated receptor-gamma activity by mammalian target of rapamycin and amino acids in adipogenesis. Diabetes. 2004;53(11):2748-56.

Koffler M, Ramirez LC, Raskin P. Insulin resistance and diabetes, mechanism and possible intervention. Diabetes Res Clin Pract. 1989;7(2):83-98.

Krause U, Bertrand L, Maisin L, Rosa M, Hue L. Signalling pathways and combinatory effects of insulin and amino acids in isolated rat hepatocytes. Eur $\mathrm{J}$ Biochem. 2002;269(15):3742-50.

Laplante M, Festuccia WT, Soucy G, Gélinas Y, Lalonde J, Berger JP, et al. Mechanisms of the depot specificity of peroxisome proliferator-activated receptor gamma action on adipose tissue metabolism. Diabetes. 2006;55(10):2771-8.

Laplante M, Sell H, MacNaul KL, Richard D, Berger JP, Deshaies Y. PPAR-gamma activation mediates adipose depot-specific effects on gene expression and lipoprotein lipase activity: mechanisms for modulation of postprandial lipemia and differential adipose accretion. Diabetes. 2003;52(2):291-9.

Layman DK. The role of leucine in weight loss diets and glucose homeostasis. J Nutr. 2003;133(1):261S-7S.

Li S, Brown MS, Goldstein JL. Bifurcation of insulin signaling pathway in rat liver: mTORC1 required for stimulation of lipogenesis, but not inhibition of gluconeogenesis. Proc Natl Acad Sci U S A. 2010;107(8):3441-6.

Lima FB, Matsushita DH, Hell NS, Dolnikoff MS, Okamoto MM, Cipolla Neto J. The regulation of insulin action in isolated adipocytes. Role of the periodicity of food intake, time of day and melatonin. Braz J Med Biol Res. 1994;27(4):995-1000.

Lynch CJ, Patson BJ, Anthony J, Vaval A, Jefferson LS, Vary TC. Leucine is a directacting nutrient signal that regulates protein synthesis in adipose tissue. Am J Physiol Endocrinol Metab. 2002;283(3):E503-13.

Macotela Y, Emanuelli B, Bång AM, Espinoza DO, Boucher J, Beebe K, et al. Dietary leucine--an environmental modifier of insulin resistance acting on multiple levels of metabolism. PLoS One. 2011;6(6):e21187.

McDaniel ML, Marshall CA, Pappan KL, Kwon G. Metabolic and autocrine regulation of the mammalian target of rapamycin by pancreatic beta-cells. Diabetes. 2002;51(10):2877-85.

Meikle AW, Klain GJ. Effect of fasting and fasting-refeeding on conversion of leucine into CO 2 and lipids in rats. Am J Physiol. 1972;222(5):1246-50.

Minemura T, Lacy WW, Crofford OB. Regulation of the transport and metabolism of amino acids in isolated fat cells. Effect of insulin and a possible role for adenosine 3',5'-monophosphate. J Biol Chem. 1970;245(15):3872-81.

Moraes JC, Coope A, Morari J, Cintra DE, Roman EA, Pauli JR, et al. High-fat diet induces apoptosis of hypothalamic neurons. PLoS One. 2009;4(4):e5045. 
Mourier A, Bigard AX, de Kerviler E, Roger B, Legrand H, Guezennec CY. Combined effects of caloric restriction and branched-chain amino acid supplementation on body composition and exercise performance in elite wrestlers. Int $\mathrm{J}$ Sports Med. $1997 ; 18(1): 47-55$.

Muoio DM, Newgard CB. Mechanisms of disease: molecular and metabolic mechanisms of insulin resistance and beta-cell failure in type 2 diabetes. Nat Rev Mol Cell Biol. 2008;9(3):193-205.

Nairizi A, She P, Vary TC, Lynch CJ. Leucine supplementation of drinking water does not alter susceptibility to diet-induced obesity in mice. J Nutr. 2009;139(4):715-9.

Ortega FJ, Mayas D, Moreno-Navarrete JM, Catalán V, Gómez-Ambrosi J, Esteve E, et al. The gene expression of the main lipogenic enzymes is downregulated in visceral adipose tissue of obese subjects. Obesity (Silver Spring). 2010;18(1):13-20.

Palou M, Sánchez J, Priego T, Rodríguez AM, Picó C, Palou A. Regional differences in the expression of genes involved in lipid metabolism in adipose tissue in response to short- and medium-term fasting and refeeding. J Nutr Biochem. 2010;21(1):23-33.

Pedersen O, Kahn CR, Kahn BB. Divergent regulation of the Glut 1 and Glut 4 glucose transporters in isolated adipocytes from Zucker rats. J Clin Invest. 1992;89(6):1964-73.

Prentki M, Tornheim K, Corkey BE. Signal transduction mechanisms in nutrientinduced insulin secretion. Diabetologia. 1997;40(Suppl 2):S32-41.

Rachdi L, Aïello V, Duvillié B, Scharfmann R. L-leucine alters pancreatic $\beta$-cell differentiation and function via the mTor signaling pathway. Diabetes. 2012;61(2):409-17.

Reaven GM. Banting lecture 1988. Role of insulin resistance in human disease. Diabetes. 1988;37(12):1595-607.

Reaven GM. Pathophysiology of insulin resistance in human disease. Physiol Rev. 1995;75(3):473-86.

Reeves PG. Components of the AIN-93 diets as improvements in the AIN-76A diet. J Nutr. 1997;127(5 Suppl):838S-41S.

Reynoso R, Salgado LM, Calderón V. High levels of palmitic acid lead to insulin resistance due to changes in the level of phosphorylation of the insulin receptor and insulin receptor substrate-1. Mol Cell Biochem. 2003;246(1-2):155-62.

Rodbell M. Metabolism of isolated fat cells. i. effects of hormones on glucose metabolism and lipolysis. J Biol Chem. 1964;239:375-80.

Roh C, Han J, Tzatsos A, Kandror KV. Nutrient-sensing mTOR-mediated pathway regulates leptin production in isolated rat adipocytes. Am J Physiol Endocrinol Metab. 2003;284(2):E322-30. 
Ropelle ER, Pauli JR, Fernandes MF, Rocco SA, Marin RM, Morari J, et al. A central role for neuronal AMP-activated protein kinase (AMPK) and mammalian target of rapamycin (mTOR) in high-protein diet-induced weight loss. Diabetes. 2008;57(3):594-605.

Rosenthal J, Angel A, Farkas J. Metabolic fate of leucine: a significant sterol precursor in adipose tissue and muscle. Am J Physiol. 1974;226(2):411-8.

Rous S, Bas S, Sengupta S. Contribution of leucine in the fatty acid synthesis and ketogenesis in mice adipose tissue. Int J Biochem. 1980;11(5):337-40.

She P, Van Horn C, Reid T, Hutson SM, Cooney RN, Lynch CJ. Obesity-related elevations in plasma leucine are associated with alterations in enzymes involved in branched-chain amino acid metabolism. Am $J$ Physiol Endocrinol Metab. 2007;293(6):E1552-63.

Shi H, Kokoeva MV, Inouye K, Tzameli I, Yin H, Flier JS. TLR4 links innate immunity and fatty acid-induced insulin resistance. J Clin Invest. 2006;116(11):3015-25.

Soliman GA, Acosta-Jaquez HA, Fingar DC. mTORC1 inhibition via rapamycin promotes triacylglycerol lipolysis and release of free fatty acids in 3T3-L1 adipocytes. Lipids. 2010;45(12):1089-100.

Spiegelman BM, Flier JS. Adipogenesis and obesity: rounding out the big picture. Cell. 1996;87(3):377-89.

Teodoro GF, Vianna D, Torres-Leal FL, Pantaleão LC, Matos-Neto EM, Donato J, et al. Leucine is essential for attenuating fetal growth restriction caused by a proteinrestricted diet in rats. J Nutr. 2012;142(5):924-30.

Torres-Leal FL, Fonseca-Alaniz MH, Rogero MM, Tirapegui J. The role of inflamed adipose tissue in the insulin resistance. Cell Biochem Funct. 2010;28(8):623-31.

Torres-Leal FL, Fonseca-Alaniz MH, Teodoro GF, de Capitani MD, Vianna D, Pantaleão LC, et al. Leucine supplementation improves adiponectin and total cholesterol concentrations despite the lack of changes in adiposity or glucose homeostasis in rats previously exposed to a high-fat diet. Nutr Metab (Lond). $2011 ; 8(1): 62$.

Tsukumo DM, Carvalho-Filho MA, Carvalheira JB, Prada PO, Hirabara SM, Schenka $\mathrm{AA}$, et al. Loss-of-function mutation in Toll-like receptor 4 prevents diet-induced obesity and insulin resistance. Diabetes. 2007;56(8):1986-98.

Velloso LA, Araújo EP, de Souza CT. Diet-induced inflammation of the hypothalamus in obesity. Neuroimmunomodulation. 2008;15(3):189-93.

Vianna D, Resende GF, Torres-Leal FL, Pantaleão LC, Donato J, Tirapegui J. Longterm leucine supplementation reduces fat mass gain without changing body protein status of aging rats. Nutrition. 2012;28(2):182-9. 
Yeh WC, Bierer BE, McKnight SL. Rapamycin inhibits clonal expansion and adipogenic differentiation of 3T3-L1 cells. Proc Natl Acad Sci U S A. 1995;92(24):11086-90.

Zeanandin G, Balage M, Schneider SM, Dupont J, Hébuterne X, Mothe-Satney I, et al. Differential effect of long-term leucine supplementation on skeletal muscle and adipose tissue in old rats: an insulin signaling pathway approach. Age (Dordr). 2012;34(2):371-87.

Zhang Y, Guo K, LeBlanc RE, Loh D, Schwartz GJ, Yu YH. Increasing dietary leucine intake reduces diet-induced obesity and improves glucose and cholesterol metabolism in mice via multimechanisms. Diabetes. 2007;56(6):1647-54. 
ANEXO 


\section{ANEXO A \\ ARTIGOS DE PERIODICOS}

Artigo 1 de Oliveira AC, Andreotti S, Farias TaS, Torres-Leal FL, de Proença AR, Campaña $A B$, et al. Metabolic Disorders and Adipose Tissue Insulin Responsiveness in Neonatally STZ-Induced Diabetic Rats Are Improved by Long-Term Melatonin Treatment. Endocrinology. 2012;153(5):217888.

Artigo 2 Teodoro GF, Vianna D, Torres-Leal FL, Pantale,o LC, Matos-Neto EM, Donato $\mathrm{J}$, et al. Leucine is essential for attenuating fetal growth restriction caused by a protein-restricted diet in rats. J Nutr. 2012;142(5):924-30.

Artigo 3 Torres-Leal FL, Fonseca-Alaniz MH, Rogero MM, Tirapegui J. The role of inflamed adipose tissue in the insulin resistance. Cell Biochem Funct. 2010;28(8):623-31.

Artigo 4 Vianna D, Resende GF, Torres-Leal FL, Pantaleão LC, Donato J, Tirapegui J. Long-term leucine supplementation reduces fat mass gain without changing body protein status of aging rats. Nutrition. 2012;28(2):182-9.

Artigo 5 Torres-Leal FL, Fonseca-Alaniz MH, Teodoro GF, de Capitani MD, Vianna D, Pantaleão LC, et al. Leucine supplementation improves adiponectin and total cholesterol concentrations despite the lack of changes in adiposity or glucose homeostasis in rats previously exposed to a high-fat diet. Nutr Metab (Lond). 2011;8(1):62.

Artigo 6 Matos-Neto EM, Torres-Leal FL, Oliveira, FE, Poltronier F, Marreiro DN. Parâmetros Bioquímicos Relativos ao Magnésio em Nadadores Adolescentes. Nutrição em Pauta. 2011;1:44-7.

Artigo 7 Vianna D, Teodoro G, Torres-Leal FL, Tirapegui J. Regulation of protein synthesis by leucine. Brazilian Journal of Pharmaceutical Sciences. 2010;46(1):29-36.

Artigo 8 Bento-Silva MT, Martins MCC, Torres-Leal FL, Almeida FRC. Effects of administrering testosterone undecanoate in rats subjected to physical exercise: effects on the estrous cycle, motor behavior and morphology of the liver and kidney. Brazilian Journal of Pharmaceutical Sciences. 2010;46(1):79-89. 
Artigo 9 Torres-Leal FL, Vianna D, Teodoro G, Capitani MD, Tirapegui J. Aspects of the branched chain amino acid leucine in glycemic control and in the insulin resistance. Nutrire (São Paulo). 2010;35(2):131-43.

Artigo 10 Leitão HA, Rocha FC, Matos-Neto EM, Figueiredo RG, Torres-Leal FL. Efeito ergogênico da cafeína sobre o desempenho físico progressivo máximo em ciclistas. Brazilian Journal of Health. 2010;1(2):110-7.

Artigo 11 Torres-Leal FL, Bento-Silva, MT, Matos-Neto EM, Figueiredo RG, Rodrigues GP, Araujo DM E, Marreiro DN. Effect of creatine monohydrate on power and fatigue production during anaerobic sprints in soccer players. Brazilian Journal of Health. 2020;1(2):156-64. 


\title{
Metabolic Disorders and Adipose Tissue Insulin Responsiveness in Neonatally STZ-Induced Diabetic Rats Are Improved by Long-Term Melatonin Treatment
}

\author{
Ariclécio C. de Oliveira, Sandra Andreotti, Talita da S.M. Farias, \\ Francisco L. Torres-Leal, André R.G. de Proença, Amanda B. Campaña, \\ Arnaldo H. de Souza, Rogério A.L. Sertié, Ângelo R. Carpinelli, José Cipolla-Neto, \\ and Fábio B. Lima \\ Superior Institute of Biomedical Sciences (A.C.d.O.), State University of Ceará, Fortaleza, Ceará 60135- \\ 420, Brazil; and Department of Physiology and Biophysics (A.C.d.O., S.A., T.d.S.M.F., F.L.T.-L., \\ A.R.G.d.P., A.B.C., A.H.d.S., R.A.L.S., A.R.C., J.C.-N., F.B.L.), Institute of Biomedical Sciences, University \\ of São Paulo, São Paulo 05508-900, Brazil
}

\begin{abstract}
Diabetes mellitus is a product of low insulin sensibility and pancreatic $\beta$-cell insufficiency. Rats with streptozotocin-induced diabetes during the neonatal period by the fifth day of age develop the classic diabetic picture of hyperglycemia, hypoinsulinemia, polyuria, and polydipsia aggravated by insulin resistance in adulthood. In this study, we investigated whether the effect of long-term treatment with melatonin can improve insulin resistance and other metabolic disorders in these animals. At the fourth week of age, diabetic animals started an 8-wk treatment with melatonin (1 $\mathrm{mg} / \mathrm{kg}$ body weight) in the drinking water at night. Animals were then killing, and the sc, epididymal (EP), and retroperitoneal (RP) fat pads were excised, weighed, and processed for adipocyte isolation for morphometric analysis as well as for measuring glucose uptake, oxidation, and incorporation of glucose into lipids. Blood samples were collected for biochemical assays. Melatonin treatment reduced hyperglycemia, polydipsia, and polyphagia as well as improved insulin resistance as demonstrated by constant glucose disappearance rate and homeostasis model of assessment-insulin resistance. However, melatonin treatment was unable to recover body weight deficiency, fat mass, and adipocyte size of diabetic animals. Adiponectin and fructosamine levels were completely recovered by melatonin, whereas neither plasma insulin level nor insulin secretion capacity was improved in diabetic animals. Furthermore, melatonin caused a marked delay in the sexual development, leaving genital structures smaller than those of nontreated diabetic animals. Melatonin treatment improved the responsiveness of adipocytes to insulin in diabetic animals measured by tests of glucose uptake (sc, EP, and RP), glucose oxidation, and incorporation of glucose into lipids (EP and RP), an effect that seems partially related to an increased expression of insulin receptor substrate 1, acetyl-coenzyme A carboxylase and fatty acid synthase. In conclusion, melatonin treatment was capable of ameliorating the metabolic abnormalities in this particular diabetes model, including insulin resistance and promoting a better long-term glycemic control. (Endocrinology 153: 2178-2188, 2012)
\end{abstract}

ISSN Print 0013-7227 ISSN Online 1945-7170

Printed in U.S.A.

Copyright (C) 2012 by The Endocrine Society

doi: 10.1210/en.2011-1675 Received August 24, 2011. Accepted February 2, 2012. First Published Online February 28, 2012
Abbreviations: ACC, Acetyl-coenzyme A carboxylase; b.w., body weight; C group, control group; CV, coefficient of variation; 2-DG, 2-deoxy-D-glucose; D group, diabetic group; DM, diabetes mellitus; EP, epididymal; FAS, fatty acid synthase; Glut 4, glucose transporter type 4; GTT, glucose tolerance test; HDLc, high-density lipoprotein cholesterol; HOMA-IR, homeostasis model of assessment-insulin resistance; IRS 1, insulin receptor substrate $1 ; I T$, insulin tolerance test; $K_{I T}$, glucose disappearance rate; $\mathrm{M}$ group, melatonin group; MT1, melatonin receptor subtype 1; NEFA, nonesterified fatty acid; po, per os; RP, retroperitoneal; STZ, streptozotocin; TAG, triacylglycerol 


\title{
Leucine Is Essential for Attenuating Fetal Growth Restriction Caused by a Protein- Restricted Diet in Rats ${ }^{1-3}$
}

Gabriela Fullin Resende Teodoro, ${ }^{4}$ Daiana Vianna, ${ }^{4}$ Francisco Leonardo Torres-Leal, ${ }^{4}$ Lucas Carminatti Pantaleão, ${ }^{4}$ Emídio Marques Matos-Neto, ${ }^{4}$ Jose Donato Jr, ${ }^{5,6}$ and Julio Tirapegui ${ }^{4,6 *}$

${ }^{4}$ Department of Food Science and Experimental Nutrition, Faculty of Pharmaceutical Sciences, and ${ }^{5}$ Department of Physiology and Biophysics, Institute of Biomedical Sciences, University of São Paulo, São Paulo, Brazil

\begin{abstract}
Certain amino acids, such as leucine (Leu) are not only substrates for protein synthesis but also are important regulators of protein metabolism. Moreover, it is known that alterations in intrauterine growth favor the development of chronic diseases in adulthood. Therefore, we investigated the role of Leu in combination with other BCAA on effects that are induced by maternal protein restriction on fetal growth. Wistar rats were divided into 4 groups according to the diet provided during pregnancy: control (C; 20\% casein); V+l [5\% casein + 2\% L-valine (Val) + 2\% L-isoleucine (Ile)]; KYT [5\% casein $+1.8 \%$ L-lysine (Lys) $+1.2 \%$ L-tyrosine $(T y r)+1 \%$ L-threonine $(\mathrm{Thr})]$; and BCAA (5\% casein $+1.8 \%$ L-Leu $+1.2 \%$ $\mathrm{L}-\mathrm{Val}+1 \% \mathrm{~L}$-lle). Maternal protein restriction reduced the growth and organ weight of the offspring of dams receiving the $\mathrm{V}+\mathrm{I}$ and $\mathrm{KYT}$ diets compared with the $\mathrm{C}$ group. Supplementation with BCAA reversed this growth deficit, minimizing the difference or restoring the mass of organs and carcass fat, the liver and muscle protein, and the RNA concentrations compared with newborns in the $C$ group $(P<0.05)$. These effects could be explained by the activation of the mTOR signaling pathway, because phosphorylation of $4 \mathrm{E}-\mathrm{BP} 1$ in the liver of offspring of the BCAA group was greater than that in the $C, V+l$, and KYT groups. The present results identify a critical role for Leu in association with other BCAA in the activation of the mTOR signaling pathway for the control of altered intrauterine growth induced by a maternal low-protein diet. J. Nutr. 142: 924-930, 2012.
\end{abstract}

\section{Introduction}

During pregnancy, the growth and development of the fetus depends entirely on maternal nutrition. Modifications of the maternal diet have been shown to lead to alterations in fetal health as a result of adaptations to the adverse intrauterine environment. Importantly, the effects induced in the intrauterine environment are strongly associated with the development of chronic diseases in adulthood $(1,2)$. In this respect, maternal malnutrition has been shown to cause the redistribution of intrauterine blood flow, accompanied by metabolic and physiological adaptations that result in intrauterine growth restriction (3). Various experimental models have been developed to induce

\footnotetext{
${ }^{1}$ Supported by the São Paulo State Research Foundation (research grants 07/51964-9, 07/59291-3 to J. Tirapegui) and by the Conselho Nacional de Desenvolvimento Científico e Tecnológico (fellowship).

${ }^{2}$ Author disclosures: G. F. R. Teodoro, D. Vianna, F. L. Torres-Leal, L. C. Pantaleão, E. M. Matos-Neto, J. Donato Jr, and J. Tirapegui, no conflicts of interest.

${ }^{3}$ Supplemental Tables 1 and 2 and Supplemental Figure 1 are available from the "Online Supporting Material" link in the online posting of the article and from the same link in the online table of contents at jn.nutrition.org.

${ }^{6}$ Jose Donato Jr. and Julio Tirapegui are co-senior authors.

* To whom correspondence should be addressed. E-mail: tirapegu@usp.br
}

this condition and the most frequently used model is maternal protein restriction $(4,5)$.

Although the effects of this maternal dietary modification on fetal growth have been extensively studied, the mechanisms whereby protein restriction affects fetal growth are still unclear. It is known that embryo cells can directly respond to amino acid deficiency by altering the expression of a variety of genes that regulate growth, differentiation, and apoptosis (6). Moreover, amino acids directly control protein synthesis in various fetal and placental tissues by regulating the activity and/or expression of proteins that are involved in mRNA translation (7).

In this respect, studies have shown that mammalian cells possess an important nutritional sensor, known as mammalian target of rapamycin $(\mathrm{mTOR})^{7}$, which regulates cell growth and protein synthesis by controlling the rates of gene transcription (8) and mRNA translation (9). The activity of mTOR is sensitive

\footnotetext{
${ }^{7}$ Abbreviations used: BCAA group, rats receiving protein-restricted diet $(5 \%$ casein) and supplementation with $4 \%$ BCAA; $C$ group, control rats receiving diet containing 20\% casein; elF, eukaryotic initiation factor; KYT group, rats receiving protein-restricted diet ( $5 \%$ casein) and supplementation with $1.8 \%$ Lys, $1.2 \%$ Tyr, and $1 \% \mathrm{Thr}$; mTOR, mammalian target of rapamycin; $\mathrm{V}+\mathrm{l}$ group, rats receiving protein-restricted diet (5\% casein) and supplementation with $2 \%$ Val and $2 \% \mathrm{lle}$
} 


\title{
The role of inflamed adipose tissue in the insulin resistance
}

\author{
Francisco L. Torres-Leal ${ }^{1 * \dagger}$, Miriam H. Fonseca-Alaniz ${ }^{2 \dagger}$, Marcelo M. Rogero ${ }^{3 \dagger}$ and Julio Tirapegui ${ }^{1}$ \\ ${ }^{1}$ Department of Food Science and Experimental Nutrition, University of São Paulo, São Paulo, Brazil \\ ${ }^{2}$ Laboratory of Genetics and Molecular Cardiology, Heart Institute, University of São Paulo Medical School, São Paulo, Brazil \\ ${ }^{3}$ Department of Nutrition, School of Public Health, University of São Paulo, São Paulo, Brazil
}

In this article, we discuss inflammation associated with adipose tissue dysfunction as a potential link with obesity-related insulin resistance, and how obesity-related inflammatory components, such as immune cells, cytokines/chemokines and adipocytokines, induce obesity-related pathologies. Copyright (C) 2010 John Wiley \& Sons, Ltd.

KEY WORDS - adipose tissue; obesity; insulin resistance; cytokines

\section{INTRODUCTION}

Modern life has brought profound alterations in lifestyle, promoting an increase in the prevalence of cardiovascular disease (CVD). Sustained increase in body mass, particularly fat mass, unhealthy diet and sedentary lifestyle trigger metabolic alterations that increase cardiometabolic risks. Obesity, metabolic syndrome (MS) and type 2 diabetes mellitus (DM2) have become epidemic public health problems. ${ }^{1}$ Individuals who are overweight or obese are associated with almost $70 \%$ of DM2 risk in the US. ${ }^{2}$

Insulin resistance - which can be triggered by the presence of metabolic stressors, such as high-fat diets, obesity and high blood non-esterified fatty acids (FA) levels ${ }^{3,4}$ - is featured as the primary metabolic dysfunction responsible for the development of MS. With regard to the relationship between high-fat diets, obesity, and DM2, it is highlighted that the presence of high-blood non-esterified FA concentrations compromises insulin sensitivity, reducing the action of this hormone in peripheral tissues, such as the liver, skeletal muscle and adipose tissue. It also impairs glucose and lipid metabolism, with the development of compensatory hyperinsulinemia. ${ }^{5}$ As well as in the obesity, insulin resistance is accompanied by the presence of a chronic low-grade inflammatory state. ${ }^{6-8}$

\footnotetext{
* Correspondence to: F. L. Torres-Leal, Faculty of Pharmaceutical Sciences, Department of Food Science and Experimental Nutrition, Avenida Prof. Lineu Prestes, 580, Bloco 14, University of São Paulo, São Paulo 05508900, SP, Brazil. E-mail: torresleal@usp.br

${ }^{\dagger}$ These authors contributed equally to this work.
}

The amount of white adipose tissue (WAT) may represent more than $50 \%$ of total body mass in obese individuals (body mass index $\geq 30 \mathrm{~kg} / \mathrm{m}^{2}$ ). The role of WAT as an ordinary tissue responsible for lipid energy storage has been replaced due to studies that demonstrate the central activity of WAT in lipid and glucose metabolism and its ability to secrete factors with endocrine, paracrine and autocrine effects. For example, recent studies suggest that pro-inflammatory and anti-inflammatory substances produced by WAT contribute to the development of insulin resistance. ${ }^{9-12}$

Based on the recent functions attributed to WAT, this paper aims to outline the adipocyte dysfunction that is associated with inflammation and to describe the relationship between adipose tissue inflammatory components and obesity-related insulin resistance.

\section{WAT AS AN ENDOCRINE ORGAN}

Until the 1990s, WAT was considered an inert depot for excess metabolic fuel. The discovery of leptin, a hormone derived from WAT that can 'tell' the state of these energy reserves to the central nervous system, introduced a new perspective on the study of adipose tissue role in the body energy homeostasis and metabolism. Subsequently, new substances secreted by WAT have been characterized, which allowed its classification as an endocrine organ, capable of controlling the metabolism of several tissues and organs.

WAT is the predominant type of adipose tissue found in humans and others mammals and, for a long time, the functions related to this tissue were only associated with passive energy storage, thermal insulation and organ 
Basic nutritional investigation

\title{
Long-term leucine supplementation reduces fat mass gain without changing body protein status of aging rats
}

\author{
Daiana Vianna M.Sc. ${ }^{\text {, }}$ Gabriela Fulin Teodoro Resende M.Sc. ${ }^{a}$, Francisco Leonardo Torres-Leal M.Sc. ${ }^{a}$, \\ Lucas Carminatti Pantaleão M.Sc. a , Jose Donato Jr. Ph.D. b, Julio Tirapegui Ph.D. ${ }^{\text {a,* }}$
}

${ }^{a}$ Department of Food and Experimental Nutrition, Faculty of Pharmaceutical Sciences, University of São Paulo, São Paulo, São Paulo, Brazil

${ }^{\mathrm{b}}$ Department of Internal Medicine, Division of Hypothalamic Research, University of Texas Southwestern Medical Center, Dallas, Texas, USA

\section{A R T I C L E I N F O}

\section{Article history:}

Received 12 January 2011

Accepted 10 April 2011

\section{Keywords:}

Aging

Branched-chain amino acids

Body composition

Lean mass

Adiposity

\begin{abstract}
A B S T R A C T
Objective: Aging is characterized by alterations in body composition such as an increase in body fat and decreases in muscle mass (sarcopenia) and bone density (osteopenia). Leucine supplementation has been shown to acutely stimulate protein synthesis and to decrease body fat. However, the long-term effect of consistent leucine supplementation is not well defined. This study investigated the effect of leucine supplementation during aging.

Methods: Six-month-old rats were divided into three groups: an adult group $(n=10)$ euthanized at 6 mo of age, a leucine group $(n=16)$ that received a diet supplemented with $4 \%$ leucine for $40 \mathrm{wk}$, and a control group $(n=19)$ that received the control diet for $40 \mathrm{wk}$. The following parameters were evaluated: body weight, food intake, chemical carcass composition, indicators of acquired chronic diseases, and indicators of protein nutritional status.

Results: Body weight and fat were lower in the leucine group after $40 \mathrm{wk}$ of supplementation compared with the control group but still higher than in the adult group. The lipid and glycemic profiles were equally altered in the control and leucine groups because of aging. In addition, leucine supplementation did not affect the changes in protein status parameters associated with aging, such as decreases in body and muscle protein and total serum protein.

Conclusion: The results indicate that leucine supplementation attenuates body fat gain during aging but does not affect risk indicators of acquired chronic diseases. Furthermore, supplemented animals did not show signs of a prevention of the decrease in lean mass associated with aging.
\end{abstract}

(c) 2012 Elsevier Inc. All rights reserved.

\section{Introduction}

The process of aging is associated with different physiologic alterations such as a decrease in the secretion of anabolic hormones, e.g., growth hormone and insulin-like growth factor1 (IGF-1) [1]. Concomitantly, aging is related to changes in body composition, including a progressive increase in body fat, especially visceral adipocytes, associated with increased plasma concentrations of insulin and leptin and increased insulin resistance [2]. In addition, decreases in muscle mass (sarcopenia),

Dr. Donato and Dr. Tirapegui are co-senior authors.

This work was supported by grants 07/51964-9, 07/56230-3, and 07/59291-3 from the São Paulo State Research Foundation (FAPESP) and grants from the Coordination for the Improvement of Higher Education Personnel (CAPES) and the National Council for Scientific and Technological Development (CNPq).

* Corresponding author. Tel.: +55-11-3091-3309; fax: +55-11-3815-4410.

E-mail address: tirapegu@usp.br (J. Tirapegui). strength, and functional capacity are observed, and there is an increased risk of acquired chronic diseases such as obesity and type 2 diabetes [2]. These changes in body composition are observed in humans [3] and rodents [2].

Studies involving elderly humans and rats have shown a decrease in the stimulus of muscle protein synthesis after the consumption of a normal protein meal $[4,5]$. The mechanisms involved in this alteration remain obscure because this synthesis responds normally when a large amount of amino acids is continuously infused into aging rats or when administered orally to elderly humans [4-6]. Katsanos et al. [7] studied young and elderly humans receiving a mixture of essential amino acids containing $1.7 \mathrm{~g}$ (26\%) or $2.8 \mathrm{~g}(41 \%)$ of leucine and found that only the higher dose of leucine was effective in stimulating protein synthesis in the elderly subjects, whereas the two doses stimulated the fractional synthetic rate of muscle protein in young subjects. Rieu et al. [8] supplemented 22-mo-old rats with milk proteins that differed in leucine content: $\beta$-lactoglobulin 


\title{
Leucine supplementation improves adiponectin and total cholesterol concentrations despite the lack of changes in adiposity or glucose homeostasis in rats previously exposed to a high-fat diet
}

Francisco L Torres-Leal1 ${ }^{\text {** }}$, Miriam H Fonseca-Alaniz², Gabriela FR Teodoro ${ }^{1}$, Mariana D de Capitani ${ }^{1}$, Daiana Vianna', Lucas C Pantaleão', Emidio M Matos-Neto', Marcelo M Rogero', Jose Donato $\mathrm{Jr}^{4}$ and Julio Tirapegui ${ }^{1}$

\begin{abstract}
Background: Studies suggest that leucine supplementation (LS) has a therapeutic potential to prevent obesity and to promote glucose homeostasis. Furthermore, regular physical exercise is a widely accepted strategy for body weight maintenance and also for the prevention of obesity. The aim of this study was to determine the effect of chronic LS alone or combined with endurance training (ET) as potential approaches for reversing the insulin resistance and obesity induced by a high-fat diet (HFD) in rats.
\end{abstract}

Methods: Forty-seven rats were randomly divided into two groups. Animals were fed a control diet-low fat $(n=$ 10) or HFD ( $n=37)$. After 15 weeks on HFD, all rats received the control diet-low fat and were randomly divided according to treatment: reference (REF), LS, ET, and LS+ET ( $n=7-8$ rats per group). After 6 weeks of treatment, the animals were sacrificed and body composition, fat cell volume, and serum concentrations of total cholesterol, HDLcholesterol, triacylglycerol, glucose, adiponectin, leptin and tumor necrosis factor-alpha (TNF- $\alpha$ ) were analyzed.

Results: At the end of the sixth week of treatment, there was no significant difference in body weight between the REF, LS, ET and LS+ET groups. However, ET increased lean body mass in rats $(P=0.019)$. In addition, ET was more effective than $L S$ in reducing adiposity $(P=0.019)$, serum insulin $(P=0.022)$ and TNF- $\alpha(P=0.044)$.

Conversely, LS increased serum adiponectin $(P=0.021)$ levels and reduced serum total cholesterol concentration ( $P$ $=0.042$ ).

Conclusions: The results showed that LS had no beneficial effects on insulin sensitivity or adiposity in previously obese rats. On the other hand, LS was effective in increasing adiponectin levels and in reducing total cholesterol concentration.

Keywords: Leucine, Adipose tissue, Endurance training, Body composition, Obesity, Adiponectin

\section{Background}

Obesity is associated with a number of health problems that are often summarized as the metabolic syndrome, and its etiology may be associated with the consumption of high energy-dense foods [1]. Excessive intake of dietary fat promotes adipocyte hypertrophy, altering their normal endocrine function to an inflammatory

\footnotetext{
* Correspondence: torresleal@usp.br

${ }^{1}$ Department of Food Science and Experimental Nutrition, Faculty of

Pharmaceutical Sciences, University of São Paulo, São Paulo, Brazil

Full list of author information is available at the end of the article
}

pathologic condition that increases the secretion of tumor necrosis factor-alpha (TNF- $\alpha$ ) and interleukin- 6 (IL-6), among other proinflammatory cytokines, and concomitantly reducing adiponectin secretion $[2,3]$.

Previous studies have demonstrated that dietary leucine regulates body weight and glucose homeostasis [410]. Within this context, several studies support the hypothesis that leucine plays an important role in the regulation of metabolism and energy balance by directly affecting peripheral tissues, such as white adipose tissue, liver, and muscle. For example, leucine has been shown 


\section{Y Nutrição̊}
- Inicial
- Eventos
- A Revista
- Assinaturas
a Ações Sociais
- Edições Anteriores
a Promoções
E Editorial
1. Notícias Científicas
a Revista Eletronica
घ Entrevistas
a Matéria da Capa
a Alimentos Funcionais
a Enteral Parenteral
a Food Service
v Gastronomia
a Nutrição Clínica
a Nutrição e Ecologia
a Nutrição e Esporte
v Nutrição Hospitalar
- Nutrição e Pediatria
- Saúde Pública
a Loja Virtual
- Contato

\section{Arrea de Assinantes}

\begin{tabular}{|l|}
\hline email \\
\hline CPF \\
\hline senha \\
\hline
\end{tabular}

Esqueceu sua senha?

entrar

Busca

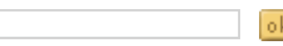

Busca Avançada

\section{Nevisletter}

Receba as notícias da Nutrição em Pauta

em seu e-mail

\begin{tabular}{|l|}
\hline nome \\
\hline email \\
\hline cidade \\
\hline
\end{tabular}

Estado cadastrar

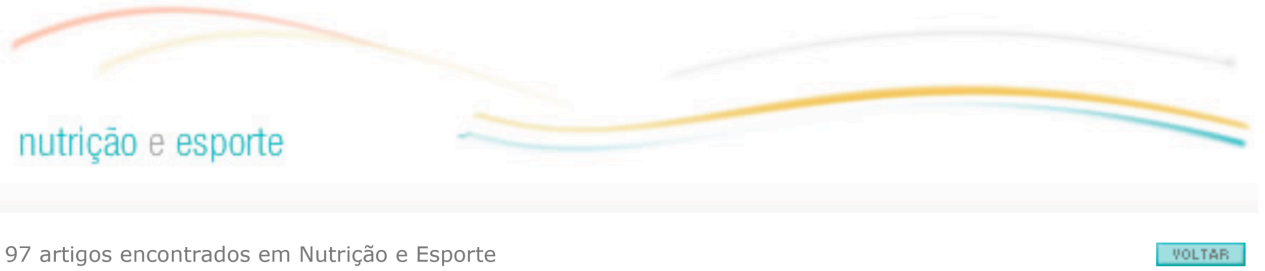

97 artigos encontrados em Nutrição e Esporte

Parâmetros Bioquímicos Relativos ao Magnésio em Nadadores Adolescentes

Biochemical Parameters Related to Magnesium in Adolescent Swimmers

palavras-chave: estado nutricional, exercício, magnésio, metabolismo.

Keywords: nutritional status, exercise, magnesium, metabolism

resumo

O objetivo deste estudo foi avaliar, por meio de parâmetros bioquímicos, o estado nutricional relativo ao magnésio, em nadadores adolescentes. O estudo de natureza analítica e experimental avaliou 12 nadadores ativos, com idade entre 14 e 19 anos, do gênero masculino, que praticavam $2 \mathrm{~h}$ diárias de treinos de resistência aeróbia. As avaliações de magnésio no plasma e na urina de 24 horas foram realizadas por método colorimétrico. As concentrações médias de magnésio plasmático e urinário foram de 2,11 $\pm 0,07 \mathrm{mg} / \mathrm{dL}$ e de 97,71 $\pm 13,15 \mathrm{mg} / \mathrm{dL}$, respectivamente, sendo os valores de referência: de 1,6 a $1,8 \mathrm{mg} / \mathrm{dL}$ no plasma e de 120 a $140 \mathrm{mg} / \mathrm{dL}$ na urina. Diante dos resultados obtidos, pode-se indicar a ocorrência de alterações na compartimentalização do magnésio, com elevadas concentrações deste mineral no plasma e reduzidas na urina, nos nadadores adolescentes avaliados.

\section{abstract}

This study was evaluated by biochemical parameters, the nutritional status of magnesium in adolescent swimmers. The study of analytical and experimental assessed 12 active swimmers aged between 14 and 19 , males, who practiced 2 hours daily of aerobic endurance training. The assessment of magnesium in plasma and urine of 24 hours was performed according to the colorimetric method using the

spectrophotometer automation. The concentrations of plasma and urinary magnesium were $2.11 \pm 0.07$ $\mathrm{mg} / \mathrm{dL}$ and $97.71 \pm 13.15 \mathrm{mg} / \mathrm{dL}$, respectively, and the references values are from 1.6 to $1.8 \mathrm{mg} / \mathrm{dL}$ in plasma and 120 to $140 \mathrm{mg} / \mathrm{dL}$ in urine. Considering the results obtained, we can indicate the occurrence of changes in compartmentalization of magnesium, with high concentrations of this mineral in plasma and urine reduced in adolescent swimmers evaluated.

\section{Autores}

Emidio Marques de Matos Neto

Educador Físico, Universidade Federal do Piauí, Teresina/PI - Brasil

\section{Francisco Erasmo Oliveira}

Farmacêutico, Laboratório MedImagem, Teresina/PI - Brasil

\section{Francisco Leonardo Torres-Leal}

Educador Físico e Mestrando em Nutrição Humana Aplicada - Departamento de Alimentos e Nutrição Experimental FCF - USP - Brasil.

\section{Glauber Castelo Branco Silva}

Educador Físico, Universidade Federal do Piauí, Teresina/Pi - Brasil

Profa Dra. Fabiana Poltronieri

Nutricionista, Profa. Dra. do Centro Universitário São Camilo, São Paulo/SP - Brasil.

\section{Profa. Dra. Dilina do Nascimento Marreiro}

Professora Doutora do Departamento de Nutrição - Centro de Ciências da Saúde, Departamento de Nutrição, Universidade Federal do Piauí, Piauí - Brasil.

Os autores estão em ordem alfabética.

Este artigo eletrônico é um resumo. O artigo eletrônico em sua íntegra pode ser encontrado na revista Nutrição em Pauta, edição eletrônica de Mar/2011
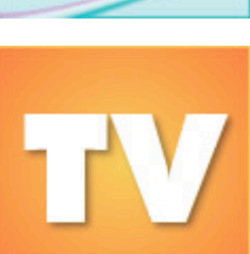

NUTRIÇC̄O EM PAUTA

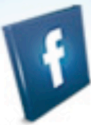

Curta nossa página

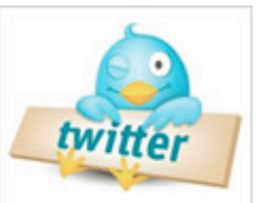

Nutrição em Pauta 


\title{
Protein synthesis regulation by leucine
}

\author{
Daiana Vianna1, Gabriela Fullin Resende Teodoro', Francisco Leonardo Torres-Leal², \\ Julio Tirapegui ${ }^{1,2, *}$
}

\author{
${ }^{\prime}$ Department of Food Science and Experimental Nutrition, Faculty of Pharmaceutical Sciences, University of São Paulo, \\ ${ }^{2}$ Department of Food Science and Experimental Nutrition, Faculty of Pharmaceutical Sciences, PRONUT, University of São Paulo.
}

\begin{abstract}
In vivo and in vitro studies have demonstrated that high protein diets affect both protein synthesis and regulation of several cellular processes. The role of amino acids as substrate for protein synthesis has been established in the literature. However, the mechanism by which these amino acids modulate transcription and regulate the mRNA translation via mTOR-dependent signaling pathway has yet to be fully determined. It has been verified that mTOR is a protein responsible for activating a cascade of biochemical intracellular events which result in the activation of the protein translation process. Of the aminoacids, leucine is the most effective in stimulating protein synthesis and reducing proteolysis. Therefore, it promotes a positive nitrogen balance, possibly by favoring the activation of this protein. This amino acid also directly and indirectly stimulates the synthesis and secretion of insulin, enhancing its anabolic cellular effects. Therefore, this review aimed to identify the role of leucine in protein synthesis modulation and to discuss the metabolic aspects related to this aminoacid.
\end{abstract}

Uniterms: Leucine. Protein synthesis. Transcription Factors. mTOR. Translation Protein.

Estudos in vivo e in vitro verificaram que dietas hiperprotéicas influenciam a síntese protéica e regulam vários processos celulares. O papel dos aminoácidos como substrato para a síntese de proteínas já está bem evidenciado na literatura, porém as formas como esses aminoácidos modulam a etapa da transcrição e regulam a tradução do RNAm, pela via de sinalização dependente da mTOR, ainda não estão totalmente esclarecidas. Tem-se verificado que a mTOR é uma proteína responsável por ativar uma cascata de eventos bioquímicos intracelulares que culminam na ativação do processo de tradução protéica. Dentre todos os aminoácidos, a leucina é a mais eficaz em estimular a síntese protéica, reduzir a proteólise e, portanto, favorecer o balanço nitrogenado positivo, possivelmente por favorecer a ativação desta proteína. Além disso, este aminoácido estimula direta e indiretamente a síntese e a secreção de insulina, e, assim, aumenta as propriedades anabólicas celulares. Nesse sentido, a presente revisão tem como objetivo identificar o papel da leucina na modulação da síntese protéica e abordar aspectos metabólicos relacionados a este aminoácido.

Unitermos: Leucina. Síntese protéica. Fator de transcrição. mTOR. Tradução de proteínas.

\section{INTRODUCTION}

Protein synthesis in tissue is rapidly stimulated after nutrient consumption. Insulin and aminoacids stimulate protein anabolism, acting in a posterior step of gene transcription, i.e., on protein translation. However, the mechanism by which the aminoacids stimulate protein translation has yet to be fully determined (Proud, 2002).

*Correspondence: J. Tirapegui. Departamento de Alimentos e Nutrição Experimental, Faculdade de Ciências Farmacêuticas - USP. Av. Prof. Lineu Prestes, n. 580 - Bloco 14 -05508-900 - São Paulo - SP, Brazil. E-mail: tirapegu@usp.br
Some studies have verified that high-protein diets stimulate protein synthesis. Some of the benefits promoted by this diet on body composition can be attributed to high consumption of branched-chain aminoacids (BCAA), which include the aminoacids leucine, valine and isoleucine (Donato et al., 2004; Layman, Walker, 2006; Katsanos et al., 2006). According to this hypothesis, high protein consumption not only increases the availability of substrates (aminoacids) for protein synthesis, but also stimulates anabolic processes observed after high protein consumption (Campos et al., 1999).

Leucine has been shown to modulate the rate of 


\title{
Effects of administering testosterone undecanoate in rats subjected to physical exercise: effects on the estrous cycle, motor behavior and morphology of the liver and kidney
}

\author{
Moisés Tolentino Bento-Silva ${ }^{1,3, *}$, Maria do Carmo de Carvalho e Martins ${ }^{2}$, Francisco Leonardo \\ Torres-Leal ${ }^{1,3}$, Talvany Luiz Barros ${ }^{3}$, Ingrid Lara do Nascimento Ferreira de Carvalho ${ }^{2}$, Hugo \\ Aparecido Carvalho Filho ${ }^{2}$, Fernanda Regina de Castro Almeida ${ }^{3}$
}

\author{
${ }^{1}$ Department of Physical Education, Federal University of Piaui, ${ }^{2}$ Department of Physiology and Biophysics, Federal \\ University of Piaui, ${ }^{3}$ Medicinal Plants Research Center, Federal University of Piaui
}

\begin{abstract}
The aim of the work was evaluate the effects of testosterone undecanoate (TU) treatment combined with moderate physical training on: the estrous cycle, body weight (BW), motor behavior (MB), and the morphohistology of the reproductive system, the liver and kidney in rats. Female Wistar rats $(180 \mathrm{~g}$ $-250 \mathrm{~g})$ were divided as follows: sedentary $+\mathrm{TU}(\mathrm{S}+\mathrm{TU})$, trained $+\mathrm{TU}(\mathrm{T}+\mathrm{TU})$, sedentary + vehicle $(\mathrm{S}+\mathrm{V})$, trained + vehicle $(\mathrm{T}+\mathrm{V})$. The rats swam $50 \mathrm{~min} /$ Day, strapped with a $5 \% \mathrm{BW}$ load, for 4 weeks. During this training, (BW) was monitored daily as well as the estrous cycle (EC) by vaginal smear. The TU ( $15 \mathrm{mg} / \mathrm{kg} \mathrm{s.c)}$ ) was administered 3 times/week for 4 weeks. At the end of the study, data on MB, BW and morphohistopathological changes in viscera were compiled. The $(\mathrm{T}+\mathrm{TU})$ group had on average, a higher (BW) in the fourth week compared to the first week, and (BW) higher than (S + V) and (S + TU) groups. We noted an interruption in the EC and a decrease in weight of ovaries in animals treated with TU. In addition, there was an increase in the relative weight of the heart in groups $(\mathrm{T}+\mathrm{V})$ and $(\mathrm{T}+\mathrm{TU})$, and kidneys in group $(\mathrm{T}+\mathrm{TU})$. Histopathological analysis showed periportal congestion and isolated foci of hepatic necrosis in rats with TU. Thus, TU combined with training abolished the EC, promoted ovarian atrophy, liver necrosis, cardiac hypertrophy and a decrease in motor activity.
\end{abstract}

Uniterms: Androgenic anabolic steroids/experimental study. Endurance training. Testosterone undecanoate.

\begin{abstract}
O objetivo do trabalho foi avaliar o efeito do tratamento com undecanoato de testosterona (UT) combinado ao treinamento físico moderado sobre ciclo estral, peso corporal, estruturas do sistema reprodutor, comportamento motor e morfologia hepática e renal em ratas. Ratas Wistar $(180 \mathrm{a} 250 \mathrm{~g})$ foram divididas em: sedentárias + UT $(\mathrm{S}+\mathrm{UT})$, treinadas + UT $(\mathrm{T}+\mathrm{UT})$, sedentárias + veículo $(\mathrm{S}+\mathrm{V})$, treinadas + veículo $(\mathrm{T}+\mathrm{V})$. As ratas nadaram $50 \mathrm{~min} /$ dia com sobrecarga de $\sim 5 \%$ do peso corporal por 4 semanas. Durante o período de treinamento foi realizado acompanhamento diário do peso corporal (PC) e do ciclo estral (CE) pelo esfregaço vaginal. O UT (15 mg/kg s.c.) foi administrado $3 \mathrm{x} / \mathrm{semana}$ durante 4 semanas. Ao final foram avaliados comportamento motor, pesos e alterações histopatológicas de alguns órgãos. $\mathrm{O}$ grupo $\mathrm{T}+\mathrm{UT}$ apresentou PC maior na quarta semana do que na primeira, com pesos corporais maiores que os grupos $\mathrm{S}+\mathrm{V}$ e $\mathrm{S}+\mathrm{UT}$. Houve interrupção no $\mathrm{CE}$ e redução do peso dos ovários nos animais tratados com UT. Houve aumento do peso relativo do coração, nos grupos T+V e T+UT, e do peso relativo dos rins, no grupo T+UT. A análise histopatológica revelou congestão periportal e focos isolados de necrose hepática nas ratas com UT. O UT combinado com treinamento produziu supressão do ciclo estral, atrofia ovariana, necrose hepática, hipertrofia cardíaca e redução da atividade motora.
\end{abstract}

Unitermos: Esteróides androgênicos anabólicos/estudo experimental. Exercício físico. Undecanoato de testosterona.

*Correspondence: M. T. Bento-Silva. Departamento de Educação Física,

Universidade Federal do Piauí, Campus Petronio Portela, s/n - 64049-550 -

Teresina - PI, Brasil. E-mail: moisesfisio@yahoo.com.br 


\section{Aspectos atuais do efeito da leucina sobre 0 controle glicêmico e a resistência à insulina Current aspects of leucine effect on glucose control and insulin resistance}

\section{ABSTRAGT}

TORRES-LEAL, F. L.; VIANNA, D.; TEODORO, G. F. R.; CAPITANI, M. D.; TIRAPEGUI, J. Current aspects of leucine effect on glucose control and insulin resistance. Nutrire: rev. Soc. Bras. Alim. Nutr. = J. Brazilian Soc. Food Nutr., São Paulo, SP, v. 35, n. 2, p. 131-143, ago. 2010.

The incidence of obesity and type 2 diabetes mellitus is increasing in epidemic proportions. Currently, several studies have suggested that signals from amino acids and hormones present convergence that can lead to changes in glucose metabolism and insulin sensitivity, thus having effects on the maintenance of body weight. Although in vitro and in vivo studies show considerable effects of leucine on energy bomeostasis, by possible effects on satiety and on energy expenditure increase, as well as on genes and on protein expression in several tissues mainly in adipocytes, other effects have been noted to impair glucose homeostasis by promoting insulin resistance and increased gluconeogenesis. Furthermore, leucine signaling is integrated by the protein target of rapamycin in mammals (mTOR), a sensor of energy that phosphorylates $56 \mathrm{~K}$ protein, which is able to phosphorylate serine 307 of the insulin receptor 1 substrate as a negative feedback and therefore favor insulin resistance. Thus, the understanding of integrated transductional, hormonal and nutrient (leucine) signals may favor the clarification over new approaches to the treatment of various metabolic diseases such as obesity and diabetes. In conclusion, the objective of this study was to review the role of leucine in glycemic control and insulin resistance.

Keywords: Adipocytes. Leucine.

Blood Glucose. Insulin Resistance.
FRANCISCO LEONARDO

TORRES-LEAL'; DAIANA

VIANNA ${ }^{1}$; GABRIELA

FULLIN RESENDE

TEODORO'; MARIANA

DUTILH DE CAPITANI';

JULIO TIRAPEGUI

${ }^{1}$ Departamento de Alimentos e Nutrição Experimental

- Faculdade de Ciências

Farmacêuticas -

Universidade de São Paulo

Endereço para

correspondência:

Julio Tirapegui

Av. Prof. Lineu Prestes, 580,

Bloco 14 - Faculdade de Ciências Farmacêuticas -

Universidade de São Paulo CEP 05508-900

São Paulo - SP - Brasil e-mail: tirapegu@usp.br

Agradecimentos:

à FAPESP pela concessão da bolsa de mestrado de

Francisco Leonardo Torres-Leal

(Processo: 07-51964-9)

e ao apoio financeiro

(Processo: 07-592913). 


\title{
Braz J Health, 2010; 1: 110-117
}

\section{Efeito Ergogênico da Cafeína sobre o Desempenho Físico Progressivo Máximo em Ciclistas}

\author{
Ergogenic Effect of Caffeine on the Physical Performance \\ Progressive Maximum of Cyclists
}

Hélcyo dos Anjos Leitão ${ }^{1}$, Francisco das Chagas da Rocha ${ }^{1}$, Emídio Matos Marques-Neto ${ }^{2}$, Rodrigo Galvão Figueiredo ${ }^{1}$, Francisco Leonardo Torres-Leal ${ }^{2}$

${ }^{1}$ Universidade Federal do Piaú, Teresina, Brasil. ${ }^{2}$ Universidade de São Paulo, São Paulo, Brasil.

\section{Resumo}

O objetivo do estudo foi examinar o efeito ergogênico da cafeína sobre o desempenho físico em exercício progressivo máximo. Para tanto, quatorze ciclistas, saudáveis, foram distribuídos aleatoriamente em grupo cafeína $(\mathrm{GC} \mathrm{n}=7)$ e grupo placebo (GPL $n=7)$. Os indivíduos receberam em sistema duplo-cego, doses de cafeína ou placebo-amido (5 $\mathrm{mg} / \mathrm{kg}$ ). Um protocolo de exercício progressivo máximo em cicloergômetro foi usado para avaliar o desempenho físico antes e após o período de suplementação ou placebo. Para tratamento estatístico foi utilizado ANOVA, seguido pelo teste de post hoc Tukey, quando $P<0,05$. Observou-se efeito significante na tolerância ao esforço de $131 \%$ para o GC $(\mathrm{p}<0,05)$. Além disso, o GC apresentou um incremento significativo de aproximadamente 157\% no mesmo parâmetro físico quando comparado ao GPL $(\mathrm{p}<0,05)$.

Palavras chaves: cafeína; suplementação; exercício aeróbico

\begin{abstract}
The aim of this study was to examine the ergogenic effect of caffeine on physical performance in incremental to maximal exercise. To this end, fourteen cyclists, healthy, were randomly assigned to Caffeine group $(\mathrm{CG} n=7)$ and the placebo group (GPL $\mathrm{n}=7$ ). Subjects received in a double-blind, doses of caffeine or placebo-starch $(5 \mathrm{mg} / \mathrm{kg})$. A maximal graded exercise protocol on a cycle ergometer was used to assess physical performance before and after the period of supplementation or placebo. For statistical analysis ANOVA was used followed by post hoc Tukey test, $\mathrm{P}$ $<0.05$. We observed a significant effect on exercise tolerance of $131 \%$ for $C G(p<0.05)$. Moreover, the CG showed a significant increase of about $157 \%$ in the same physical parameter as compared to PLG $(\mathrm{p}<0.05)$.
\end{abstract}

Keywords: Caffeine; supplementation; aerobic exercise 


\title{
Braz J Health, 2010; 1: 156-164
}

\section{Effect of creatine monohydrate on power and fatigue production during anaerobic sprints in soccer players}

\section{Efeito da creatina monohidratada na produção de energia e fadiga durante sprints anaeróbicos em jogadores de futebol}

Francisco Leonardo Torres-Leal ${ }^{1}$; Moises Tolentino Bendo da Silva ${ }^{1}$; Emídio Marques de Matos Neto ${ }^{1}$; Rodrigo Galvão Figueiredo; Gilmara Péres Rodrigues ${ }^{2}$; David Marcos Emérito de Araújo ${ }^{1}$; Dilina Nascimento Marreiro ${ }^{2}$

${ }^{1}$ Departament of Physical Education, Health Sciences Center, Federal University of Piauí, Teresina, PI, Brazil ${ }^{2}$ Department of Nutrition, Health Sciences Center, Federal University of Piauí, Teresina, PI, Brazil

\begin{abstract}
Objective: This study investigated the effect of creatine supplementation on production of power and reduction in muscle fatigue during high-intensity sprints. Methods: Nineteen River Futebol Club's soccer players, established in Teresina/PI, were submitted to the following 3 phases of the study: pre-supplementation $\mathrm{T}_{1}$ and post-supplementation $\mathrm{T}_{2}$ acute $\left(20\right.$ g.d $\mathrm{d}^{-1}$, for 1 day); and $\mathrm{T}_{3}$ chronic $\left(20 \mathrm{~g} \cdot \mathrm{d}^{-1}\right.$ for 14 days +5 g.d $\mathrm{d}^{-1}$ for 6 days). The experimental protocol consisted of 6 maximal 35-m sprints with 10-s interval. At the end of each phase, the anaerobic power tests. Results: Evaluation of performance of medium power $\mathrm{T}_{2}$ was from $524.69 \pm 98.95$ to $701.01 \pm 148.66 \mathrm{w}$ (p $<0.01$ ). Thus, minimum power $\mathrm{T}_{2}$ presented $\mathrm{p}<0.001$, when compared with $\left(\mathrm{T}_{1}\right)$. Conclusion: Based on the data obtained in this study, it may be concluded that acute form $\mathrm{Cr}$ supplementation favored improvement of performance of the athletes in short-lasting high-intensity sprints. Although the mechanisms are not yet completely clarified, the literature points to a possible increase in total $\mathrm{Cr}$ stores which may favor phosphocreatine replenishment.
\end{abstract}

Key-Words: performance, sprints, creatine, supplementation, soccer

\section{Resumo}

Objetivo: Este estudo investigou o efeito da suplementação com creatina $(\mathrm{Cr})$ na produção de potência e na redução da fadiga muscular durante sprints de alta intensidade. Métodos: Dezenove jogadores de futebol integrantes do Clube do River em Teresina/PI, foram submetidos a 3 fazes do estudo, quais sejam: pré-suplementação $\left(\mathrm{T}_{1}\right)$ e pós-suplementação ( $\mathrm{T}_{2}$ - agudo, $20 \mathrm{~g} \cdot$ dia-1 por $1 \mathrm{dia}$; e $\mathrm{T}_{3}$ - crônico, $20 \mathrm{~g} \cdot$ dia-1 por 14 dias $+5 \mathrm{~g} \cdot$ dia-1 por 6 dias ). O protocolo experimental consistiu de 6 sprints máximos de 35-m com 10-s de intervalo e no término de cada fase, os testes de 


\section{ANEXO B \\ GEL PARA VERIFICAR A INTEGRIDADE DO RNA TOTAL EXTRAÍDO NO TAB}

Gel 1 Tecido adiposo branco subcutâneo

Gel 2 Tecido adiposo branco periepididimal 
Gel 1 - Tecido adiposo branco subcutâneo.

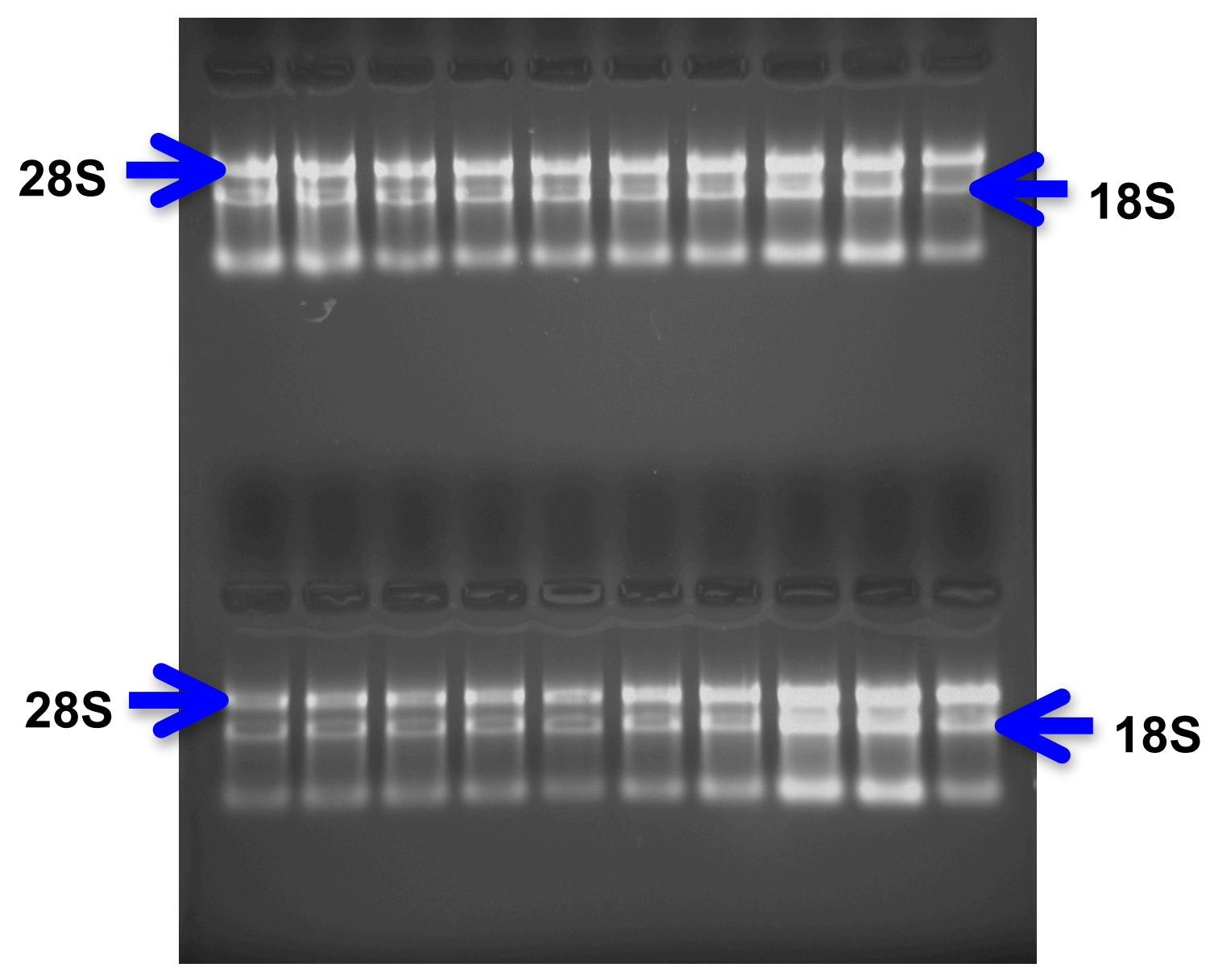

As bandas ilustradas representam as subunidades $28 \mathrm{~S}$ e $18 \mathrm{~S}$ do RNA ribossomal. Fonte: Torres-Leal (2012). 
Gel 2 - Tecido adiposo branco periepididimal.

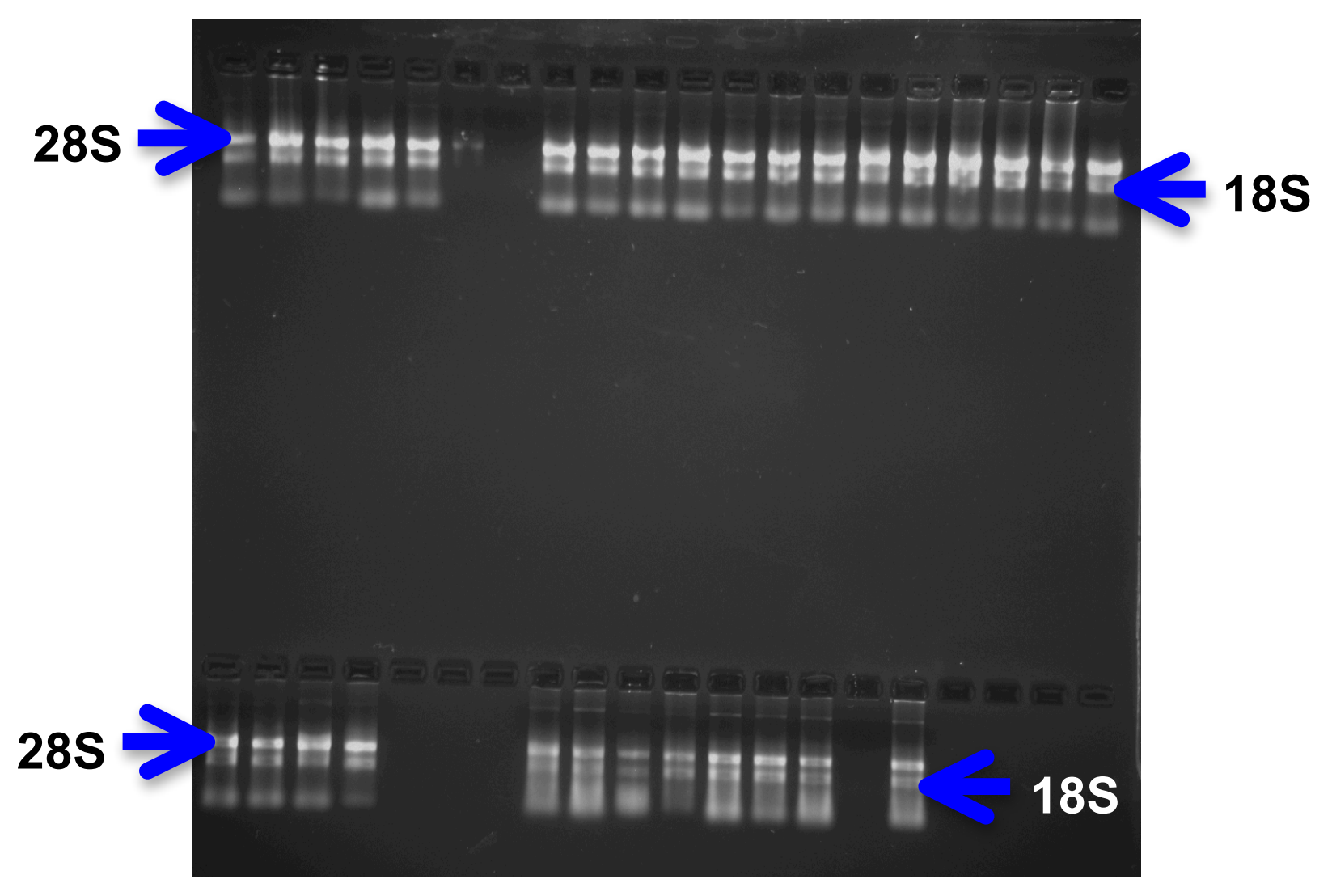

As bandas ilustradas representam as subunidades $28 \mathrm{~S}$ e $18 \mathrm{~S}$ do RNA ribossomal. Fonte: Torres-Leal (2012). 